\title{
Le site gaulois et antique de « La Carie », entre oppidum et ville romaine à Entrammes (Mayenne)
}

The Gallic and ancient site of "La Carie" - between an oppidum and a roman town at Entrammes (Mayenne)

Gérard Guillier, Emmanuelle Coffineau, Richard Delage, ValérieDeloze, Alain Valais, Séverine Lemaitre, Fabien Pilon et Laure Simon

\section{OpenEdition}

\section{Journals}

Édition électronique

URL : https://journals.openedition.org/rao/1761

DOI : $10.4000 /$ rao. 1761

ISBN : 978-2-7535-2790-4

ISSN : $1775-3732$

Éditeur

Presses universitaires de Rennes

Édition imprimée

Date de publication : 30 décembre 2012

Pagination : 145-201

ISBN : 978-2-7535-2641-9

ISSN : 0767-709X

Référence électronique

Gérard Guillier, Emmanuelle Coffineau, Richard Delage, ValérieDeloze, Alain Valais, Séverine Lemaitre, Fabien Pilon et Laure Simon, "Le site gaulois et antique de " La Carie », entre oppidum et ville romaine à Entrammes (Mayenne) », Revue archéologique de l'Ouest [En ligne], 29 | 2012, mis en ligne le 30 décembre 2014, consulté le 22 août 2022. URL : http://journals.openedition.org/rao/1761 ; DOI https://doi.org/10.4000/rao.1761

Ce document a été généré automatiquement le 22 août 2022.

Tous droits réservés 


\section{Le site gaulois et antique de « La Carie », entre oppidum et ville romaine à Entrammes (Mayenne)}

The Gallic and ancient site of "La Carie" - between an oppidum and a roman town at Entrammes (Mayenne)

Gérard Guillier, Emmanuelle Coffineau, Richard Delage, ValérieDeloze, Alain Valais, Séverine Lemaitre, Fabien Pilon et Laure Simon

\section{NOTE DE L'ÉDITEUR}

Manuscrit proposé le 30 novembre 2011, accepté le $1^{\text {er }}$ décembre 2011.

\section{Introduction}

1 Le site de La Carie a été découvert en 2004-2005 lors de diagnostics archéologiques préalables à la réalisation d'un échangeur routier au nord-ouest d'Entrammes (Pétorin et al., 2004 ; Valais, 2005). Cette ville est localisée à dix kilomètres au sud de Laval, en rive gauche de la Mayenne, au sein de la cité gauloise et gallo-romaine des Aulerques Diablintes (fig. 1 et 2). La zone de fouille, de forme triangulaire (environ $65 \times 85 \mathrm{~m}$ ), implantée en rive droite de la Jouanne (fig. 3), occupe une surface de cinq mille mètres carrés environ. Elle a livré des vestiges de La Tène, du Haut et Bas Empire ainsi que du Haut Moyen Âge (Guillier, 2006b). 
Figure 1 : Localisation du site d'Entrammes (Mayenne). Figure 1: Position of the Entrammes site in Mayenne.
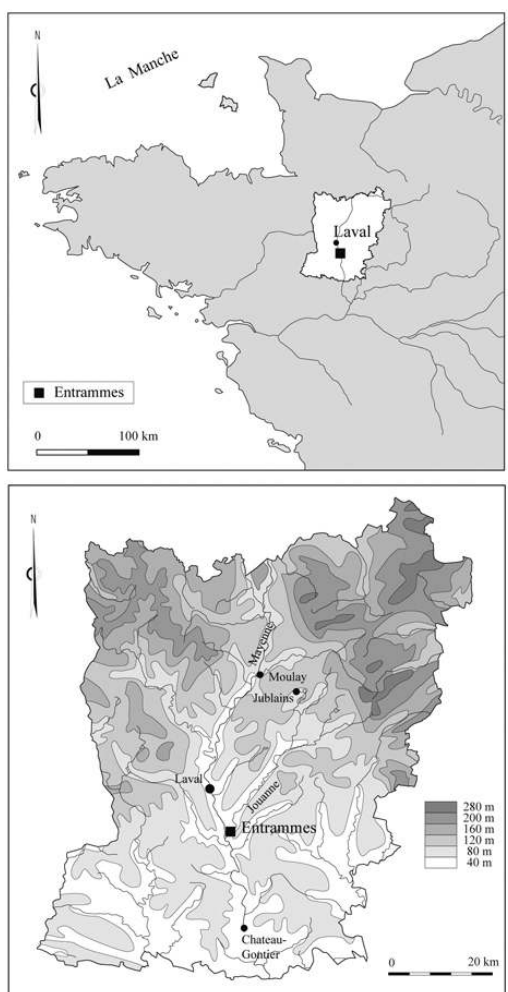

Figure 2 : Les peuples de l'Ouest de la Gaule (d'après E. Le Goff, 2003) et localisation d'Entrammes au sein de la cité des Diablintes.

Figure 2: The peoples of western Gaul (from E. Le Goff, 2003) and the position of Entrammes in the city of the Diablintes.

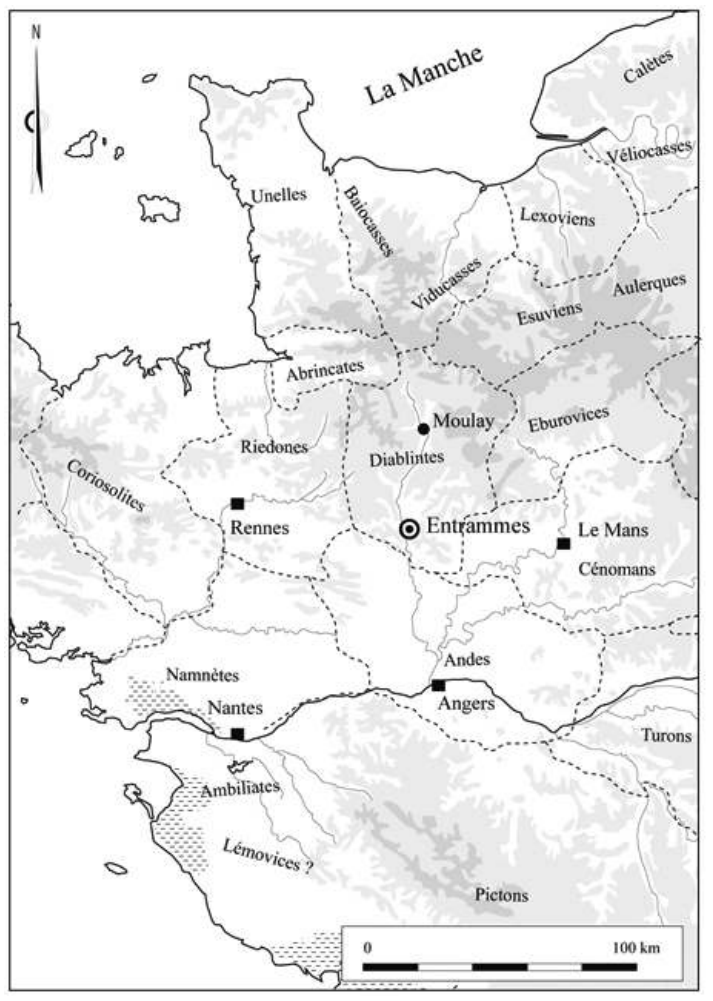


Figure 3 : Localisation topographique de l'oppidum du Port du Salut, de la ville d'Entrammes, de la voie antique Le Mans (Vindinum) - Rennes (Condate) et du site de "La Carie».

Figure 3: Topographic position of the oppidum, the "Port du Salut", the town of Entrammes, the ancient highway from Le Mans (Vindinum) to Rennes (Condate) and the site of "La Carie".

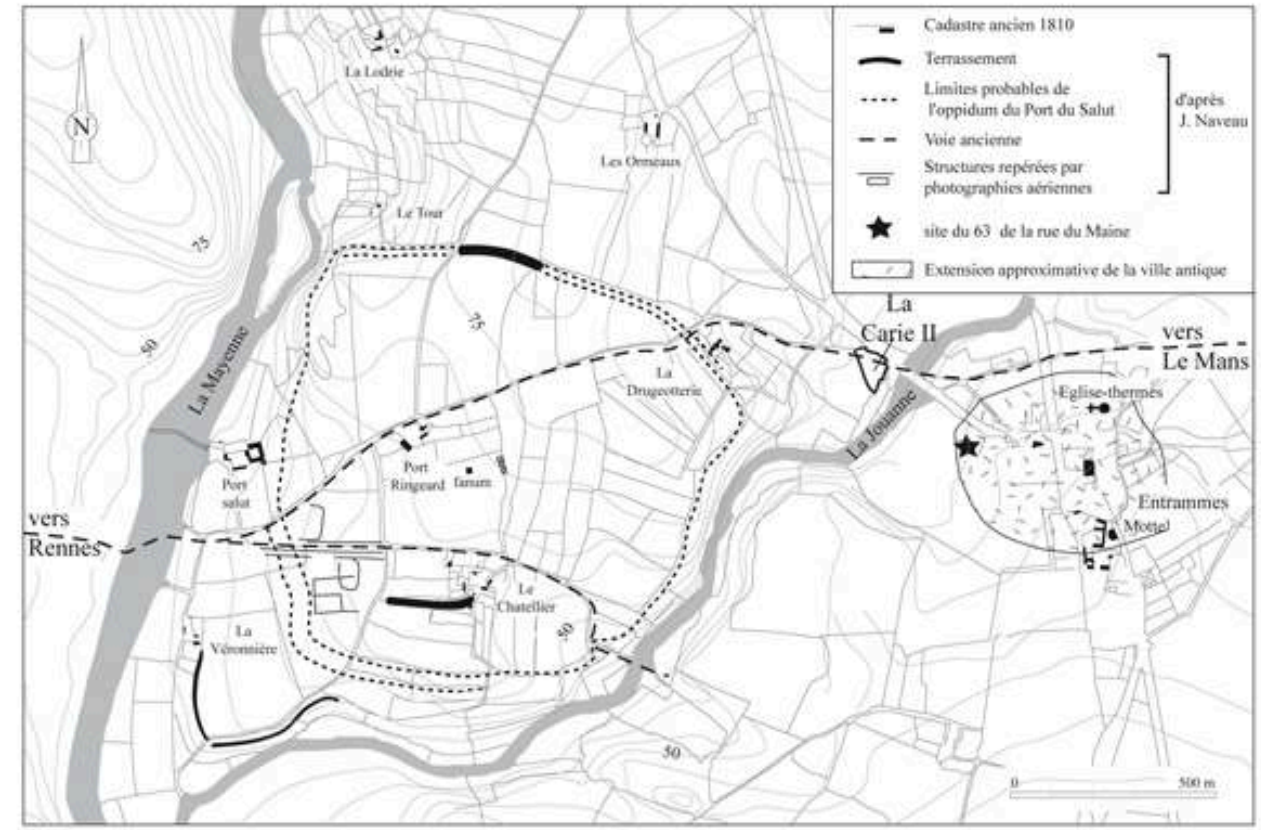

C'est une équipe de six à huit personnes qui a œuvré du 18 juillet au 10 novembre 2005. Le décapage du site s'est effectué au plus près des niveaux archéologiques à l'aide d'une pelle hydraulique. L'épaisseur des stériles au sud atteignait 0,80 mètre - sur la partie centrale quelques solins ont été mis au jour à moins de 0,20 mètre de profondeur tandis qu'au nord, de récents apports de terre ont porté ces stériles à près d'un mètre d'épaisseur.

3 La voie antique, immédiatement identifiée, était bordée au sud par un vaste bâtiment qui a fait l'objet d'un minutieux travail de dégagement et de relevés, pierre à pierre. Un second bâtiment a aussi été dégagé au nord de la voie ainsi que des fours de potiers. La voie étant bien délimitée, nous avons choisi de la fouiller à l'aide de sondages transversaux permettant d'en appréhender la complexité. Un second décapage mécanique, mené sur 0,30 à 0,40 mètre d'épaisseur a ensuite été entrepris au sud de la voie, avec pour but de mettre éventuellement au jour une occupation gauloise sousjacente à celle de l'époque antique.

4 L'étude stratigraphique des vestiges jointe à celle du mobilier archéologique issu des différentes couches archéologiques fouillées, individualisées sous la numérotation F1 à Fn, a défini six horizons, de l'horizon I à VI, qui seront décrits successivement. Le cas échéant, des subdivisions précisent une articulation plus fine de cette chronologie.

\section{Un contexte archéologique déterminant (G. Guillier, A. Valais)}

Le pagus d'Entrammes recouvre, du bassin de Laval à Château-Gontier, le tiers sud de la cité gauloise et gallo-romaine des Aulerques Diablintes (fig. 2) dont le chef-lieu a été successivement localisé pour ces périodes sur l'oppidum de Moulay près de Mayenne (fig. 1) et à Nouiodunum/Jublains (Naveau, 1992a, 1997). Il est possible qu'un gué sur la 
Mayenne ait attiré très tôt l'occupation dans ce secteur; situé à l'ouest de l'actuelle abbaye du Port-du-Salut, ce point de passage connu depuis 1870 par des monnaies romaines (Angot, 1910), pourrait être plus ancien. Ce franchissement est emprunté par la voie gallo-romaine menant de Vindinum (Le Mans) à Condate (Rennes), dont le tracé est visible sur le cadastre ancien (fig. 3). De nombreux chemins convergent vers ce gué, seul réel point de passage sur la Mayenne dans la moitié sud du département (Angot, 1910 ; Naveau, 1991b, 1992a et 1997), leur disposition en étoile autour d'Entrammes met en relief l'importance de ce site (Naveau, 1997, fig. 19).

6 Ce passage devait être, à l'époque gauloise, contrôlé par l'oppidum du Port-du-Salut (fig. 3), ce qui fait écrire à Jacques Naveau pour la voie Le Mans-Rennes (1997, p. 53) " [...] qu'il s'agit d'une création romaine qui peut utiliser des tronçons (de voie) de l'âge du Fer au voisinage des gués». Cet oppidum est ponctuellement reconnu par des tronçons de rempart et les traces d'un fossé associé qui apparaissent sur les photographies aériennes. Ailleurs, les limites de la zone fortifiée ont été mises en évidence sur les cadastres (fig. 3). L'ensemble occupe une surface de cinquante-cinq hectares et domine le site de "La Carie ", situé en contrebas, à environ trois cents mètres à l'est. Le mobilier de La Tène finale, mis au jour lors de la fouille du fanum, au centre de l'oppidum, peut être comparé à celui d'un tronçon de fossé fouillé en 1976 à la carrière d'Écorcé à quatre cents mètres à l'est-nord-est des thermes d'Entrammes, fossé qui marquerait une occupation indigène située le long de la voie Le Mans-Rennes (Naveau, 1977, 1992a). D'autres ensembles fossoyés, remontant à l'Indépendance ou à la période gallo-romaine, sont situés à l'intérieur de l'oppidum (Naveau, 1991b). Il en existe également une dizaine d'autres, repérés depuis un avion, sur le reste de la commune, correspondant vraisemblablement à des fermes indigènes (Naveau, 1991b, 1992a).

7 Si la fin de l'âge du Fer est bien illustrée et montre un territoire densément occupé et mis en valeur, la période suivante fournit aussi des vestiges spectaculaires. Il s'agit du fanum de plan carré de treize mètres de côté, accompagné d'un vaste bâtiment rectangulaire à galerie de façade, situé au centre de l'oppidum (Naveau, 1982, 1992a ; fig. 3), mais nous songeons surtout aux thermes (fig. 3) mis au jour dans l'église paroissiale en 1987 (Naveau, 1991a, 1992b). C'est cette découverte qui a véritablement initié les recherches archéologiques modernes dans la région d'Entrammes. Pourtant, depuis, force est de constater que peu de découvertes sont venues compléter ce tableau. Signalons la mise au jour d'importantes structures maçonnées au 63 de la rue du Maine à Entrammes (Guillier, 2006a ; fig. 3). Ce site, situé à moins de trois cents mètres à l'estsud-est de «La Carie ", permet pour la première fois depuis la découverte des thermes d'entrevoir une partie de l'étendue du chef-lieu du pagus d'Entrammes et de découvrir un aspect insoupçonné de sa parure monumentale.

Entrammes, au haut Moyen Âge, est citée parmi les paroisses les plus anciennes du diocèse du Mans. Elle aurait été fondée par saint Julien à la fin du IV siècle ou au début du siècle suivant: "ecclesias dedicavit... de Intramnis" (Actus). Si nous n'avons aucune preuve de cet événement, les aménagements retrouvés dans les thermes montrent une transformation précoce en édifice de culte, au plus tard au VII siècle (Naveau, 1992b) et soulignent « une continuité d'occupation entre l'Antiquité et le Moyen Âge » (Naveau, 1991b). Le haut Moyen Âge est aussi illustré par des sarcophages de calcaire coquillier (ou falun), retrouvés près de l'église actuelle, rue d'Anjou et près de la confluence Mayenne-Jouanne (Colleter, 2003). Une monnaie mérovingienne à la légende «Interamnis²/AVDIGISILUS », est attribuée à Entrammes (Ponton d'Amécourt, 1883). 
Deux établissements religieux y existaient, dont dès le $\mathrm{IX}^{\mathrm{e}}$ siècle, un monastère de femmes. En 863, Salomon, roi des Bretons, rencontre Charles le Chauve au gué d'Entrammes, la Mayenne constituant alors la frontière entre les royaumes de Bretagne et des Francs. Une motte féodale arasée ainsi qu'une possible chapelle castrale sont localisées au sud de l'église (fig. 3). Enfin, un prieuré de chanoines réguliers du Salut est fondé en 1233 sur l'oppidum du Port-du-Salut, par Thibault de Mathefelon, seigneur d'Entrammes, à proximité du gué ancien et de la voie antique, il s'agit de l'actuelle abbaye du Port.

\section{Le contexte naturel (V. Deloze $\left.{ }^{3}\right)$}

Le site placé entre 42 et 46 m NGF d'altitude, apparaît en rive droite de la Jouanne dans une vallée sinueuse et encaissée qui conflue avec la Mayenne à deux kilomètres au sudouest. La morphologie dominante est celle d'une pénéplaine peu ondulée, dépassant rarement cent mètres d'altitude, où les vallées principales sont encaissées mais les vallons larges et peu profonds.

\section{Le contexte géologique général}

Le substrat, des siltites, grès et conglomérats du Carbonifère, est traversé par un massif volcanique où prédominent les ignimbrites rhyolitiques (Ménillet et al., 1988). À l'est et au sud d'Entrammes, ces roches sont localement recouvertes de sables et graviers pliocènes et de sables éocènes. Des grès lustrés tertiaires, éolisés au Quaternaire, se rencontrent en blocs isolés. La vallée est comblée d'alluvions holocènes: sables, graviers et limons.

\section{Les données du terrain}

11 Le profil de la rive droite de la Jouanne (fig. 4), s'étageant de quarante-deux mètres d'altitude au sud-sud-est et à quarante-six mètres au nord-nord-ouest, se caractérise par une rupture de pente entre la voie et l'habitat gaulois puis gallo-romain.

Figure 4 : Profil synthétique du versant de " La Carie » à Entrammes (53).

Figure 4: Simulated profile of the slope of "La Carie" at Entrammes (France 53).

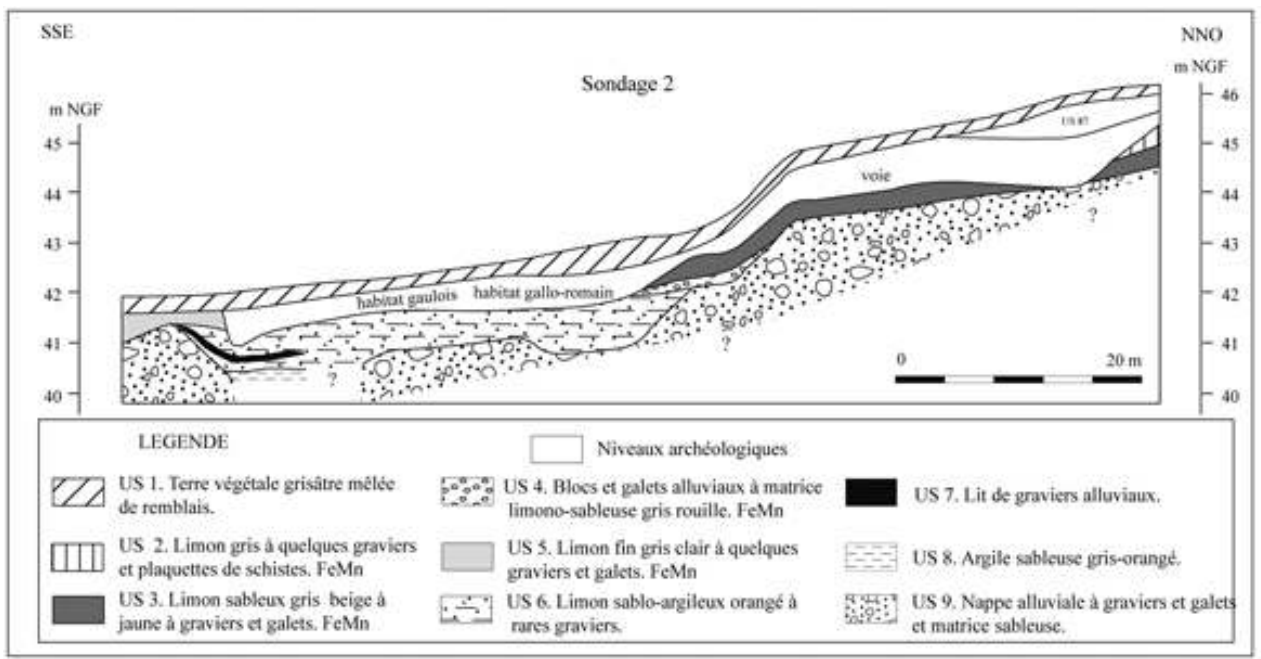



sud-est, elles sont sur-creusées d'un mètre sur plus de trente-cinq mètres de long par un chenal actif d'une époque où la Jouanne avait une morphologie en tresse, à multiples bras peu profonds et instables (Campy, Macaire, 2003). Son comblement est argilosableux gris-orangé (US 8) puis limono-sablo-argileux orangé (US 6), avec une lentille de graviers alluviaux (US 7).

13 À l'extrémité sud-sud-est, ce chenal et une partie des alluvions sont coiffés d'un limon fin gris clair à rares graviers, hydromorphe (US 5), correspondant à l'ennoiement intermittent de la plaine d'inondation lors de crues. La rupture de pente se caractérise par une fine et longue lentille de galets à matrice limono-sableuse gris-rouille (US 4), résultant d'une érosion de (US 9) au niveau de la rupture de pente, ou de la solifluxion d'une partie des matériaux du versant. Dans la moitié nord-nord-ouest, la lentille et les alluvions sont recouverts par un limon sableux gris-beige à jaune (US 3), avec des graviers à la base. Un limon gris à hydromorphie légère (US 2), contenant des fragments de tuiles et du charbon de bois, conservé en lambeaux au nord-nord-ouest, résulte du remaniement sur le versant de matériaux provenant des occupations environnantes. $\mathrm{Au}$ sommet, le sol actuel (US 1) surmonte des remblais modernes (US 87).

\section{Étude pétrographique des matériaux de construction}

Les matériaux de construction ont été étudiés au niveau de la canalisation F154, du mur F233, de la cave K, de la bordure de voie F267 et du bâtiment nord-ouest. La roche claire à débit schisteux qu'on y trouve majoritairement, est une ignimbrite rhyolitique ${ }^{4}$. Elle a pu être prélevée non loin du site au niveau d'un affleurement. Deux roches sombres ont été aussi utilisées : une spilite volcanique dans la pièce $\mathrm{K}$ (affleurement à plus de dix kilomètres au sud-est) et une rhyolite bleu acier massive, du massif volcanique d'Entrammes, dans l'aménagement F267 de la voie flavienne et antonine (affleurement local).

\section{L'horizon I : la période gauloise}

\section{Une occupation qui s'affirme}

Les éléments matérialisant la période gauloise, la voie et les structures qui se développent au sud de celle-ci seront détaillés successivement et, pour ces dernières plus particulièrement, en fonction de la chronologie mise en évidence au sein de l'horizon I, les horizons I ancien, moyen et récent (fig. 5 et 6 ).

Revue archéologique de l'Ouest, 29 | 2012 
Figure 5 : Entrammes, « La Carie » : plan général des structures de la période gauloise : I'Horizon I. Figure 5: General layout of the buildings during the Gallic period: Horizon I.

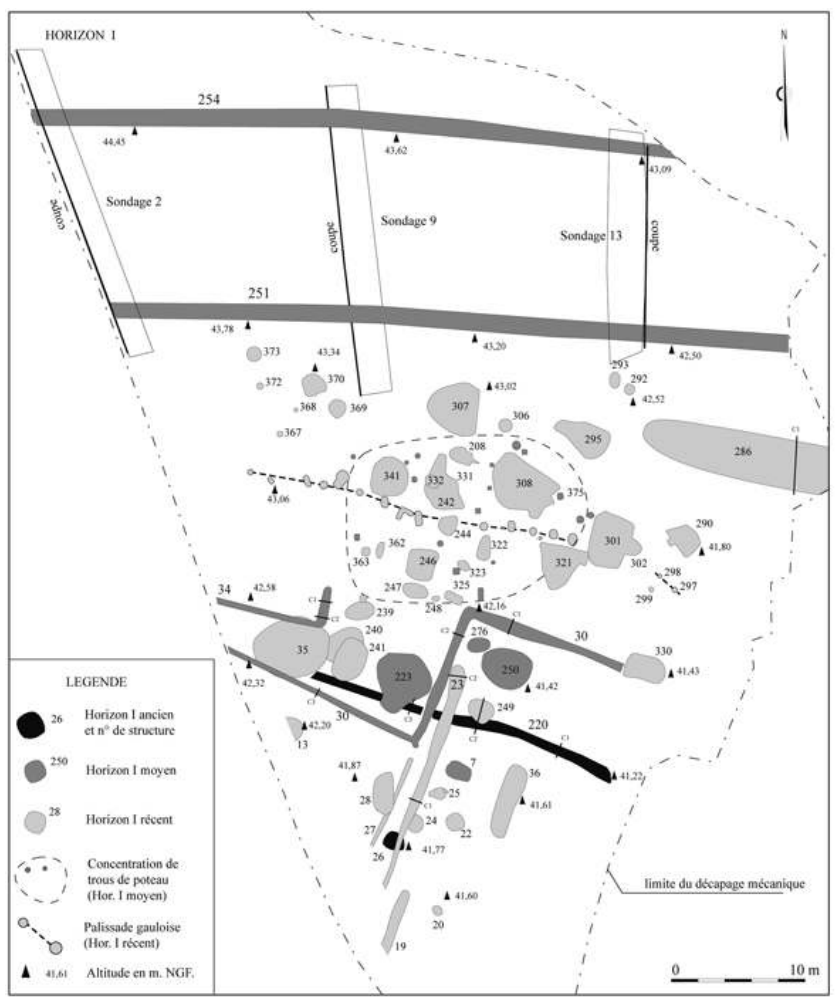

Figure 6 : Entrammes, « La Carie » : I'Horizon I, les états ancien, moyen et récent. Figure 6: Horizon I, ancient, intermediate and recent states.

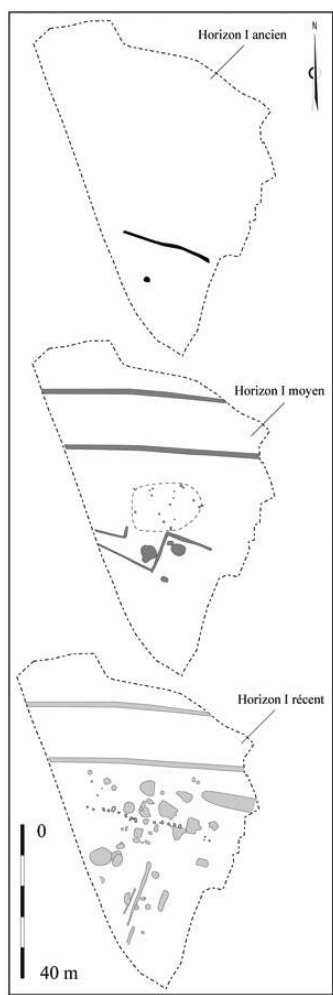


L'horizon I ancien est seulement matérialisé par la fosse F26 et le fossé F220 (fig. 5 et 6). Ce dernier, orienté ouest-nord-ouest - sud-sud-est, large de 0,90 mètre et profond de 0,15 à 0,40 mètre, offre un profil presque trapézoïdal (fig. 7). Il montre, sur les vingtcinq mètres mis au jour, un comblement uniforme de limon sableux gris clair, hydromorphe. La structure F26, attribuable à la charnière $\mathrm{III}^{\mathrm{e}}-\mathrm{II}^{\mathrm{e}}$ siècle av. notre ère, est de forme rectangulaire, aux angles légèrement arrondis. Elle mesure en surface $2 \times 1,50$ mètre pour 0,70 mètre de profondeur et possède des bords quasi-verticaux et un fond pratiquement plat. Cette fosse se rapporterait par ces caractéristiques à des structures à caractère artisanal ou destinées au stockage de denrées alimentaires, resserre ou cave; des parallèles sont par exemple relevés à Levroux dans l'Indre (Buchsenschutz et al., 1993). Son comblement, formé d'une alternance de limons grisjaune et de fines couches charbonneuses et cendreuses en position secondaire, est chargé d'argile rubéfiée (fig. 7).

Figure 7 : Entrammes, « La Carie » : choix de structures représentatives des Horizon I ancien, moyen et récent.

Figure 7: Selection of buildings representative of Horizon I: ancient, intermediate and recent.

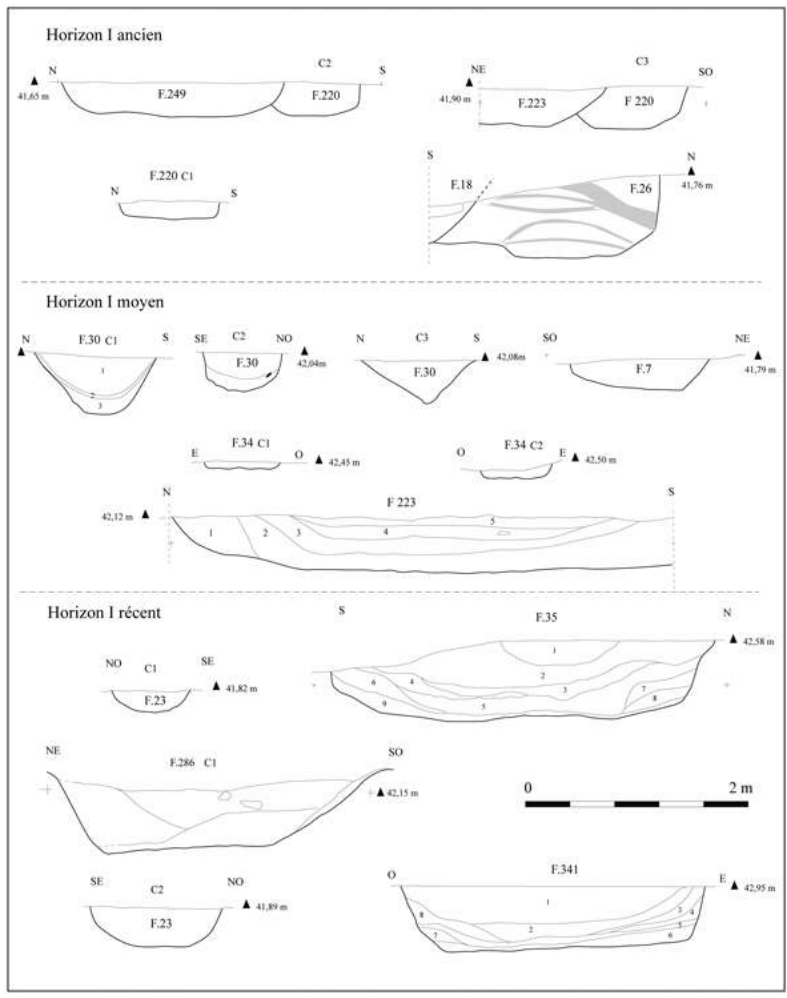

17 Il ne semble pas que la voie soit déjà matérialisée sur le site à ce stade. Toutefois, le fossé F220 marquerait un premier état de parcellaire dont nous remarquons qu'il est sensiblement parallèle aux orientations des structures des états postérieurs (horizon I moyen et récent) qui sont, elles, chronologiquement liées à la voie.

\section{La voie gauloise est-ouest}

Les fossés qui tracent la voie gauloise sont attribuables, à partir du mobilier dont nous disposons, aux horizons I moyen et récent (fig. 5 et 6). Cette voie orientée est-ouest suit la pente naturelle du terrain ouest-est, d'environ $3 \%$, vers le gué sur la Jouanne. 
Découverte sur une longueur de soixante mètres environ, elle est matérialisée par les fossés-limite ${ }^{5}$ nord et sud; parallèles et espacés de douze à treize mètres. Leurs comblements sont liés à la nature des substrats dans lesquels ils sont creusés, limoneux à l'ouest et graveleux plus à l'est (S9). Ponctuellement, des empierrements lui seraient attribuables : F101 (S2 : fig. 8).

Figure 8 : Entrammes, « La Carie » : la voie gauloise et antique, les coupes des sondages 2, 9 et 13. Figure 8: The Gallic and ancient highway, sample sections 2, 9 and 13.

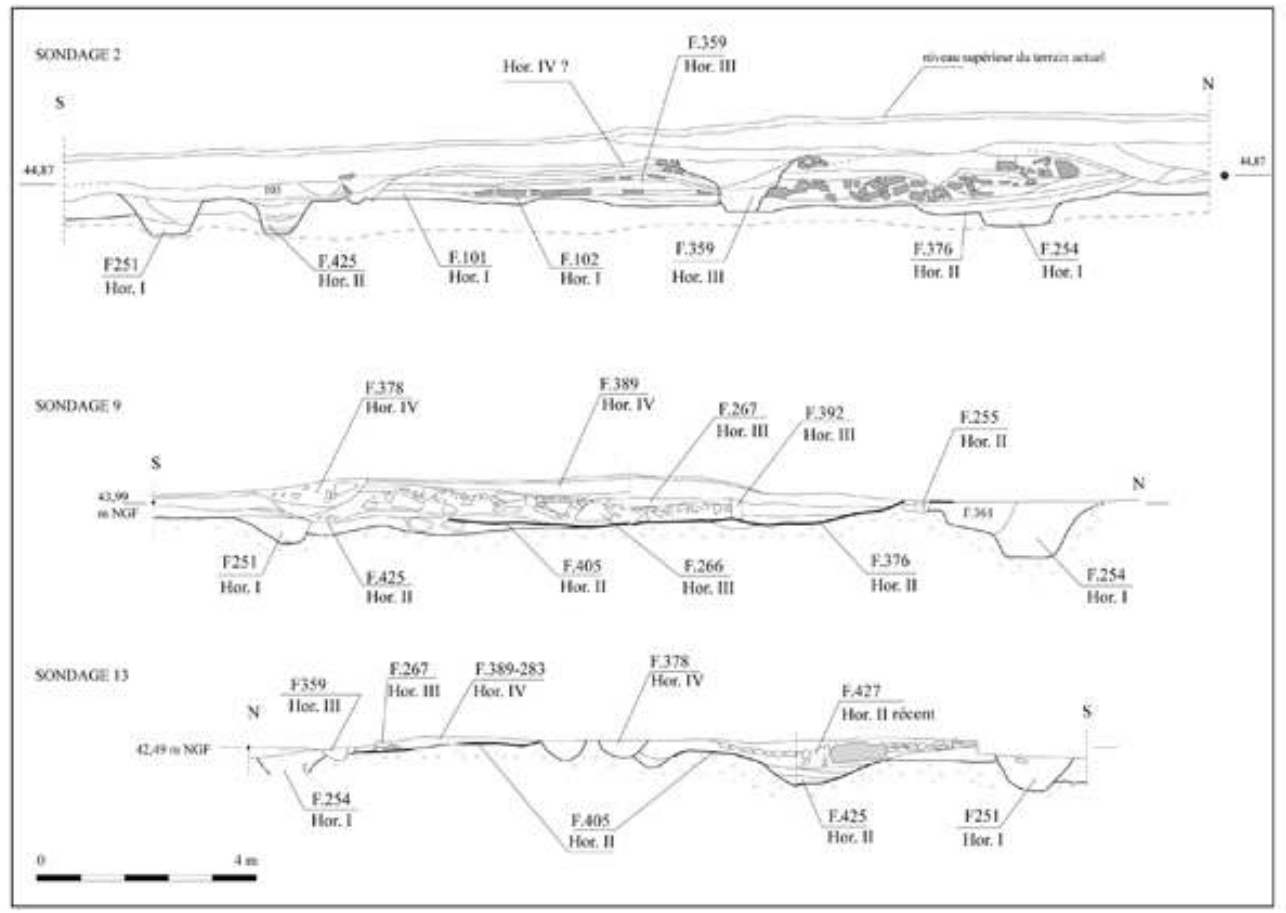

19 Le fossé nord, F254 (fig. 5 et 8), de profil trapézoïdal, large à l'ouverture de 1,30 à 1,60 mètre, a une profondeur de 0,60 à 0,80 mètre. Le fossé $\mathrm{F} 361$ (S9) est un recreusement ponctuel de F254. Le fossé sud, F251 (fig. 5 et 8) adopte un profil en forme de «U » aux bords évasés, parfois trapézoïdal (S2). Il est large de 1 à 1,50 mètre pour une profondeur de 0,50 à 0,70 mètre.

Si ces fossés-limite sont espacés de douze à treize mètres, il ne faut pas en déduire une bande de roulement équivalente : l'espace entre les fossés était aussi occupé par deux bas-côtés pouvant, d'après les modèles antiques reconnus, atteindre trois à quatre mètres de large chacun, destinés aux cavaliers, aux piétons et aux troupeaux (Chevallier, 1997).

\section{Des structures gauloises concentrées au sud de la voie}

\section{L'horizon I moyen : quelques fosses et fossés}

21 L'horizon I moyen est constitué des fossés F30 et F34, des fossés-limite de la voie F251 et F254 et des fosses F7, F223, F250 et F276; une concentration de trous de poteaux, localisée entre F30 et le fossé sud de la voie, complète cet horizon (fig. 5 et 6).

Le fossé $\mathrm{F} 30$ au plan en « $\mathrm{Z}$ » présente un profil trapézoïdal ou en « $\mathrm{U}$ », profond de 0,20-0,30 mètre et large de 0,60 à 1 mètre (fig. 7). Le fossé F34, au plan en forme de « L ", montre un fond plat profond de 0,08 mètre et large de 0,70 mètre (fig. 7). Ces fossés 
offrent un comblement de limon sableux gris clair, hydromorphe, avec de petites concentrations de charbon de bois. Ils définissent un axe général est-sud-est - ouestnord-ouest, marquant le parcellaire d'un habitat implanté au sud de la voie, qui est matérialisé au sol dès cet horizon I moyen par les fossés-limite F251 et F254. Le plan dessiné par les fossés F30 et F34 signalerait une entrée en chicane, pour un enclos à animaux par exemple.

Les quatre fosses attribuables à cet horizon I moyen, toutes au sud de l'axe matérialisé par le fossé $\mathrm{F} 34$ et la branche nord de $\mathrm{F} 30$, ont des diamètres de 1,5 à 4 mètres et des profondeurs de 0,30 à 0,45 mètre. Elles présentent des comblements de limons gris plus ou moins foncés qui recelaient des déchets issus de l'habitat: vidanges de foyers, meule, plaques-foyer et tessons de céramique. Leurs profils sont en forme de « $U$ » très évasé (fig. 7: F7). Creusées dans le substrat limoneux et absentes des secteurs au substrat graveleux, ces fosses paraissent destinées à l'extraction de ces limons, par exemple pour la construction de l'habitat. Seule F223 présente un comblement complexe montrant une alternance de limons de teinte claire et de fines couches cendreuses et charbonneuses (fig. 7).

Peut-être non strictement contemporaine, la concentration de trous de poteaux localisée au débouché de l'entrée en chicane déjà évoquée, occupe un espace de 15 x 10 mètres, d'allongement sensiblement est-ouest. Si aucun plan net ne s'y dessine, il est possible d'avancer l'hypothèse d'un habitat grâce à la nature des déchets présents dans les quelques fosses alentours. Ayant une orientation différente de la voie, les fossés F30 et F34 ont sensiblement la même que le fossé F220 de l'horizon I ancien: l'habitat relèverait de contraintes différentes de la voie, mais toujours affirmées.

\section{L'horizon I récent : le développement de l'occupation gauloise}

Il est figuré par deux fossés, de nombreuses fosses et par une palissade (fig. 5 et 6). Deux nouveaux fossés sont creusés; le premier, F23, orienté est-nord-est - sud-sud-ouest, adopte un profil en forme de «U» ouvert, il s'élargit et se creuse vers son extrémité nord, arrondie (fig. 7). Son remplissage est formé d'un limon sableux, gris à gris-jaune, hydromorphe. Son tracé s'intègre à la trame définie à l'horizon I moyen. Le second, F286, mis au jour au sud-est de la voie, lui est pratiquement parallèle et s'échappe sous la berme, vers l'est et la Jouanne. Le segment découvert, large de trois mètres et profond de 0,90 mètre, adopte un profil trapézoïdal (fig. 7), éléments le distinguant des autres fossés. Son comblement, hydromorphe, recèle du charbon de bois, de la terre cuite et de la céramique. Il pourrait s'agir non d'un fossé de parcellaire, mais d'une structure liée à la gestion de l'eau.

Les fosses sont localisées seulement au niveau de la nappe limono-sableuse et deux types se distinguent : celles caractérisées par un comblement « simple » et celles, vastes et plus profondes, au comblement stratifié (tab. 1). Les premières sont des structures de taille petite à moyenne, aux profils en " $\mathrm{U}$ » évasés. Leurs comblements constitués d'un limon hydromorphe de teinte grise, sont enrichis de débris issus d'un habitat : charbon de bois, argile rubéfiée, fragments de plaques-foyer et céramique. Les secondes, au nombre de six, ont un comblement marqué par l'apport successif de rejets d'habitat cendreux, riches en mobilier archéologique et de limons argileux brun clair, jaune ou gris souvent hydromorphes. 
Tableau 1 : Entrammes, « La Carie » : dimensions des fosses au comblement " simple » et au comblement stratifié de l'Horizon I récent (dimensions exprimées en mètres).

Table 1: Dimensions of trenches with "simple" filling and a recent graded filling: Horizon I (metric dimensions).

\begin{tabular}{|c|c|c|c|}
\hline $\mathbf{N}^{\circ}$ & longueur & largeur & profondeur \\
\hline \multicolumn{4}{|c|}{ structures "simples" } \\
\hline 13 & 1,9 & 1,9 & 0,25 à 0,35 \\
\hline 22 & 1,5 & 1,5 & 0,2 \\
\hline 24 & 1,3 & 0,9 & 0,3 \\
\hline 25 & 1,2 & 0,9 & 0,2 \\
\hline 28 & 3 & 1,5 & 0,4 \\
\hline 36 & 6 & 1,7 & 0,4 \\
\hline 239 & 2,2 & 1,2 & 0,55 \\
\hline 246 & 1,7 & 1,4 & 0,75 \\
\hline 247 & 1,8 & 1 & 0,4 \\
\hline 249 & 1,8 & 1,4 & 0,3 \\
\hline 290 & 1,5 & 1 & 0,3 \\
\hline 292 & 0,8 & 0,8 & 0,25 \\
\hline 307 & 4 & 3,6 & 0,25 \\
\hline 322 & 2 & 1 & 0,6 \\
\hline 325 & 2 & 1,2 & 0,05 \\
\hline 330 & 2,7 & 1,8 & 0,3 à 0,4 \\
\hline \multicolumn{4}{|c|}{ structures stratifiées } \\
\hline $35 / 240$ & 5,5 & 5,2 & 0,7 \\
\hline 241 & 2,3 & 2,2 & 0,4 \\
\hline $301 / 302$ & 4 & 3 & 0,8 \\
\hline 308 & 4 & 3 & 0,6 \\
\hline 331 & 2,9 & 2,9 & 1 \\
\hline 341 & 2,8 & 2,5 & 0,6 \\
\hline
\end{tabular}

La palissade suit l'orientation ouest-nord-ouest/est-sud-est commune aux fossés de parcellaire des horizons I ancien et moyen. Suivie sur trente-cinq mètres de long (fig. 5), elle devait se prolonger vers l'ouest. À l'est, elle s'interrompt avec le poteau F297. Les trous de poteau sont de plan quadrangulaire ou plus ou moins circulaires, leurs intervalles se situent autour d'un mètre.

Ces vestiges adoptent une orientation comparable à ceux des horizons I ancien et moyen. Leur orientation ne change pas malgré la présence prégnante de la voie au nord, orientée différemment. Ils obéiraient donc, sur un long terme, à des logiques distinctes.

\section{La céramique laténienne (E. Coffineau et S. Lemaître)}

La céramique offre un répertoire typologique caractéristique du second âge du Fer dans l'ouest de la Gaule (fig. 9 à 12). Si le taux de fragmentation des vases n'a pas toujours permis de distinguer les formes basses des formes «mi-hautes », les grandes catégories repérées cernent la nature de l'occupation et contribuent à la connaissance du vaisselier local du milieu et de la seconde moitié du II siècle av. notre ère et à affiner la chronologie du site. 
Figure 9 : Entrammes, « La Carie »: I'Horizon I, écuelles et coupes. Figure 9: Horizon I : bowl and chalice.

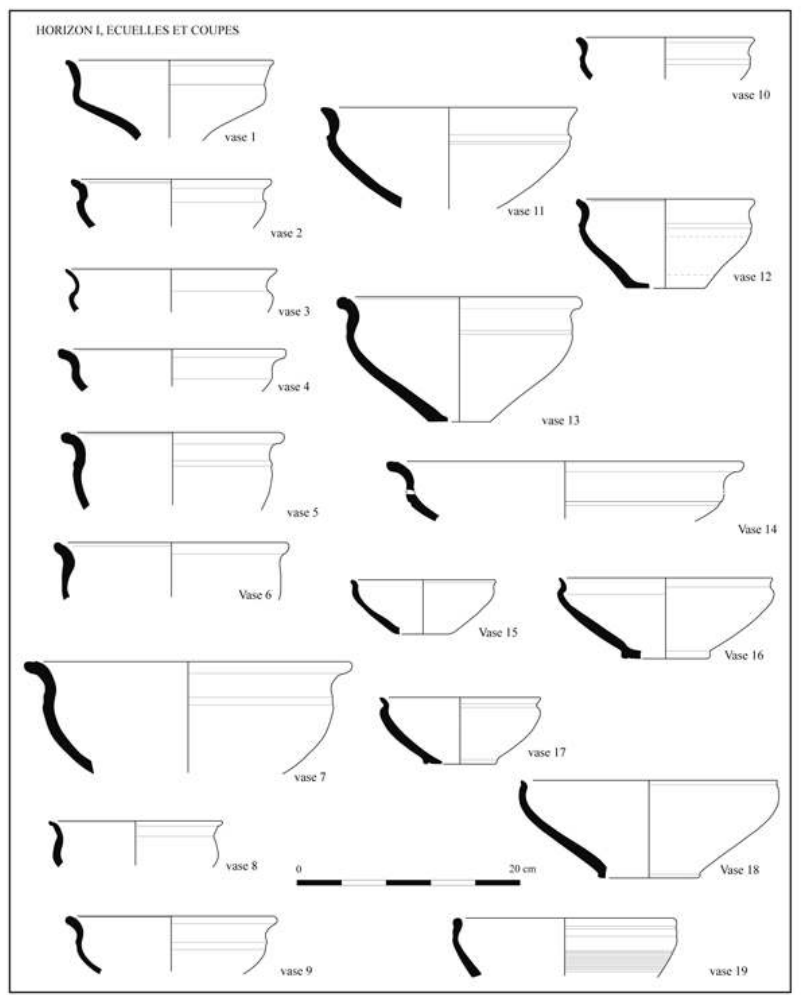

Figure 10 : Entrammes, "La Carie » : I'Horizon I, pots gobelets et vases de stockage. Figure 10: Horizon I: jars, goblets and storage pots.

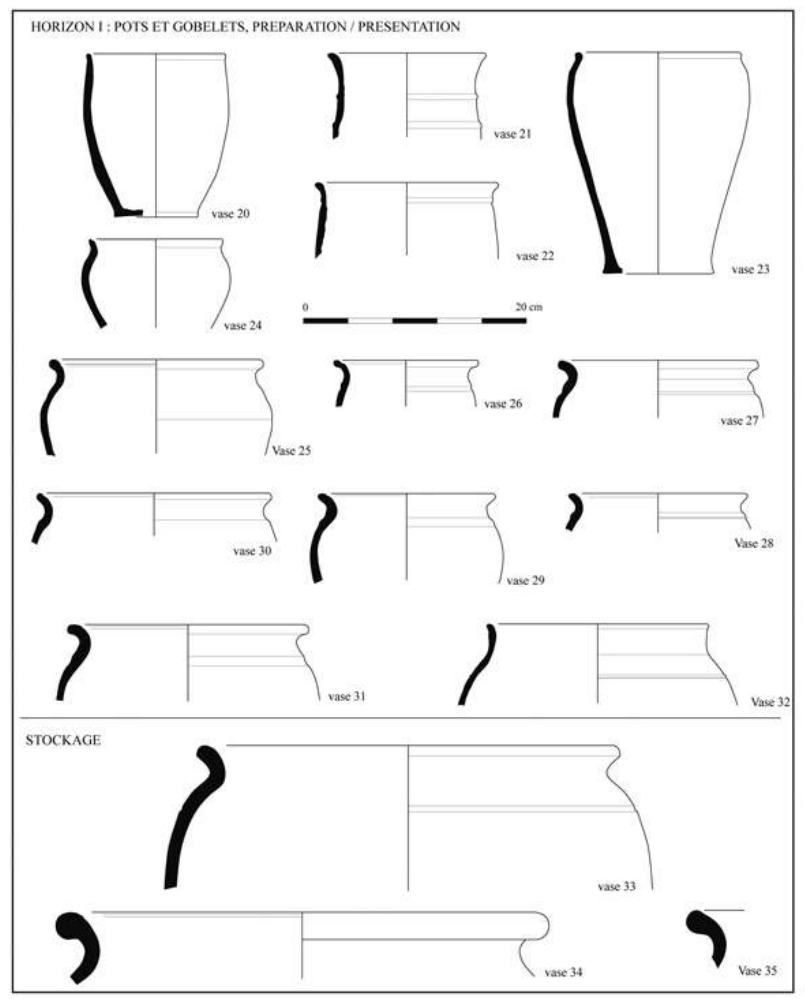


Figure 11 : Entrammes, « La Carie »: I'Horizon I, le vase balustre de F26 et le répertoire des décors. Figure 11: Horizon I: F26 baluster vase and decorative inventory.

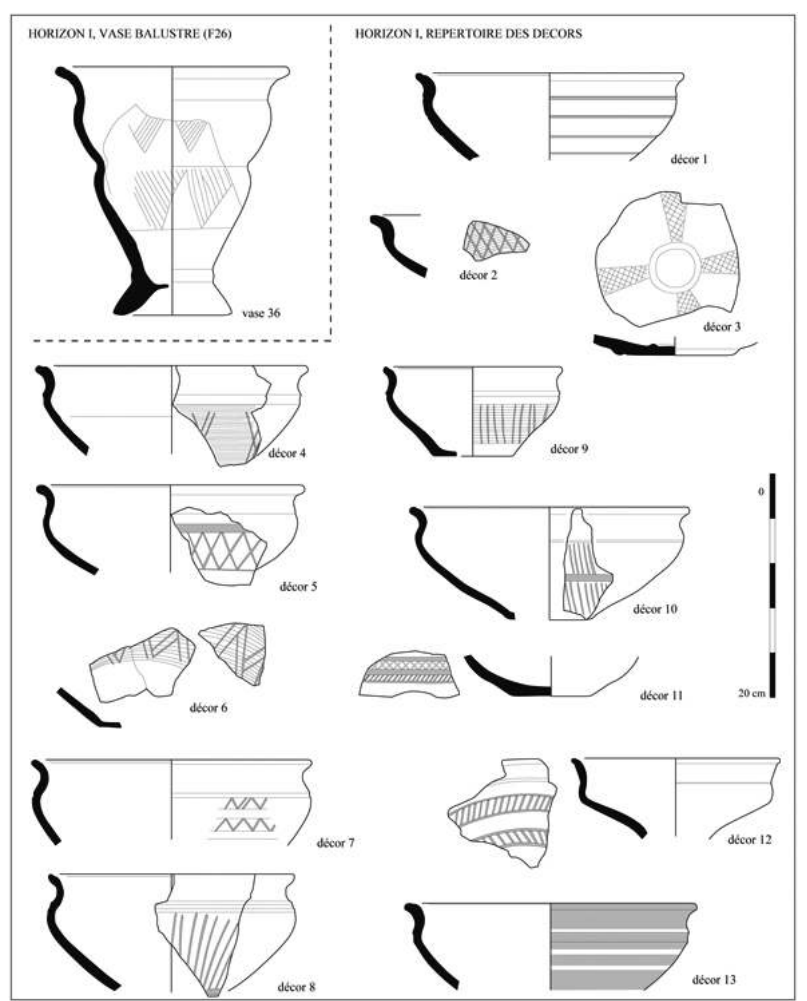

Figure 12 : Entrammes, «La Carie » : Horizon I : les amphores. Figure 12 : Horizon I: amphorae.

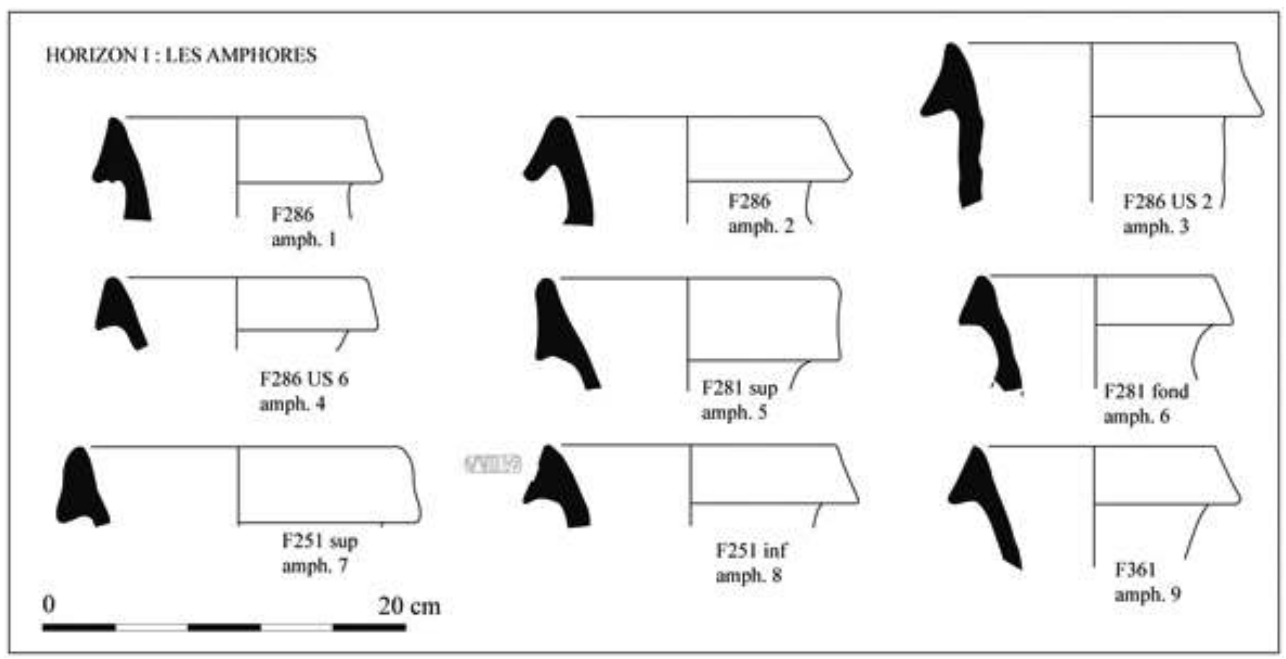

Ce sont 892 fragments de panses, 117 bords, 18 lèvres et 50 fonds qui ont été mis au jour. Leur diversité typologique se retrouve dans leurs caractéristiques technologiques : il existerait plusieurs sources d'approvisionnement, facilitées par la position du site le long d'une voie. On distingue quatre groupes techniques: les céramiques à pâte siliceuse micacée, brune à noire, granuleuse et parfois lissée, les gros contenants à pâte siliceuse grossière, grise à noire, à la surface externe souvent peignée ; les vases à pâte siliceuse orange et enfin, la vaisselle à pâte fine micacée noire, soigneusement lissée et spécifiquement destinée à la table. Ces céramiques accompagnées d'amphores gréco- 
italiques/Dressel 1A, sont présentées sous la forme d'un corpus reprenant les principaux types par grandes catégories : les écuelles et coupelles, les pots, les gobelets et les amphores.

\section{Les écuelles, les coupelles et les formes mi-hautes} (vase 24) ou à lèvre haute et ornés de cordons (vase 21). Ces formes peu communes trouvent une comparaison à « La Pièce de Bildoux » dans la Sarthe (Maguer et al., 2003). Les pots à cuire à panse ovoïde (dix-huit vases) sont parfois ornés d'un cordon sous le col (fig. 10, 27 à 29) ou d'une incision sur la panse (vase 25). Le seul pot à panse globulaire (vase 32) a un parallèle sur l'oppidum de Moulay (Boissel et al., 1972 ; Naveau (dir.), 1997). Les nombreux pots de stockage ont un diamètre supérieur à trente centimètres (quinze individus). Ils sont à lèvre déversée arrondie (fig. 10, vases 33 à 35) et trouvent des comparaisons à «La Carrière d'Écorcé ", à l'est d'Entrammes (Naveau, 1977).

\section{Les décors}

Les décors sont portés sur les écuelles et quelques gobelets; les incisions couvrant toute la panse sont fréquentes (fig. 11 : décor 1) ainsi que les cordons (fig. 10, vase 21) et peuvent être combinés. Le cordon, un caractère classique de La Tène finale en Mayenne (Bouvet, 1997, p. 226) est présent dès La Tène moyenne en Bretagne sur le site de Boisanne (Menez, 1996) et en Mayenne, à Entrammes à «La Carrière d'Écorcé » et sur l'oppidum (Naveau, 1982) ainsi qu'à Jublains (Naveau (dir.), 1997). Les panses, parfois 
peignées, peuvent recevoir en surimpression un décor de bandes lissées formant des croisillons simples (décors 2 et 3) ou doubles (décor 4) ainsi que des chevrons simples (décor 5), doubles (décor 6) ou sur deux registres (décor 7). L'autre répertoire est celui des bandes lissées verticales rayonnantes (décors 8 à 10). Deux écuelles ont un registre de décor plus complexe associant stries et croisillons (décor 11).

L'association du peignage avec des bandes lissées est une technique régulièrement appliquée sur la céramique mayennaise et en Sarthe par exemple (Maguer et al., 2003). Certains décors encadrés de bandes lissées sont courants en Bretagne, sur les sites de Boisanne (Menez, 1996) et Saint-Symphorien (Le Goff, 1994). Cette caractéristique armoricaine se retrouve sur les formes hautes à Jublains et sur les écuelles à Entrammes.

\section{Les amphores}

Le site a livré soixante-et-onze tessons d'amphores (NMI de 10) dans treize structures (tab. 2). Principalement d'origine italique, ce sont des productions républicaines destinées au transport du vin : amphores gréco-italiques et Dressel 1A produites dans la seconde moitié du $\mathrm{II}^{\mathrm{e}}$ siècle av.J.-C. Cette datation n'est pas démentie par les autres éléments morphologiques associés : anses, fonds et épaules. Ce lot s'apparente à celui découvert au fond des fossés de l'enclos monumental des Natteries à Cholet (Maguer, 2000).

Tableau 2 : Entrammes, « La Carie » : les amphores républicaines, données quantitatives par faits archéologiques.

Table 2: Republican amphorae, quantitative data by archeological facts.

\begin{tabular}{|c|c|c|c|c|c|c|c|c|c|}
\hline Faits & US & NR & Bords & Fonds & Anses & Épaules & Fgts & NMI & Origine \\
\hline F35 & & 1 & & & & & 1 &. & italique \\
\hline F223 & & 1 & & & & & 1 &. & italique (Campanie ?) \\
\hline F246 & & 2 & & & 1 & & 1 &. & italique \\
\hline F276 & & 4 & & & 2 & & 2 & & italique \\
\hline F307 & & 9 & 1 & & 2 & & 6 & 1 & $\begin{array}{c}\text { italique (dont 1 } \\
\text { Campanie) }\end{array}$ \\
\hline F308 & & 5 & & & 2 & & 3 & & $\begin{array}{c}\text { 1 Bétique et italique } \\
\text { (dont 1 de Campanie) }\end{array}$ \\
\hline F23 & & 1 & & & & & 1 & & $\begin{array}{c}\text { italique (dont 1 } \\
\text { Campanie) }\end{array}$ \\
\hline F286 & US 2 & 7 & 1 & & 1 & 1 & 4 & 1 & $\begin{array}{c}\text { italique (dont 2 } \\
\text { Etrurie ?) }\end{array}$ \\
\hline & US 6 & 1 & 1 & & & & & 1 & Italique (Campanie) \\
\hline & Sans n & 16 & 3 & 1 & 1 & & 11 & 2 & $\begin{array}{c}\text { italique (dont 3 } \\
\text { Campanie) }\end{array}$ \\
\hline F254 & & 2 & & & & & 2 & & $\begin{array}{c}\text { italique (dont 1 } \\
\text { Campanie) }\end{array}$ \\
\hline F281 & Niv. Sup. & 6 & 2 & & 1 & & 3 & 1 & italique \\
\hline & Niv. Inf. & 5 & 1 & & & & 4 & 1 & $\begin{array}{c}\text { italique (2 Campanie } \\
\text { et 2 Italie centrale) }\end{array}$ \\
\hline F360 & & 4 & & & & & 4 & & italique (2 Campanie) \\
\hline F251 & 1 & 1 & & & & & 1 & & italique (Etrurie ?) \\
\hline & Niv. Sup. & 2 & 1 & & & 1 & & 1 & italique \\
\hline & Niv. Inf. & 3 & 1 & & & & 2 & 1 & $\begin{array}{c}\text { italique (Italie } \\
\text { centrale ?) }\end{array}$ \\
\hline F361 & & 1 & 1 & & & & & 1 & italique \\
\hline Total & & 71 & 12 & 1 & 10 & 2 & 46 & 10 & \\
\hline
\end{tabular}




\section{Les amphores de l'habitat}

37 Six fosses ont livré des fragments en quantité modeste (F35, 223, 246, 276, 307 et 308) dont seules les trois dernières des fragments sont identifiables. Il s'agit d'anses dont les dimensions permettent de les attribuer à des amphores Dressel 1A ou des types de transition entre gréco-italique et Dressel 1A (Stöckli, 1979) de la deuxième moitié du $\mathrm{II}^{\mathrm{e}}$ siècle av. J.-C.

\section{Les amphores du fossé F286}

La hauteur des lèvres, supérieure ou égale à $30 \mathrm{~mm}$ et inférieure à $42 \mathrm{~mm}$, indique des amphores gréco-italiques / Dressel 1A de transition (fig. 12, amph. 1 à 4). Tous les bords sont de section triangulaire avec des inclinaisons comprises entre $63^{\circ}$ et $77^{\circ}$ que l'on peut associer à des formes de transition entre gréco-italiques et Dressel 1A. Cette production peut être datée entre les années 150 et 100 av. J.-C. (Tchernia, 1986).

\section{Les amphores des fossés-limite de la voie}

39 Le fragment de bord mis au jour dans le comblement supérieur du fossé nord - F254 = F281 = F360 (fig. 12, amph. 5) - appartient à une amphore de type Dressel 1A à lèvre en bandeau vertical datée des années 140-130 av. J.-C. par comparaison avec celles des « Natteries » à Cholet dans le Maine-et-Loire (Maguer, 2000). Le bord associé au comblement inférieur du même fossé, de section triangulaire (amph.6) appartient à une amphore gréco-italique (hauteur inférieure à $30 \mathrm{~mm}$ ), ce qui le placerait vers le milieu du $\mathrm{II}^{\mathrm{e}}$ siècle av. J.-C.

Le comblement du fossé sud (F251) a fourni une amphore Dressel 1A (fig. 12, amph. 7) et une amphore de transition gréco-italique / Dressel 1A (amph. 8), l'ensemble respectant le faciès du fossé F254. Le comblement de F361 a livré un bord d'amphore de transition gréco-italique / Dressel 1A (amph. 9), qui s'inscrit dans le même cadre chronologique.

\section{La céramique d'époque gauloise : éléments de conclusion}

41 Les ensembles retrouvés à «La Carie » sont constitués d'écuelles et de céramiques mihautes aux formes et aux décors variés; les pots, en quantité moindre, ont une morphologie plus standardisée, pauvre en décors. L'homogénéité chronologique de la céramique est remarquable. Elle est attribuable au milieu et à la seconde moitié du $\mathrm{II}^{\mathrm{e}}$ siècle av. J.-C., notamment par la cannelure labiale interne, un bon marqueur chronologique. Elle est fréquente durant tout le $\mathrm{II}^{\mathrm{e}}$ siècle av. J.-C. et disparaît au début $\mathrm{du} \mathrm{I}^{\mathrm{er}}$ siècle av. J.-C. Cette datation est confirmée par celle des amphores qui sont des productions « de transition » entre le type gréco-italique et le type Dressel 1A, dont on place la production dans la seconde moitié du $\mathrm{II}^{\mathrm{e}}$ siècle av. J.-C. (Tchernia, 1986). L'ensemble présente un vaisselier caractéristique des sites de consommation: on y retrouve les céramiques liées au transport et au stockage (amphores et vases à réserve), à la préparation et la consommation des denrées alimentaires (écuelles, jattes, gobelets).

42 Le vase exceptionnel de la fosse F26 (fig. 11, vase 36), le plus ancien mis au jour, signe la phase initiale du site (horizon I ancien). Cette forme haute à profil biconique est décorée de bandes lustrées formant des triangles disposés en bande sur deux registres. 
Un vase proche, sans décor, trouvé à Plouër-sur-Rance dans les Côtes-d'Armor (Menez, 1996), est daté de la transition La Tène $\mathrm{C} 1 / \mathrm{C} 2$.

\section{L'instrumentum}

Il n'est ni varié ni abondant (fig. 13). Ces éléments caractéristiques d'un environnement domestique (Buchsenschutz et al., 2000) se trouvent régulièrement sur les sites laténiens régionaux. Les plaques-foyer, quadrangulaires, sont très fragmentées. Le ressaut sur le contour d'un fragment est une particularité déjà notée à Marcé dans le Maine-et-Loire (Nillesse, 2003) ; il devait maintenir sur la plaque une préparation plus ou moins liquide mise à cuire. Le matériel de mouture, deux metae et quatre catilli, est attribuable à la fin de La Tène C2-La Tène D1 (F7-3) et à la seconde moitié de La Tène D1 ? (F223-4). Leurs matériaux, grès roussard et plusieurs granites, témoignent d'une diversité d'approvisionnement, soulignant divers points de production, non loin autour d'Entrammes.

Figure 13 : Entrammes, « La Carie » : I'instrumentum laténien : fusaïole, plaque-foyer, peson et meules.

Figure 13: La Tène instrumentum: spindle whorl, hearth stone, weighing scale and millstones.

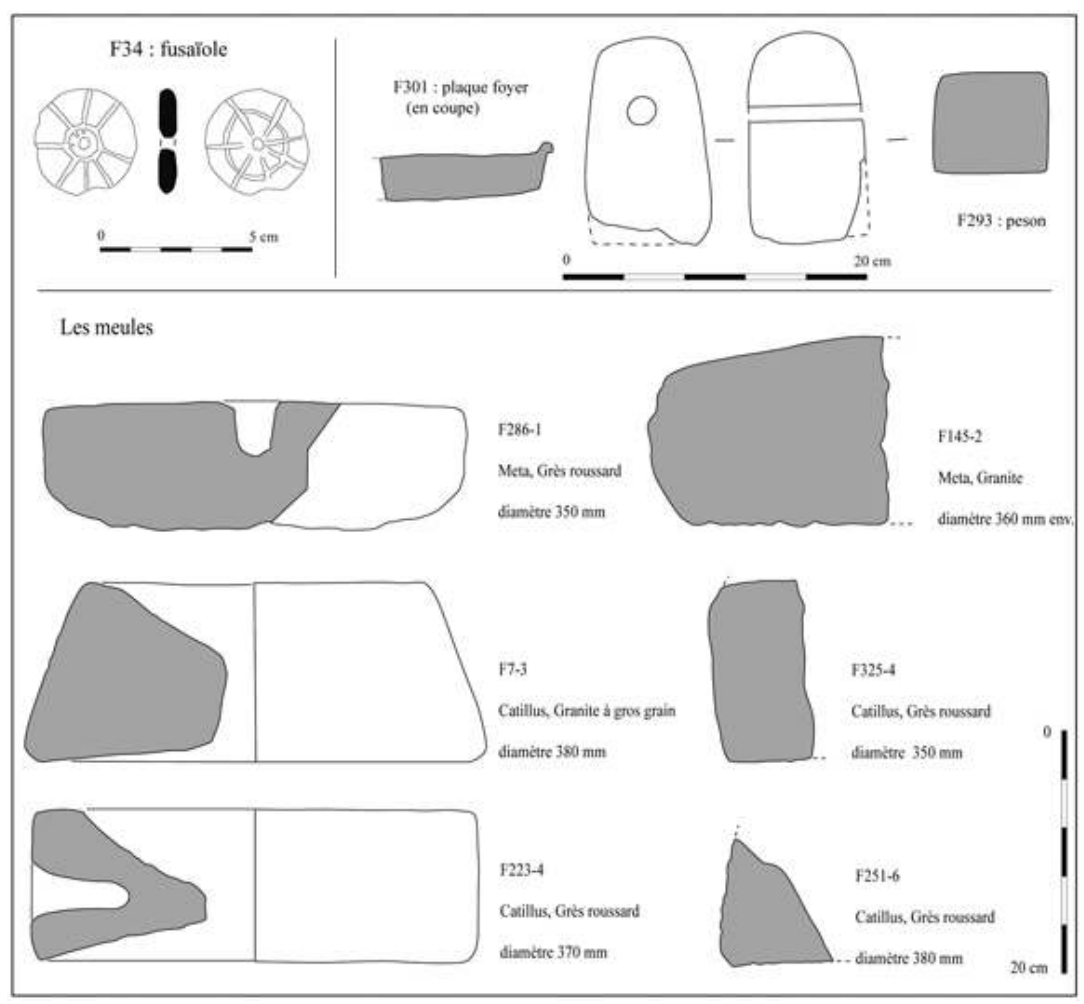

\section{La période gauloise : premiers éléments de synthèse}

Les vestiges les plus anciens apparaissent modestement dès la fin du III $/$ début du $\mathrm{II}^{\mathrm{e}}$ siècle av. notre ère (horizon $\mathrm{I}$ ancien), leur succèdent vers le milieu du $\mathrm{II}^{\mathrm{e}}$ siècle av. notre ère ou un peu avant (horizon I moyen), un petit habitat et des fossés qui marquent l'emprise d'une voie (fig.5). La seconde moitié du $\mathrm{II}^{\mathrm{e}}$ siècle voit l'aménagement de plusieurs fossés et fosses et d'une palissade (horizon I récent). Ces éléments se limitent essentiellement à une zone située entre huit et quarante mètres au 
sud de la voie et leur superposition sur un siècle (fig. 5) évoque un habitat groupé, se densifiant (fig. 6), et dont la période d'occupation ne dépasse pas la fin de La Tène D1 (fig. 9 à 12).

Nos premières interrogations ont trait à l'articulation chronologique voie-habitat. En effet, est-ce ce dernier (dès l'horizon I ancien) qui s'est établi en premier, sans rapport avec une éventuelle voie ou bien est-ce ce passage qui a généré l'habitat ? Le problème demeure entier, le parcellaire lié à l'habitat ne calquant jamais, pendant cette période, son orientation sur la voie, élément supposé structurant. Il est possible qu'elle ait existé dès l'horizon I ancien (et peut-être plus anciennement) mais sans faire l'objet d'aménagements spécifiques ; quoi qu'il en soit, les restes mis au jour dans les fosséslimite sont attribuables à l'horizon I moyen. D'une manière générale, la voie et l'habitat obéissent à des logiques différentes, l'habitat est plutôt lié à un parcellaire, relevant ici plus d'une sphère privée, locale et la voie dépendrait d'une dynamique «publique »: son tracé a pu s'effectuer hors d'une contrainte parcellaire. Nous émettons l'hypothèse d'une mise en place du parcellaire, antérieure à la matérialisation de la voie.

D'après la chronologie générale des oppida (Fichtl, 2005, p. 36-40), il semblerait que nos horizons I ancien et moyen soient antérieurs à la grande période d'édification des oppida de La Tène D1. Seuls quelques-uns, tels Závist ou Manching, prétendent à une occupation aussi haute. De nombreux autres oppida de la Gaule chevelue, tardifs (La Tène D2), tels que Villeneuve, Pommiers, Gondole ou Gergovie, remontent à une période où l'habitat de "La Carie » est déjà abandonné. Seul notre horizon I récent, couvrant la seconde moitié du $\mathrm{II}^{\mathrm{e}}$ siècle av. notre ère, correspond à une phase d'édification de quelques grands oppida comme le Titelberg, Metz, Besançon, Variscourt ou le Mont-Beuvray. La voie et l'habitat de «La Carie " préexisteraient à la création de l'oppidum du «Port-du-Salut» dont les quelques éléments matériels mis au jour remontent effectivement à La Tène C2/D1.

Enfin, en dernier lieu, quid de cette voie? Elle est matérialisée au cours de notre horizon I moyen, vers le milieu du $\mathrm{II}^{\mathrm{e}}$ siècle av. notre ère; nous sommes donc assez éloignés des datations traditionnelles qui nous renvoient au plus tôt au réseau d'Agrippa (Chevallier, 1997, p. 219). Jacques Naveau (1997, p. 53) envisageait pour la voie Le Mans-Rennes-Corseul, l'existence de tronçons dès l'âge du Fer. Il a en effet observé une corrélation entre l'implantation des habitats de cette période et le tracé de la voie supposée antique. En revanche, il n'a pas osé aller suffisamment au-delà du concept historiographique de la « voie romaine » pour la qualifier de gauloise.

En Bretagne, nous signalons une voie du III $^{\mathrm{e}}$ siècle av. notre ère à Paule dans les Côtesd'Armor (Menez, Villard-Le Tiec, 2003). Toujours en Bretagne, le franchissement de la Seiche à Visseiche en Ille-et-Vilaine par la voie antique Rennes (Condate)-Angers (Juliomagus) remonterait au milieu du $\mathrm{II}^{\mathrm{e}}$ siècle av. notre ère (Leroux, 2002). Si l'archéologie de sauvetage livre quelques éléments définissant des cheminements gaulois, les auteurs anciens, tel C. Jullian, n'hésitaient pas à en admettre l'existence entre les oppida, étant confortés en cela par des passages de César (BG, VII, § 57-62, § $10,11$ et $12, \S 42,43$ et 55$)$.

49 Si la question d'une origine gauloise de la voie antique fouillée à « La Carie » ne se pose plus, des interrogations subsistent quant à sa destination. Traditionnellement, ni la ville du Mans ni celle de Rennes ne seraient d'origine gauloise et jusqu'à une date assez récente, la ville d'Angers était dans le même cas. À la lumière de découvertes récentes à Angers (Bouvet et al., 2003), les éléments mis en évidence par G. Leroux (2002) sur la 
Seiche ne sont plus isolés et témoignent de ce que certaines des villes dites " antiques » de l'ouest de la Gaule pouvaient avoir une origine gauloise.

\section{Les premières traces de l'occupation gallo-romaine: la période julio-claudienne, I'horizon II}

50 Si la transition La Tène D1/D2 marque l'abandon des derniers habitats gaulois, les premiers éléments d'époque gallo-romaine apparaissent un siècle plus tard, à la période tibérienne voire un peu plus tôt. Entre-temps, la voie continuerait d'être utilisée, mais nous n'en avons aucune preuve directe. Dans cet intervalle, des éléments majeurs interviennent dans le paysage. L'occupation de l'oppidum du " Port-du-Salut », à l'ouest de « La Carie » est, avec la Conquête, transférée sur un site nouveau implanté à l'est de "La Carie », sous le bourg actuel d'Entrammes (fig. 3). Le tracé de la voie qui lie ces deux pôles est inchangé.

\section{Les premières structures d'époque gallo-romaine}

\section{La voie gallo-romaine}

51 L'emprise de la nouvelle voie, y compris les fossés bordiers ${ }^{6}$, varie de dix à douze mètres (fig. 14). Son tracé, reprenant nettement celui de l'horizon I, est légèrement rétréci au nord et au sud. Les nouveaux fossés ne sont pas aussi marqués que ceux de l'horizon précédent, surtout pour celui placé au nord, F376. Ce dernier est à peine creusé dans le substrat graveleux (fig. $8: \mathrm{S} 2$, S9 et S13). Large d'environ deux ou trois mètres, sa profondeur n'excède pas 0,20-0,30 mètre. Le fossé sud, F425, est bien marqué vers l'ouest de la zone fouillée (fig. $8, \mathrm{~S} 2$ ), tandis que plus bas, sur la pente, en direction du gué sur la Jouanne, il s'élargit et n'est plus qu'une simple dépression (fig. 8, S9 et S13). Sa largeur est de trois mètres pour une profondeur de 0,60 mètre. Son comblement, à l'image du fossé nord F376, est constitué d'une succession de niveaux sableux de teinte blanche, parfois salis de noir par du charbon de bois et de niveaux sablo-limoneux grisâtres à verts, localement riches en mobilier. Le niveau de cailloutis compact, F405, qui occupe tout l'espace entre les fossés de bord de voie, signale une bande de roulement à l'est (fig. $8, \mathrm{~S} 9$ et $\mathrm{S} 13$; fig. 15). Vers l'ouest, cette dernière est matérialisée par de grands blocs schisteux soigneusement disposés à plat (fig. 8, S2, F102). 
Figure 14 : Entrammes, « La Carie » : plan général des structures de la période julio-claudienne : I'Horizon II.

Figure 14: general layout of buildings from the Julio-Claudian period: Horizon II.

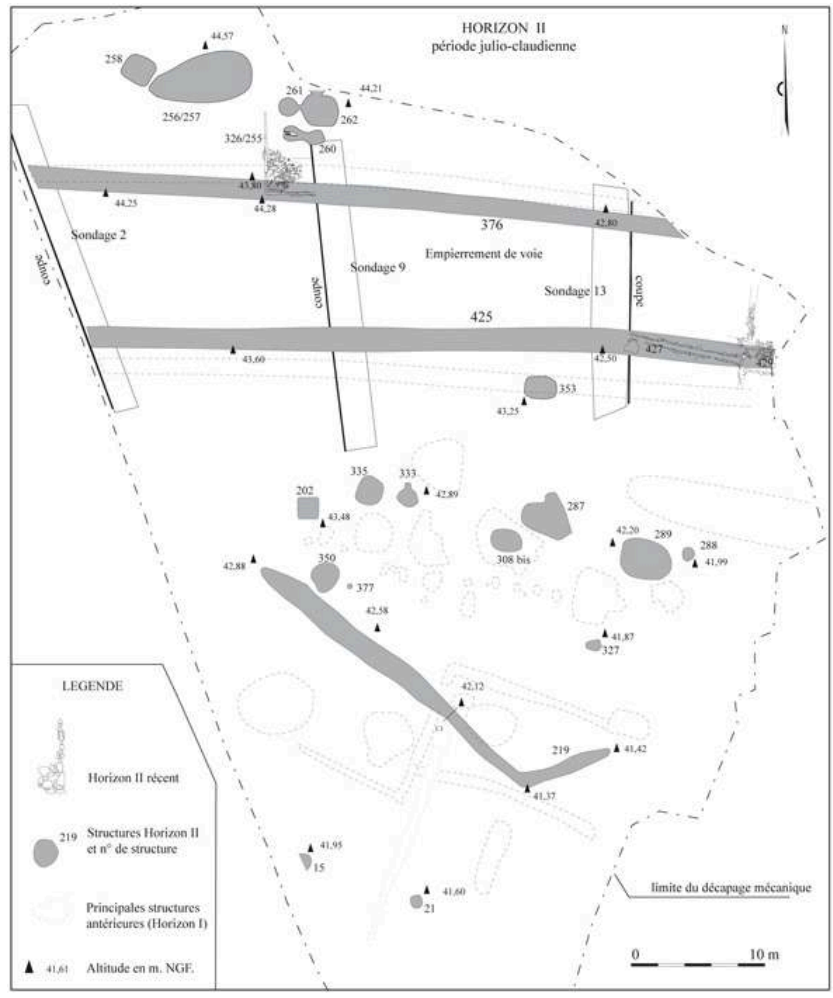


Figure 15 : Entrammes, « La Carie » : le niveau de voie F405 de l'Horizon II (ler plan) et le remblai de voie F283 de l'Horizon IV (2e plan) au niveau du sondage 13, vue prise vers l'ouest (cliché équipe de fouille).

Figure 15: The level of route F405, Horizon II (foreground) and the backfilling on route F283,

Horizon IV (background) at sampling level $n^{\circ} 13$, looking west (photo: excavation team).

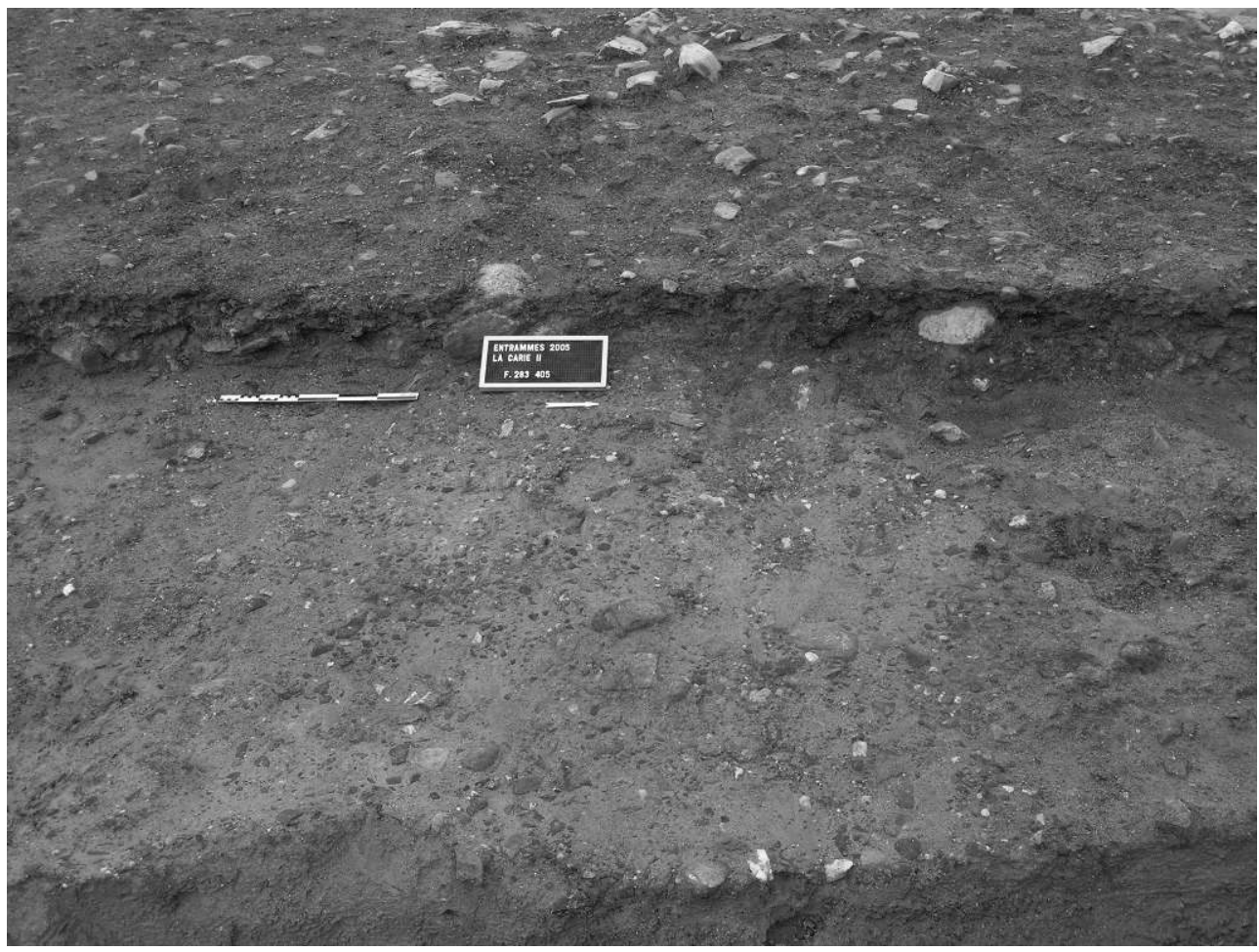

\section{Les structures au sud de la voie}

Il s'agit du fossé F219 et d'une petite série de fosses (fig. 14) dont deux, tibériennes, aux traits spécifiques, seront détaillées. Le fossé F219, qui s'inscrit pleinement dans la partie décapée du site, offre un plan en forme de « $\mathrm{L}$ », légèrement ouvert. Large de 1,40 à 2 mètres et profond de 0,50 mètre, son profil est en forme de " $U$ » ouvert (fig. 16, haut). Son comblement est constitué d'un limon sableux gris, hydromorphe. Ses orientations ne présentent aucun parallèle, notamment par rapport à l'horizon I. Le fossé F219 matérialise une limite nette et cohérente: l'essentiel des structures tibériennes et claudiennes est creusé dans l'espace entre ce fossé en « $\mathrm{L}$ » et la voie antique. Par sa forme caractéristique, il contraint une surface de terrain, estimée à deux cents mètres carrés, peut-être destinée à délimiter un habitat, disparu. 
Figure 16 : Entrammes, « La Carie » : coupe du fossé F219, des fosses F15, F21, plan et coupe de la fosse F353 et du four F260.

Figure 16: F21 9 - section of trench, F15 \& F21 - pits, F353 - plan and section of pit and F260 - oven.

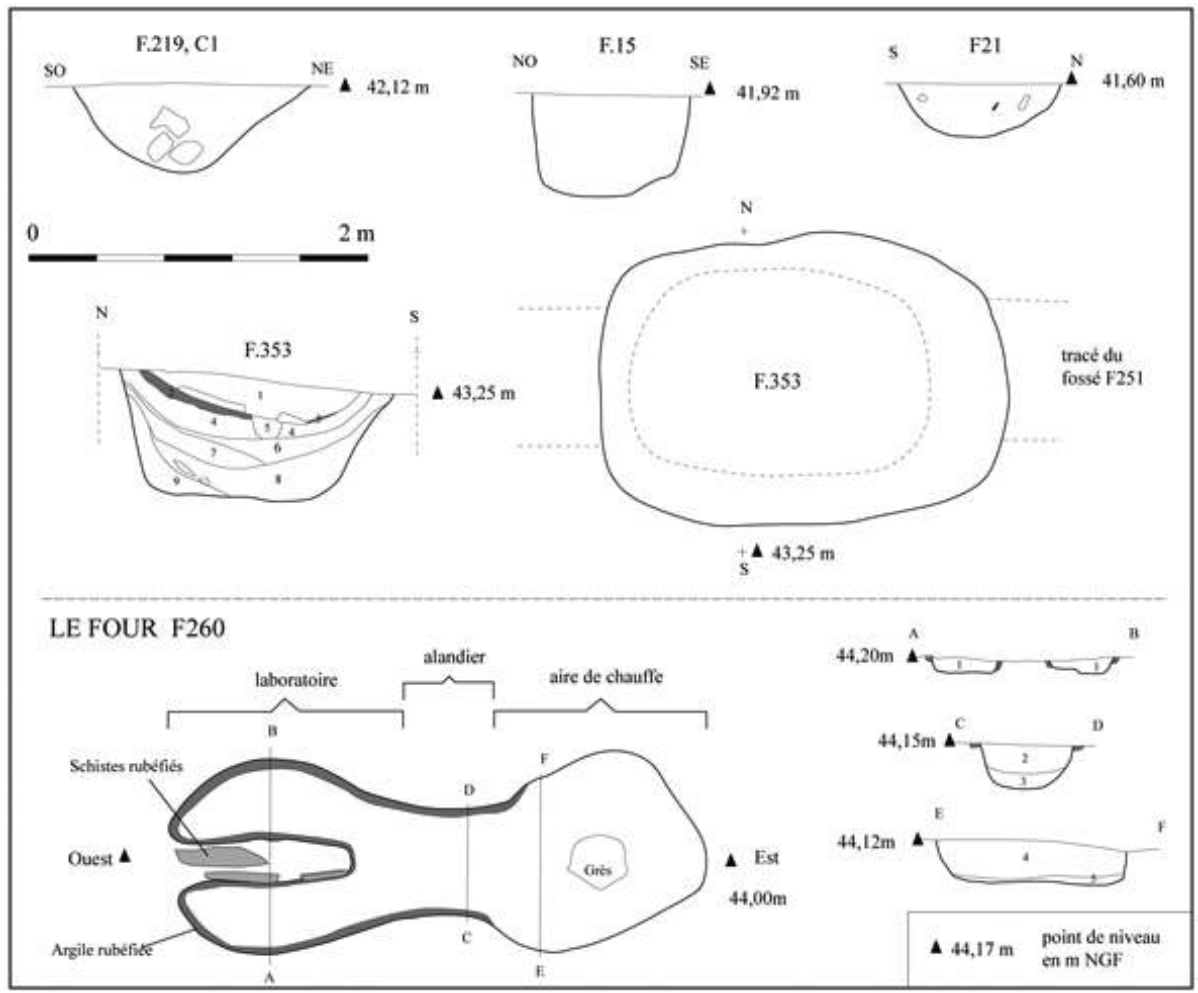

Les autres structures de l'horizon II (tab. 3), constituées de douze fosses et d'un trou de poteau (F377), se déploient entre la voie et le fossé F219; seules deux, F15 et F21, excentrées au sud de ce fossé, ne semblent pas pouvoir leur être rattachées spatialement (fig. 14). Leur répartition structure un espace cohérent : elles s'implantent à une distance d'environ dix ou douze mètres au sud de la voie ${ }^{7}$ (sauf F353) : sept fosses s'alignent d'est en ouest, parallèlement à cette dernière, et matérialisent une limite nette. Associées au fossé en « L », elles limiteraient l'espace d'habitat. Exception faite de F202 et F353 (cf. infra), ce seraient des fosses d'extraction d'argiles et de limons (comme pour l'horizon I). Elles sont de forme circulaire ou ovale, de dimensions variables et leurs profils adoptent une forme de " $\mathrm{U}$ " plus ou moins ouvert (fig. 16: F15 et F21). Pour les structures plus vastes, leurs fonds sont sensiblement plans, leurs remplissages varient peu: des limons sableux, gris à bruns, hydromorphes. Nous y retrouvons les rejets, témoins d'un habitat, que sont du charbon de bois, des cendres, de l'argile rubéfiée, des blocs de schiste ou de grès, quelques fragments de tuiles et de la céramique. 
Tableau 3 : Entrammes, « La Carie » : les fosses de l'Horizon II (dimensions en mètres). Table 3: Trenches: Horizon II (metric dimensions).

\begin{tabular}{|c|c|c|c|}
\hline $\mathbf{N}^{\circ}$ & Longueur & Largeur & Profondeur \\
\hline 15 & 1 & 1 & 0,6 \\
\hline 21 & 1 & 0,96 & 0,3 \\
\hline 202 & 1,6 & 1,6 & 1 \\
\hline 287 & 3 & 2,5 & 0,5 \\
\hline 288 & 1,5 & 1,5 & 0,4 \\
\hline 289 & 4 & 3 & 0,45 \\
\hline 308 bis & 2 & 1,5 & 0,45 \\
\hline 327 & 1,2 & 0,8 & 0,25 \\
\hline 333 & 1,2 & 1 & 0,4 \\
\hline 335 & 2 & 2 & 0,3 \\
\hline 350 & 2 & 2 & 0,6 \\
\hline 353 & 2 & 1,4 & 0,7 \\
\hline 377 (TP) & 0,6 & 0,4 & 0,8 \\
\hline
\end{tabular}

Deux fosses présentent des caractères notables. La première, F202, de plan carré de 1,60 mètre de côté, aux parois verticales et à fond plat, est profonde de 0,80 mètre. Comblée d'une succession de niveaux de limons gris ou bruns, elle recèle du charbon de bois, des tuiles et de la céramique. Les archéologues voient habituellement dans ces excavations des resserres ou de petites caves, destinées au stockage de matières périssables, mais elles peuvent aussi témoigner d'activités artisanales: tissage, tabletterie... La seconde fosse, F353, est implantée sur le tracé du fossé gaulois de bord de voie F251, alors probablement encore en partie visible. Cette fosse quadrangulaire, aux angles nettement arrondis, offre un profil en « $U$ » ouvert à fond plat (fig. 16). Dans son comblement, des rejets cendreux et deux nappes d'argile rubéfiée suggèrent de la lier à un four domestique (fosse de travail ?).

\section{De nouvelles structures au nord de la voie : les fours de potiers}

\section{Le petit four F260}

Il est situé à deux mètres au nord du fossé soulignant la voie. Long de 3,10 mètres, il est constitué d'ouest en est d'un laboratoire, d'un alandier et d'une aire de chauffe (fig. 16, bas). Le laboratoire de forme oblongue, de 1,10 à 1,20 mètre de diamètre, présente en son milieu une languette, rattachée à la paroi opposée à l'alandier, ses parois sont rubéfiées. L'alandier, large de 0,50 mètre, est conservé sur 0,25 mètre de profondeur. L'aire de chauffe, exiguë, mesure de 1 à 1,10 mètre de côté ; la profondeur conservée varie de 0,20 à 0,26 mètre et la rubéfaction de l'alandier s'y prolonge un peu, matérialisant le gueulard ${ }^{8}$. L'état d'arasement de ce four s'expliquerait par le fait qu'il ait été creusé dans le talus bordant au nord la voie gauloise. 


\section{Le grand four F261/262} est, ce sont un laboratoire (F261), un alandier rétréci et une aire de chauffe (F262) ; l'ensemble mesure 4,50 mètres de long (fig. 17 et 18).

Figure 17 : Entrammes, « La Carie » : le four F261/262, plan, coupes et relevé de détail de la languette.

Figure 17 : F261 \& 262 - oven, plan, sections and detail of the narrow tongue.

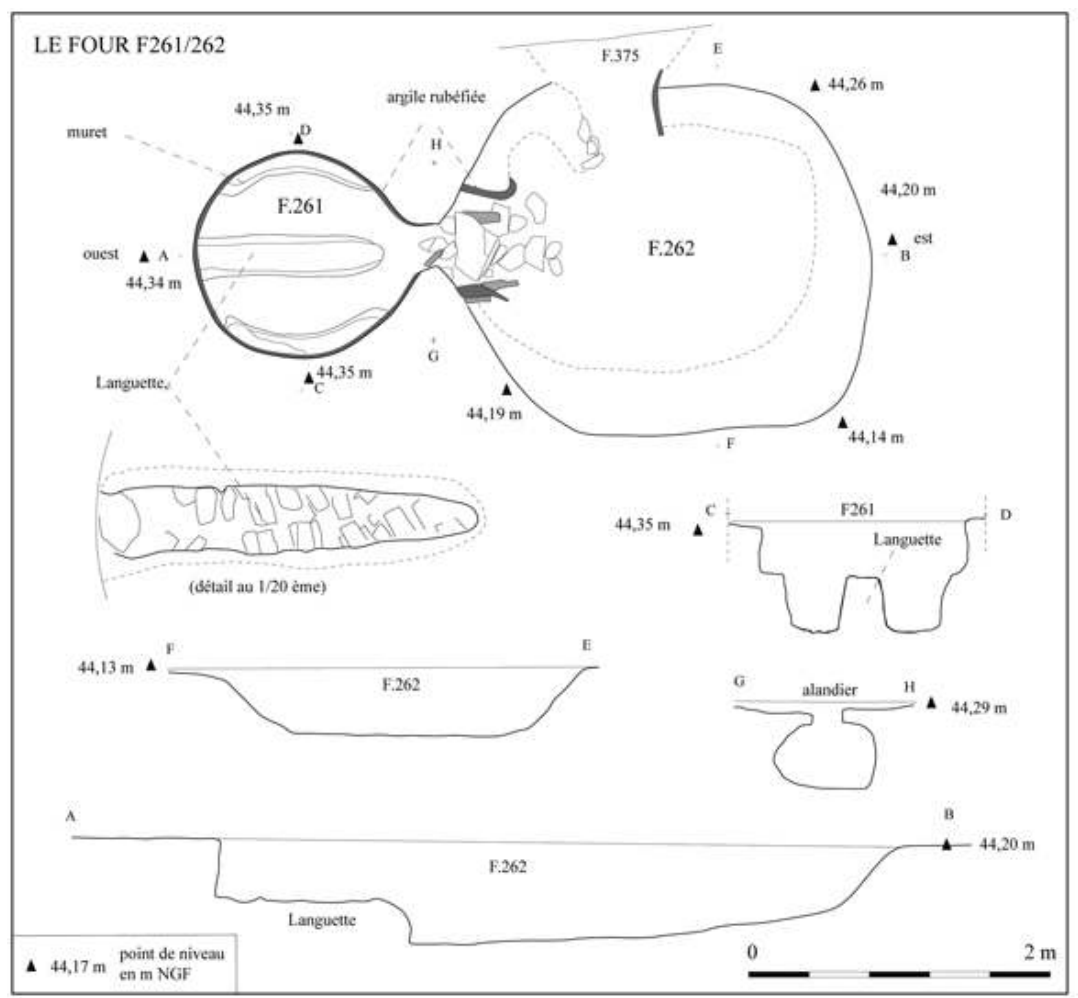


Figure 18 : Entrammes, « La Carie » : le four F261/262, vue générale, prise vers l'ouest. Cliché équipe de fouille.

Figure 18 : F261 \& 262 - oven, general view looking west. Photo: excavation team.

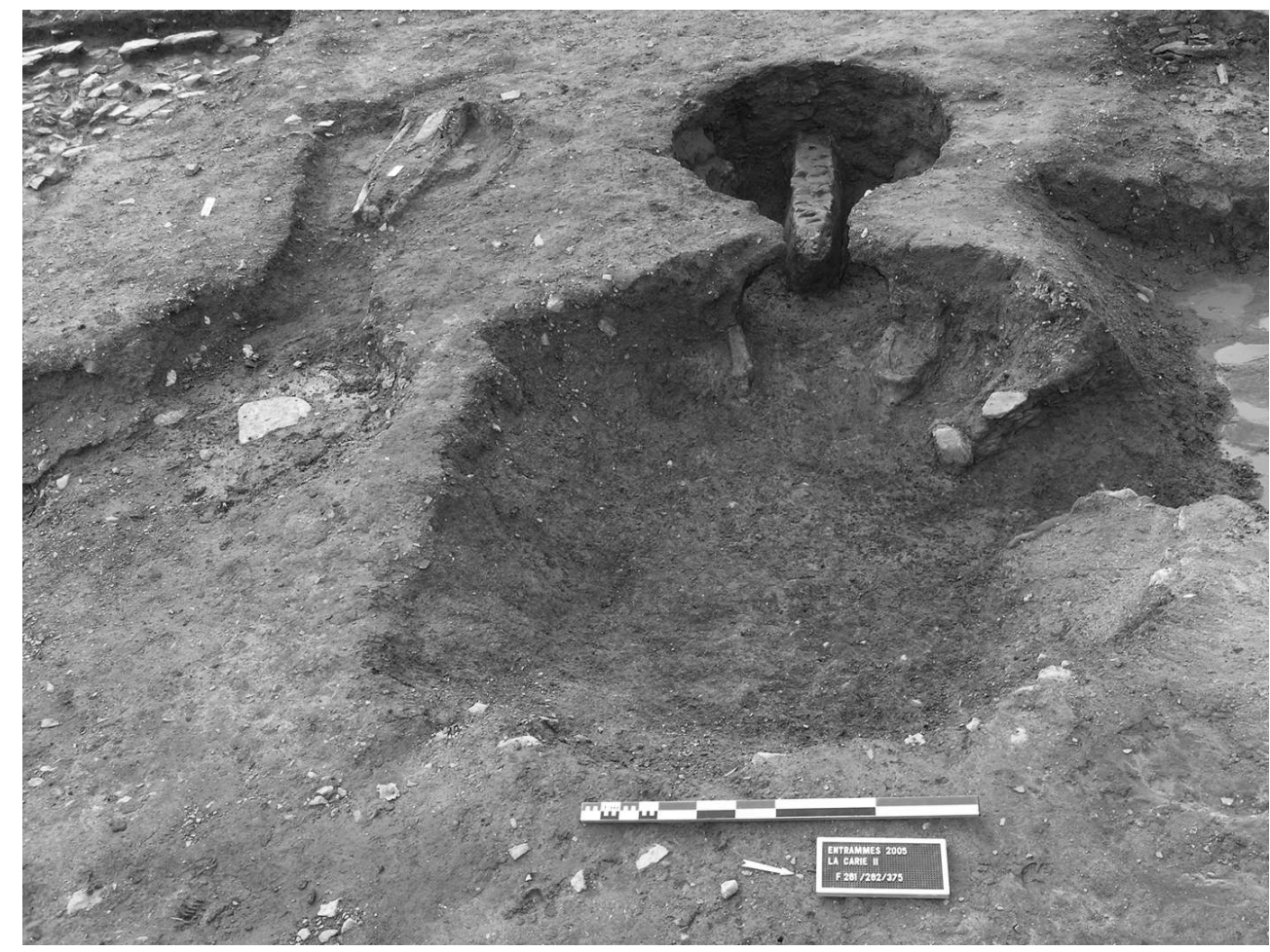

57 Le laboratoire F261, circulaire et intégralement rubéfié, mesure 1,40 mètre de diamètre et sa profondeur est de 0,70 à 0,75 mètre. Il présente en son milieu une languette rattachée à la paroi opposée à l'alandier (coupe A-B). Cette languette, intacte, mesure 1,24 mètre de long, elle est large de 0,20 à 0,28 mètre (à la base) pour une hauteur de 0,40 mètre. Sa partie supérieure, plane et soigneusement lissée, présente une série d'encoches rectangulaires ou losangiques effectuées dans l'argile fraîche (F261 : relevé de détail et fig. 19). Nous avons aussi relevé, placés symétriquement par rapport à la languette, deux petits murets (ou margelles), plaqués contre les parois nord et sud du four et formant une saillie de 0,16 à 0,20 mètre de largeur. Les niveaux supérieurs de ces murets et de la languette sont placés sur le même plan (coupe C-D). L'alandier, relativement court, est totalement rubéfié et presque intact; son profil est circulaire (coupe G-H). L'aire de chauffe F262 mesure 2,70 x 2,30 mètres, et est profonde de 0,60 à 0,64 mètre; elle offre des parois évasées et un fond plan (coupes A-B et E-F). La rubéfaction de l'alandier se prolonge légèrement dans l'aire de chauffe matérialisant le gueulard.

Figure 19 : Entrammes, « La Carie » : le four F261/262, vue de détail de la languette.Cliché équipe de fouille.

Figure 19: F261 \& 262 - oven, view of detail on the narrow tongue. Photo: excavation team.

58 Un second alandier, F375, implanté au nord de l'aire de chauffe, témoigne de la présence d'un second four, détruit récemment. Il est postérieur à F261 dont l'alandier est alors obstrué de blocs de grès, de schiste et d'argile rubéfiée. Ce n'est pas une "batterie» de fours puisqu'ils se succèdent, fait presque toujours vérifié dès lors qu'une fouille minutieuse est engagée (Dufä̈, 1996, p. 307). 
59 La présence, sur le fond du laboratoire F261 de nombreux blocs de schiste rubéfiés, longs de 0,30 à 0,55 mètre, de section losangique à rectangulaire variant de 0,05 à 0,10 mètre de côté, est corrélée avec les encoches relevées sur la languette. Ces dernières, procédant d'un système rayonnant, ont été faites par l'application dans l'argile fraîche de la languette de ces blocs de schiste allongés, reposant sur la languette centrale et sur les murets annulaires - il est envisageable qu'un tel système ait été mis en œuvre dans le four F260.

Un rapide survol régional des fours de potiers sur lesquels nous sommes suffisamment documentés permet d'observer que ceux d'Entrammes font figure d'exception. Des exemples comparables sont relevés en Aquitaine et en Narbonnaise : à Saint-Cizy en Haute-Garonne, Mouliets-et-Villemartin en Gironde, Bram dans l'Aude, ClermontFerrand dans le Puy-de-Dôme (Dufaÿ, 1996), Saintes en Charente-Maritime (Santrot, 1979) ou bien encore Aiguillon dans le Lot-et-Garonne (Réginato, 2000). Quelques exemples sont localisés en Germanie, à Neuss et Bonn (Swan, 1984). Les contextes relevés datent de la fin de l'indépendance ou du début du $\mathrm{I}^{\mathrm{er}}$ siècle ap. J.-C. Mais c'est surtout en Angleterre que ce type de four a été le plus étudié (Swan, 1984 ; Dufaÿ, 1996) pour la fin de l'âge du Fer et l'époque antique, où ils sont considérés comme dérivés des fours de La Tène. Cette origine est aussi envisagée pour les fours à « rayons » du sudouest de la Gaule, les exemples plus tardifs étant considérés comme issus d'une tradition indigène (Sireix, 1994), en opposition aux fours à sole perforée de carnaux, d'influence plus méditerranéenne.

61 Parfois en calcaire comme à Saintes («stone-bars»), ces " rayons", destinés à soutenir la charge à cuire, sont souvent en argile («clay-bars»). Les «stone-bars» décelées en Angleterre dans des contextes géologiques favorables, sont considérées comme peu communes (Swan, 1984). À Entrammes, le matériau local facilement clivable l'ignimbrite rhyolitique - a donné naissance à de longs et solides « rayons ", guidant le choix des constructeurs au détriment de l'argile.

\section{Un horizon II récent}

62 Un horizon II récent se fait jour ponctuellement à l'est du site et auprès des fours. Le fossé sud de bord de voie se comblant peu à peu de sédiments, un aménagement, F427 est construit au travers de ce sédiment (fig. 14). Il s'agit de blocs de schiste posés de chant, ménageant un espace d'écoulement des eaux, large de 0,30 à 0,40 mètre et de même profondeur (fig. 7, S13). F427 se développe sur une longueur de neuf mètres environ et sa pente, est-ouest, suit celle de la voie antique qui descend vers la Jouanne, toute proche.

Le second élément attribuable à l'horizon II récent, incomplet, est localisé au sud-ouest des fours qui seraient abandonnés. Il est constitué de l'empierrement F326 limité à l'ouest et au sud par une petite tranchée au plan en forme de « L », F255, bordée de part et d'autre de blocs de schiste sur chant. Une première hypothèse pourrait envisager l'aménagement d'un petit bâti à murs palissadés en planches. 


\section{Présentation de la céramique de l'horizon II (E. Coffineau)}

\section{La céramique sigillée ${ }^{9}$}

Sur moins de deux cents tessons attribuables à cet horizon II, plus du tiers provient de contextes plus tardifs. Quelques tessons sont issus du groupe des sigillées de type italique, pour les périodes augustéenne et tibérienne. Les productions du centre de la Gaule des deux premières décennies du $\mathrm{I}^{\mathrm{er}}$ siècle arrivent régulièrement à Entrammes, mais sont vite supplantées à partir du milieu de ce siècle par des pièces de qualité du sud de la Gaule.

\section{Les céramiques fines}

Cette catégorie est représentée par des céramiques dérivées des traditions indigènes comme les gobelets de type "Beuvray » et la terra nigra. Les récipients prédominants, assiettes et coupes (fig. 20 : vases 1 à 11), complètent le répertoire des vases destinés à la boisson et au service de table. Les gobelets de type « Beuvray » sont rares (vase 12).

La terra nigra a un corpus issu du répertoire laténien - avec la présence des vases bobines - et italique avec des variantes des assiettes carénées à bord oblique Lamboglia 5/7. Les vases bobines sont lisses de type «Menez 125 » (Menez 1985; fig. 20 : vase 6) ou ornés de baguettes de type "Menez 126 » (vase 5). Les autres coupes sont à panse carénée, dont la plus courante est la forme « Menez 96 » (vase 1), le type à lèvre biseautée "Menez 110 » (vase 3 ), ou celui doté d'une dépression sur la lèvre de type «Menez 103 " (vase 2). Deux coupes hémisphériques dont le type «Menez 71 » (vase 7) seraient importées du Centre de la Gaule.

Figure 20 : Entrammes, «La Carie » : choix de céramique de l'Horizon II. Figure 20: Selection of pottery from Horizon II.

Les assiettes, majoritairement à panse conique et à bord oblique, proviennent du Centre de la Gaule, de l'Ouest ou d'Aquitaine, seule la morphologie de leurs bords diffère. Elles ont une lèvre simple de type «Menez 22 » ou biseautée de type «Menez 51 » (fig. 20: vase 11), un bord orné d'une cannelure externe de "type Menez 55 » (vase 8) ou légèrement concave de type «Menez 24 ». Une seule assiette imitant la forme italique Drag. 20 (forme «Menez $33 »$ : vase 10) a été trouvée; les gobelets sont rares (vase 4).

\section{La céramique commune}

Cette catégorie regroupe les ustensiles principalement destinés à la conservation et à la préparation des denrées alimentaires. Ce sont des cruches, des pots, des mortiers, des écuelles et des passoires. Les quelques cruches à engobe blanc seraient en partie originaires de la vallée de l'Allier, un exemplaire à col cylindrique (fig. 20 : vase 13) présente un parallèle sur le site du « Port-du-Salut » à Entrammes (Naveau, 1982).

Les pots utilisés pour la cuisson sont les plus nombreux et présentent souvent une pâte sombre. La forme caractéristique de ces contextes augusto-tibériens est l'urne de type «Besançon » (neuf exemplaires). Ces vases modelés à pâte siliceuse grossière micacée, parfois dorés au mica (fig. 20 : vase 14) sont associés à des pots tournés (six vases dont le $n^{\circ} 15$ ). Seuls deux pots ont un ressaut (vases 16 et 17) et un autre a une panse 
globulaire (vase 18) ; une céramique à la pâte vacuolaire, peut-être modelée, s'y trouve en un exemplaire (vase 19). Les autres pots sont majoritairement ovoïdes, à lèvre déversée allongée. Ils ont une pâte siliceuse plutôt grossière, variant du gris au noir (fig. 21, bas : vases 48 à 54). Produits localement, ils offrent une morphologie semblable à celle des exemplaires angevins de La Gaumont (Mortreau, Siraudeau 1997) et de la rue Delaâge (Mortreau, 2005). Ces pots ovoïdes, régulièrement retrouvés dans l'horizon II, sont identiques aux ratés de cuisson du four F261/262 dont nous présentons maintenant la production.

Figure 21 : Entrammes, "La Carie » : la production céramique du four. Figure 21: The oven pottery production.

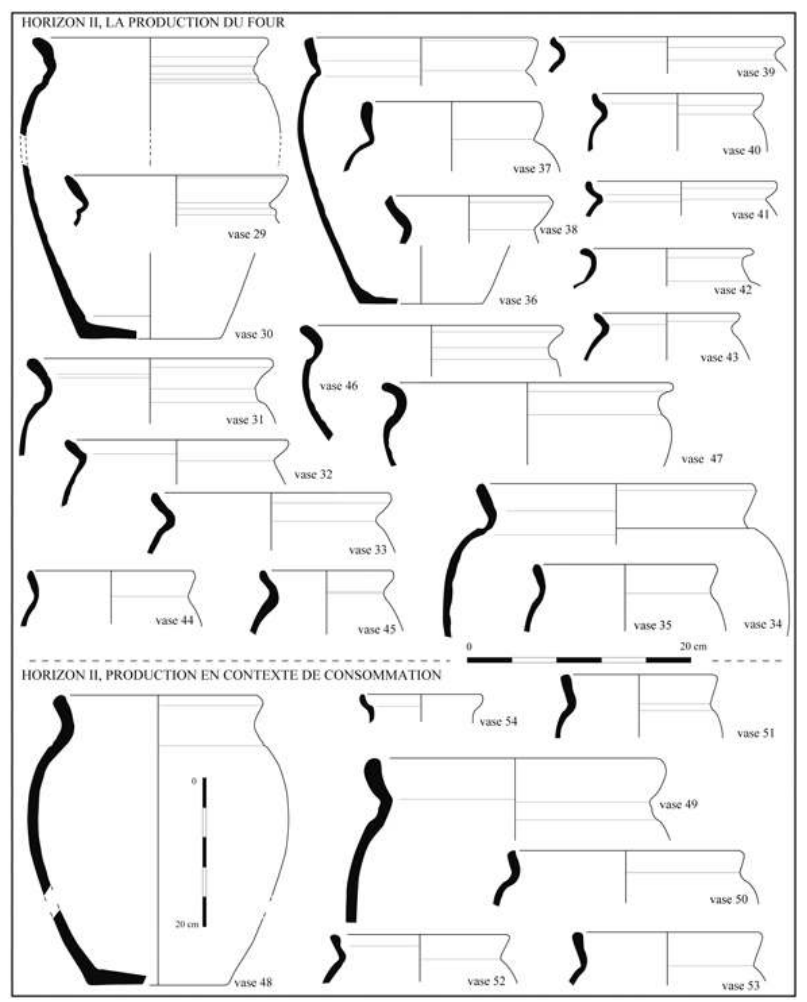

Les ratés de cuisson associés au four F261/262 (fig. 21, haut : vases 29 à 47) présentent une pâte grossière, siliceuse qui comporte des oxydes de fer et des nodules blanchâtres millimétriques (chaux ?). Ces pots sont majoritairement ovoïdes, à lèvre haute plus ou moins déversée, à col court et à fond plat (vases 30 et 36). Leurs diamètres à l'ouverture varient de 12 à 26 centimètres. Des différences morphologiques, peu accusées, se trouvent au niveau du col souligné d'un ressaut (vases 29, 30, 31 et 34) ou d'une incision (vases 31,34 et 36) et au niveau de la lèvre, qui peut être dotée d'une dépression interne (vases $32,33,36$ à 41 et 45 ). Deux jattes relèvent aussi de cette production (vases 46 et 47).

\section{Autres céramiques}

Les importations ibériques d'amphores sont peu nombreuses (Dressel 7/11, Pascual 1 de Tarraconaise et Dressel 20). Les dolia utilisés pour le transport et le stockage sont tournés; ils ont une lèvre en méplat (fig. 20 : vase 21) ou arrondie (vase 20). En bien moindre quantité, les autres céramiques employées pour la cuisson et la préparation 
des aliments sont les mortiers (vases 22 et 23) et les marmites, pourvues de pieds (vases 24 à 26). Deux passoires viennent clore le corpus (vases 27 et 28).

\section{Éléments de conclusion}

Cet échantillon est caractéristique des contextes augusto-tibériens tels qu'à Jublains (Naveau [dir.], 1997) ou Angers (Mortreau, Siraudeau, 1997 ; Mortreau, 2005). Cela se manifeste par des importations italiques (sigillées) parfois imitées dans des ateliers gaulois et par la persistance des formes de vases de tradition laténienne (les gobelets type "Beuvray ", les coupes en terra nigra et les urnes de type "Besançon »). Ces vases cohabitent avec un répertoire nouvellement introduit dans le vaisselier domestique : cruches, mortiers, marmites tripodes et assiettes. Le site de "La Carie », par la qualité de ces éléments, comparables à ceux de Jublains, offre un témoignage matériel important $d u$ faciès céramique qui se développe chez les Aulerques Diablintes. Nous ne devons pas oublier une production stéréotypée de céramique commune locale (fig. 21), avec des pots ovoïdes à pâte plutôt grossière et quelques jattes, au répertoire régional.

\section{Des structures julio-claudiennes situées dans la tradition gauloise?}

$\mathrm{Au}$ sud de la voie, ces vestiges peu perceptibles mais cohérents définissent un habitat dont les éléments apparaissent au même niveau que ceux de l'horizon I. Les fosses gallo-romaines reprennent l'axe défini par la palissade gauloise et les fosses bordant cette dernière (fig. 14). Les traces de cet habitat du début du Haut-Empire, peu marquées, sont essentiellement des fosses d'extraction ayant servi de dépotoirs; l'habitat est limité au sud par le fossé F219, le seul élément à ne pas reprendre les orientations antérieures. Il est possible d'envisager une occupation peu ancrée au sol, sur sablières basses, à l'image de celle tibéro-claudienne du site de "La Grande Boissière » à Jublains (Bocquet et al., 2004, p. 137).

Des éléments nouveaux apparaissent au nord de la voie : ce sont deux fours de potier (fig. 16 à 19). La structure de la sole du four, constituée de blocs de schiste allongés, disposés en "rayons" et reposant sur une languette centrale et deux murets périphériques, constitue une découverte notable. Ils ont livré d'intéressants ratés de cuisson illustrant la vaisselle produite localement, très essentiellement des pots (fig. 21).

75 La voie est un axe structurant le site au début du Haut-Empire. Les fines différences d'orientation décelées à l'horizon I, s'estompent. Nous distinguons, au sud de cette voie et seulement au sud, une zone de dix mètres de large environ, vide de toute structure (à l'exception de la seule F353) et limitée au sud par un alignement de fosses. Elle définirait une zone où il devait être interdit de construire (non aedificandi) ou d'empiéter : un espace public réservé, non limité à l'emprise de la voie et pouvant s'étendre en dehors. Cet espace vide se superpose à peu près à un espace presque nu, relevé au sud de la voie gauloise. L'ensemble des éléments de l'horizon II reprend le schéma d'occupation défini à l'horizon I, même si le site n'est pas occupé à La Tène D2/ augustéen (hormis la voie ?). Nous observons une densification de l'occupation au nord de la voie, avec un empiètement sur celle-ci. Sommes-nous déjà en présence d'un élément "périurbain » ou d'un habitat isolé, distant du bourg même de l'Entrammes gallo-romain et généré surtout par la présence du gué ? Nous pouvons aussi y déceler la présence d'un faubourg, au-delà de la Jouanne, avec habitat et activités artisanales, ces 
dernières nécessitant une bonne desserte, de l'espace pour les fours et les matières premières et un certain éloignement de l'habitat à cause des nuisances engendrées.

Ces structures révèlent plus une continuité d'un type d'occupation (structures légères, fosses d'extraction/dépotoir...) par rapport à l'horizon précédent qu'elles ne marquent une rupture, matérialisée seulement à l'horizon suivant.

\section{L'horizon III : le développement de l'habitat sous les Flaviens et les Antonins}

\section{Les structures archéologiques}

Cet horizon III voit, dès la période flavienne et pendant toute la période antonine, le développement d'une occupation caractérisée par des structures maçonnées ou sur solins : ce sont un habitat au sud de la voie et un second, ponctuellement reconnu au nord-ouest de celle-ci (fig. 22) ; un fossé en marque la limite sud.

\section{Une chaussée dans la continuité des précédentes}

Son tracé se superpose aux états antérieurs. Il est toutefois rétréci dans sa partie occidentale (fig. 22): l'habitat nord-ouest empiète largement sur la chaussée de l'horizon II. Vers l'ouest, la nouvelle chaussée est large de sept mètres; à l'est, elle s'élargit pour atteindre dix mètres. Elle n'est pas conservée de la même manière à l'est ou à l'ouest. Vers le gué sur la Jouanne, l'essentiel des niveaux de voirie attribuables à l'horizon III a été détruit par des occupations postérieures et vraisemblablement aussi par l'érosion. Vers l'ouest, le niveau de chaussée F267 s'appuie sur d'importants remblais (F266: statumen; S9 : fig. 8). Le côté nord de la nouvelle chaussée est souligné de plaques de rhyolite atteignant un mètre de long, soigneusement disposées bord à bord, sur deux ou trois niveaux successifs (F267 : fig. 22 et 23). Ce côté est marqué d'un fossé bordier : F359 (fig. 22), large de 0,90 à 1 mètre et profond de 0,25 à 0,30 mètre, son profil est en « $U$ » ou trapézoïdal. Ponctuellement, un aménagement a été vu le long de F267; il s'agit d'une petite excavation, F392 (fig. 8 : S9), large de 0,20 mètre pour une profondeur comparable. Ce n'est pas un petit fossé, mais la trace d'un renfort formé d'un madrier de bois équarri, disposé le long de F267. Son côté sud est ponctuellement souligné de plaques de schiste serrées les unes contre les autres et aucun fossé ne s'y distingue. 
Figure 22 : Entrammes, " La Carie » : plan général des structures de la période flavienne et antonine : I'Horizon III.

Figure 22: General layout of the buildings from the Flavian and Antonine periods: Horizon III.

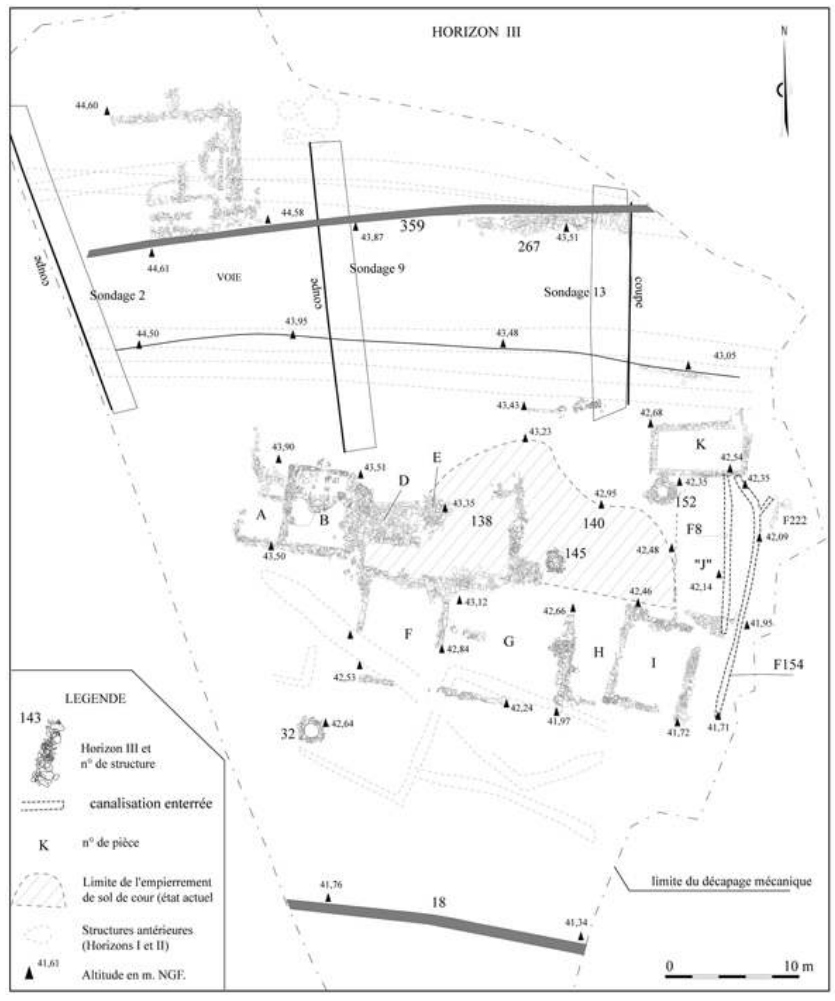

Figure 23 : Entrammes, «La Carie » : détail de l'aménagement de bord de voie F267. Cliché équipe de fouille.

Figure 23: F267 - detail of side of the road structure. Photo: excavation team.

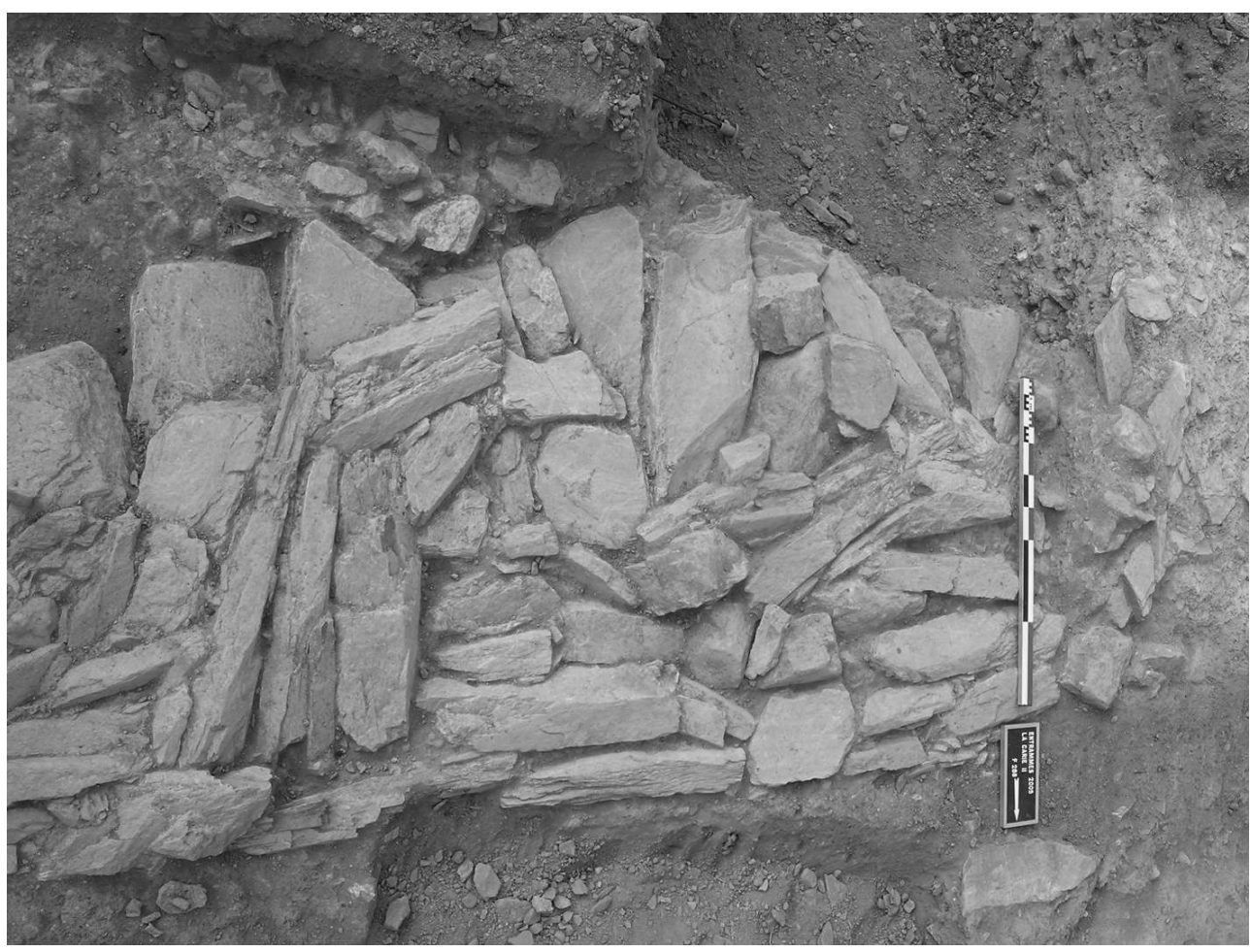




\section{Le nouvel habitat au sud de la voie}

Sur près de huit cents mètres carrés, au sud de la voie, parallèlement à celle-ci et à une distance de cinq à dix mètres, se développe un habitat sur quarante mètres de longueur et sur une profondeur de quinze à vingt-deux mètres (fig. 22). L'occupation dans son état final présente la forme d'un «U», ouvert largement au nord vers la voie, et qui enserre une cour empierrée F138/140. Des canalisations et des puits à eau complètent cet ensemble.

La chronologie de cet habitat est plus perceptible au travers de son agencement spatial que par les vestiges mobiliers et les arguments stratigraphiques; il est très érodé et affleurait sous le décapage. Nous proposons, à titre d'hypothèse, la présence d'un état initial marqué par les toutes premières constructions (état 1), d'un état plus abouti (état 2) et d'un état final (état 3 ; fig. 24). Les éléments qui matérialisent cet horizon III sont installés sur des niveaux anthropisés issus d'une destruction/nivellement des structures des horizons I et II. Sur ces niveaux, préalablement à la construction des bâtiments, a été déposée une couche de plaquettes de schiste sur 0,15 à 0,20 mètre d'épaisseur : F138 (= F140), plus épaisse au sud qu'au nord, de manière à rattraper une partie de la pente du terrain, mais aussi à l'assainir. Un tel réaménagement et rehaussement des terrains s'observe à la période flavienne à Jublains dans le quartier de La Grande Boissière (Bocquet et al., 2004, p. 139); il matérialise à Entrammes un sol de cour mesurant $23 \times 12$ mètres. Le tableau 4 présente les principales données liées à chacun des espaces ou pièces de cet habitat.

Tableau 4 : Entrammes, "La Carie » : les caractéristiques principales des espaces A à K (dimensions en mètres).

Table 4: Main features of areas A to K (metric dimensions).

\begin{tabular}{|c|c|c|c|c|c|}
\hline $\begin{array}{c}\text { Pièces } \\
\text { ou } \\
\text { espaces }\end{array}$ & $\begin{array}{l}\text { Dimensions } \\
\text { internes } \\
\text { (et surface) }\end{array}$ & $\begin{array}{l}\text { Epaisseurs } \\
\text { des murs }\end{array}$ & $\begin{array}{c}\text { Nature des } \\
\text { constructions }\end{array}$ & Remarques & $\begin{array}{c}\text { Sol } \\
\text { construit }\end{array}$ \\
\hline A & $\begin{array}{c}2,80 \times 3,80 \\
\left(10,6 \mathrm{~m}^{2}\right)\end{array}$ & $\begin{array}{c}\text { nord et ouest : } 0,40 / 0,50 \\
\text { sud : } 0,70\end{array}$ & $\begin{array}{l}\text { mur-bahut } \\
\text { mur-bahut }\end{array}$ & (habitat ?) & $\mathrm{X}$ \\
\hline $\bar{B}$ & $\begin{array}{c}4 \times 5,20 \\
\left(20,8 \mathrm{~m}^{2}\right)\end{array}$ & $\begin{array}{c}\text { nord : } 0,30 \\
\text { autres : } 0,65 / 0,70\end{array}$ & $\begin{array}{c}\text { ??? } \\
\text { mur-bahut }\end{array}$ & $\begin{array}{c}\text { structure à } \\
\text { vocation artisanale }\end{array}$ & $\mathrm{X}$ \\
\hline $\mathrm{C}$ & $1 \times 24$ & 0,3 & solin & auvent & $\mathrm{X}$ \\
\hline $\bar{D}$ & $\begin{array}{c}2,30 \times 3,50 \\
\left(8 \mathrm{~m}^{2}\right)\end{array}$ & 0,3 & & $\begin{array}{l}\text { structure en } \\
\text { aire ouverte }\end{array}$ & $\mathrm{X}$ \\
\hline $\bar{E}$ & $\begin{array}{c}1 \times 1,2 \\
\left(1,2 \mathrm{~m}^{2}\right)\end{array}$ & 0,45 & & $\begin{array}{l}\text { structure en } \\
\text { aire ouverte }\end{array}$ & $\mathrm{X}$ \\
\hline $\bar{F}$ & $\begin{array}{c}5,5 \text { à x } 7,40 \\
\left(40,7 \mathrm{~m}^{2}\right)\end{array}$ & 0,5 & solin & habitat? & $\mathrm{X}$ \\
\hline $\mathrm{G}$ & $\begin{array}{c}7,30 \times 9 \\
\left(65,7 \mathrm{~m}^{2}\right)\end{array}$ & $0,30 / 0,50$ & solin & habitat? & $\mathrm{X}$ \\
\hline $\mathrm{H}$ & $\begin{array}{c}3 / 3,80 \times 6,20 \\
\left(21 \mathrm{~m}^{2}\right)\end{array}$ & sud : 0,50 & solin & $\begin{array}{c}\text { passage puis } \\
\text { passage couvert? }\end{array}$ & \\
\hline I & $\begin{array}{l}4,5 \times 6 \\
\left(27 \mathrm{~m}^{2}\right)\end{array}$ & $\begin{array}{c}\text { nord et ouest : } 0,50 \\
\text { sud et est : } 0,70\end{array}$ & $\begin{array}{l}\text { mur-bahut } \\
\text { mur-bahut }\end{array}$ & habitat? & $\mathrm{X}$ \\
\hline "J" & $\begin{array}{c}3,80 \times 10 \\
\left(38 \mathrm{~m}^{2}\right)\end{array}$ & $0,20 / 0,30$ & solin à l'ouest? & indéterminé & - \\
\hline $\mathrm{K}$ & $\begin{array}{c}2,80 / 3 \times 6,40 / 6,50 \\
\left(18,7 \mathrm{~m}^{2}\right)\end{array}$ & 0,5 & murs maçonnés & cave & - \\
\hline
\end{tabular}




\section{L'état 1 : les premières constructions}

81 Cet état initial, d'époque flavienne, est formé d'une succession d'espaces orientés estouest, parallèlement à la voie antique (fig. 24). Un auvent, une avancée d'étage ou une pergola (C) qui les relie les uns aux autres est peut-être déjà en place. La cour empierrée, s'étend au nord de ces bâtiments. L'ensemble F/G forme la partie principale de l'habitat, il mesure $16 \times 8$ mètres. Les murs solins sont constitués de deux ou trois assises de blocs schisteux superposés et se recouvrant par moitié. Dans l'angle nordouest de la pièce $\mathrm{F}$, trois tuiles disposées à plat forment les restes d'un âtre. De petits blocs de schiste ou un cailloutis de grave, de faible densité, épais de deux à trois centimètres, tapissent ces pièces.

La pièce I, postérieure à l'ensemble $\mathrm{F} / \mathrm{G}$, matérialise un espace recouvert d'un radier de sol formé de petits fragments de schiste sur dix à quinze centimètres d'épaisseur. Ses murs sont constitués de trois à cinq niveaux de blocs de schiste. Courant sur vingt mètres le long de la façade orientée vers la voie, la structure $C$ ménage un espace de circulation, relativement étroit, d'un mètre de large, limité du côté cour par un alignement continu de blocs de schiste de 0,30 mètre de large. Il s'agirait d'une structure simple de type auvent ou d'une avancée d'étage. Son sol, ponctuellement conservé, est formé de blocs de schiste disposés à plat, serrés les uns contre les autres. La surface initiale bâtie de l'état 1 , de 106,4 mètres carrés, est portée à 133,4 mètres carrés par l'adjonction de la pièce I.

Figure 24 : Entrammes, « La Carie »: I'Horizon III, les états 1, 2 et 3. Figure 24: Horizon III, stages 1, 2 and 3.

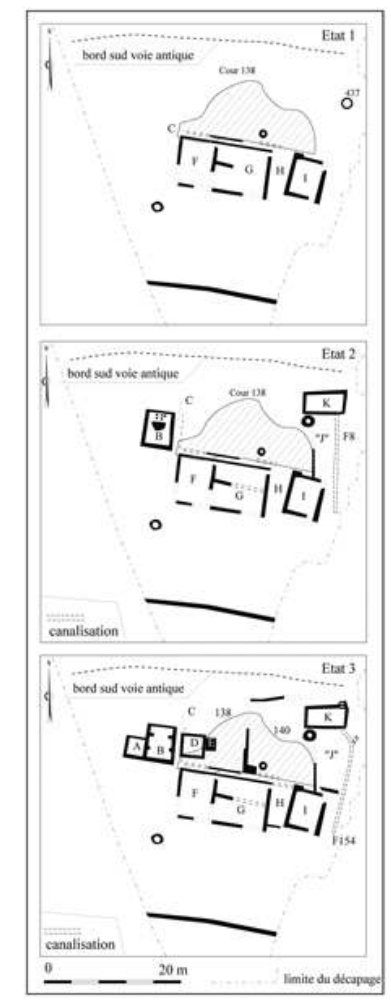




\section{L'état 2 : un agrandissement par les ailes} à 0,18 mètre d'épaisseur, larges de 0,20 à 0,50 mètre, disposés en lits réguliers, à bain de mortier de chaux de deux centimètres d'épaisseur, sur cinq à neuf assises. Aucune trace d'enduit ou de sol construit n'a été observée. Le mur sud est percé à sa base sur toute son épaisseur d'une petite ouverture, de 0,30 mètre de côté, qui se prolonge au sud par la canalisation F8 (fig. 22 et 26), qui permet de drainer les eaux d'infiltration hors de la pièce $\mathrm{K}$. La canalisation F8 est rectiligne, de douze mètres de long et orientée nord-sud. Des blocs de schiste, de 0,50 à 0,70 mètre de largeur posés à cheval sur des pierres de chant, légèrement à l'oblique, matérialisent un conduit de section trapézoïdale. Il est haut de 0,20 mètre et large de 0,10 à 0,20 mètre. Cette structure peu étanche devait doubler une canalisation en bois, hypothèse émise pour des canalisations comparables à Mâlain en Côte-d'Or (Roussel, 2003). L'extrémité sud de cette canalisation est recoupée par F154 (état 3). Enfin, mentionnons que le tracé nord-sud de F8 ne permet pas une évacuation au plus court vers la Jouanne, qui coule à l'est de la pièce $K$, probablement à cause de structures bâties entre la zone fouillée et la rivière, matérialisées par le segment de solin F222 (fig. 22). 
Figure 25 : Entrammes, « La Carie » : vue générale de la pièce/cave $K$, en direction de l'est. Cliché équipe de fouille.

Figure 25: General view of room/cellar K, looking east. Photo: excavation team.

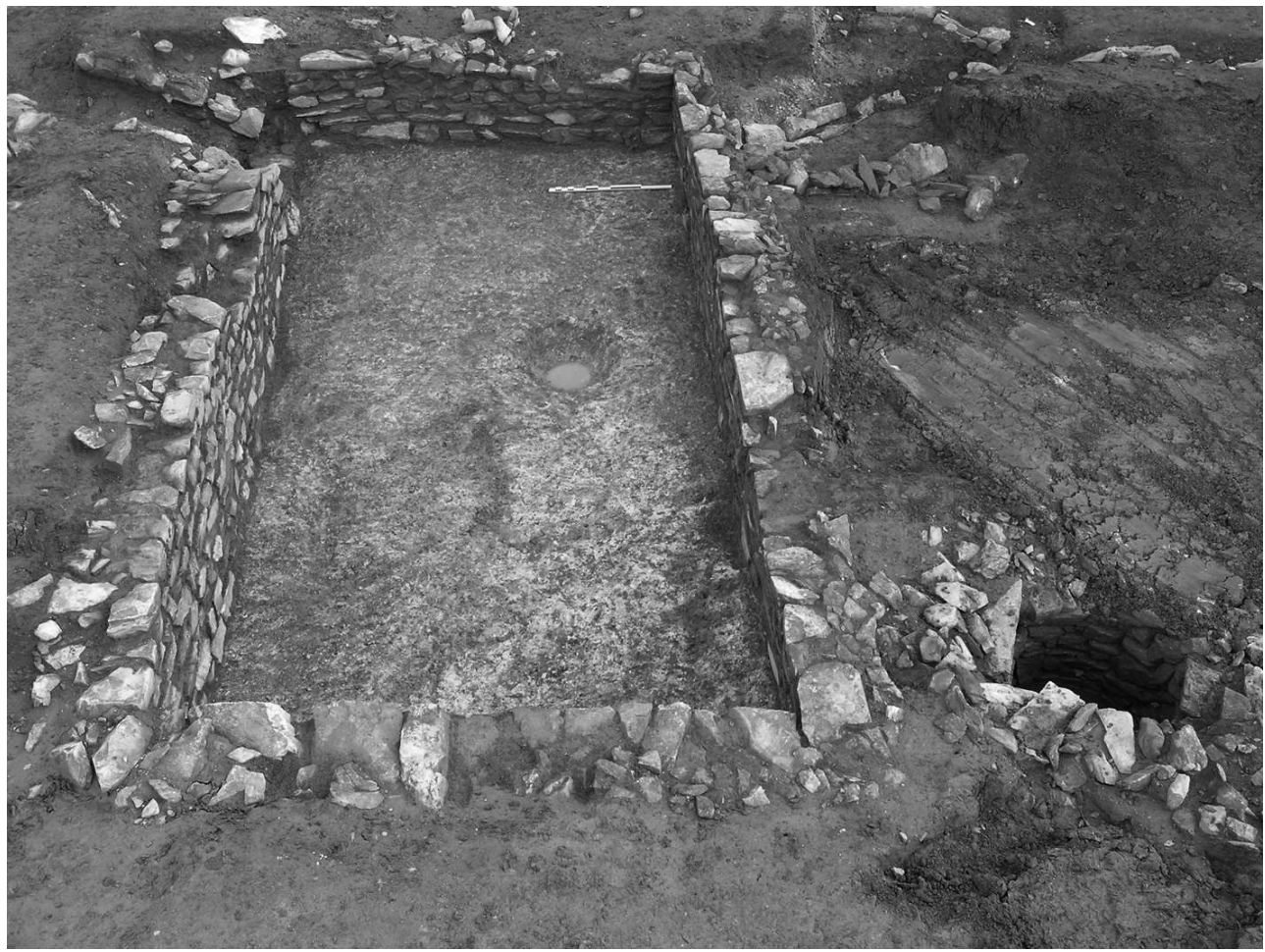

Figure 26 : Entrammes, "La Carie » : les canalisations F8 (à gauche) et F154 (à droite) au sortir de la pièce $K$, vue prise vers le nord. Cliché équipe de fouille.

Figure 26: F8 (on left) and F154 (on right) - piping leaving room K, looking north. Photo: excavation team.

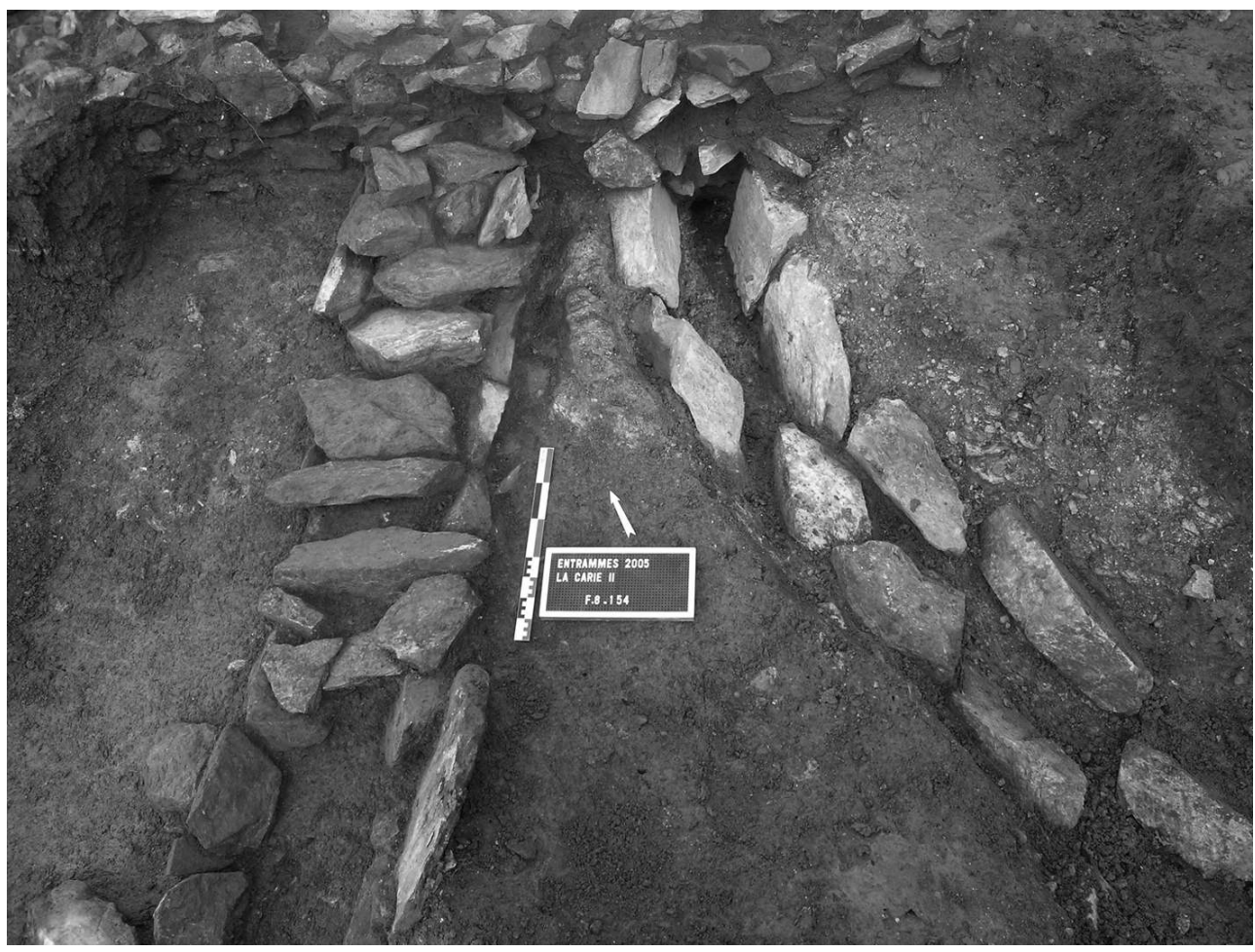


L'aile occidentale voit essentiellement s'édifier la pièce B ; elle montre, au nord, le mur F118, peu épais, fondé sur deux assises et constitué de petits blocs de grès et de schiste. Les autres murs, profondément fondés $(0,50 \mathrm{~m})$ et liés à leurs angles, sont constitués de gros blocs de schiste et de pierraille; ces murs-bahut pouvaient supporter une élévation maçonnée (et éventuellement un étage ?). Divers aménagements ont de suite aiguillonné notre intérêt (fig. 27, haut et fig. 28). À l'extérieur du mur nord, le moins épais, il a été observé un alandier (les murets F193 et F19) enserrant un fin nappage d'argile rubéfiée large de 0,38 à 0,40 mètre. Cet alandier, par une ouverture ménagée dans le mur $\mathrm{F} 118$, donne dans la pièce $\mathrm{B}$.

Figure 27 : Entrammes, "La Carie » : I'Horizon III : relevé détaillé des aménagements de la pièce $B$ (en haut) et de l'habitat nord-ouest (en bas) : états A et B.

Figure 27: Horizon III: showing detail of the arrangement of room B (top) and northwest dwelling (bottom): stages A and B.

Figure 28 : Entrammes, "La Carie » : le petit système de chauffe par hypocauste dans la pièce $B$, vue prise vers le sud. Cliché équipe de fouille. Figure 28: Small under-floor (hypocaust) heating system in room B, looking south. Photo: excavation team.

Tout d'abord, on y relève les restes de cinq pilettes hautes de quinze centimètres environ, en pierres sèches, disposées de part et d'autre de l'axe de l'alandier (fig. 27, haut : F172). Ensuite, dans l'angle nord-ouest, F171, est formé de quatre blocs de schiste longs de 0,50 à 0,60 mètre, disposés de chant, espacés de 0,30 à 0,50 mètre et recouverts de dalles en place ou effondrées. Enfin, un peu au sud, un dernier aménagement de plan grossièrement triangulaire - mesurant 2,50 x 1,50 mètres (F122) - ferme le dispositif. Il est constitué de longs blocs de schiste, disposés de chant et aménagés du nord vers le sud sur trois rangs successifs, larges respectivement de 2,50 mètres, 1,80 mètre et 1 mètre. Ces rangs étaient ceints sur les côtés du triangle par d'autres blocs sur chant, l'ensemble étant recouvert de dalles de schiste mises à plat. L'espace ménagé entre ces pierres et le sol de la pièce, est de 0,15 à 0,20 mètre.

Ces aménagements matérialisent un petit système de chauffe sur hypocauste (fig. 28), mêlant pilettes et pierres de chant, recouvertes de grosses dalles de schiste. Il y a été mis au jour une fine couche de cendres et de charbons de bois. Leur faible dimensionnement ne permet pas d'envisager une pièce chauffée à vocation thermale ou d'habitat. L'hypothèse d'une structure artisanale de type fumoir ou four de séchage est privilégiée. Les restes d'un séchoir à foyer extérieur ont été mis au jour dans le Jura à Saint-Germain-en-Montagne (Demarolle, 2005) et ceux d'un four de séchage ou de fumage à Bliesbruck en Moselle (Petit, 2005). À Schwarzenacker-en-Sarre (Allemagne), une pièce chauffée par le sol est interprétée comme un fumoir par J.-P. Petit (2005), qui souligne que les installations de chauffage ont été interprétées diversement et qu'à côté de types caractéristiques, il existe des variétés de fours, à canaux ou à pilettes, parfois confondues avec des pièces chauffées par hypocauste.

Les pièces $F, G$ et I, matérialisant le corps principal de l'habitat, ne semblent pas sensiblement modifiées à l'état 2. L'espace $\mathrm{H}$ pourrait, dès cette période, être fermé au sud par un petit solin. La surface initiale bâtie est portée à 193,9 mètres carrés (état 1 : $\left.133,4 \mathrm{~m}^{2}\right)$. 


\section{L'état 3 : Les dernières modifications} hypocauste est abandonné. type aire de battage... hydromorphe.

De nouveaux éléments animent l'habitat au sud de la voie: les espaces A, D et E se voient adjoints à l'aile ouest. Un solin central nord-sud, édifié dans la cour F138, crée deux espaces distincts F138 à l'ouest et F140 à l'est (fig. 24 - état 3).

La pièce $A$, érodée, est accolée à l'ouest de la pièce $B$. Les murs-bahut nord et ouest sont constitués d'une fondation de pierraille; seul le mur sud (sur la pente) est formé d'une assise de gros blocs de grès. La pièce $B$ voit, après l'état 2 , la construction de massifs de petits blocs de schiste, au nord F169 et F170 et au sud F177 et F178 (fig. 27, haut). Ils matérialiseraient des supports de plancher sur lambourdes, le système de chauffe par

Les espaces D et E accolés à l'est de l'auvent C, empiètent sur la cour F138. L'espace D est limité par les murets, formés de grosses dalles de schiste, jointives et soigneusement agencées, longues de 0,50 à 0,60 mètre et déposées sur deux niveaux pour le muret nord et sur quatre ou cinq niveaux pour le muret sud. L'aire interne est recouverte d'un empierrement de 0,10 à 0,15 mètre d'épaisseur, de blocs de schiste mis à plat et jointifs. L'espace E, plus petit, est de même nature. À titre d'hypothèse, sans argument pertinent autre que leur position au sein de l'habitat, ce pourrait être des structures de

Dans l'angle nord-est de la pièce $\mathrm{K}$ serait aménagée une descente d'escalier délimitée par deux murets latéraux espacés de 0,70 mètre. La canalisation F8 (état 2) qui permettait de drainer cette pièce est abandonnée au profit d'une seconde canalisation, F154, aménagée un peu plus à l'est, très comparable à la première. F154 a été mise au jour sur une longueur de vingt mètres et son extrémité sud s'arrête sensiblement dans l'axe de la façade arrière du corps principal, sans aménagement particulier.

La division de la cour en deux parties à peu près égales, est matérialisée par un solin nord-sud en retour d'angle, construit au milieu de la cour (fig. 24). Ils témoigneraient du démantèlement de la propriété : nous aurions ainsi deux « lots », ouest et est, d'une surface comparable $\left(105 \mathrm{~m}^{2}\right.$ et $\left.109 \mathrm{~m}^{2}\right)$. Les données sont moins nettes pour la partition du corps principal de l'habitat, notamment en ce qui concerne la pièce G. Le puits situé à l'arrière de la pièce $\mathrm{F}$ a peut-être été creusé à cette occasion, le « lot » ouest, n'étant pas, contrairement à l'autre, déjà muni de son système d'approvisionnement en eau.

\section{Le nouvel habitat : les structures annexes}

Sa limite sud est marquée par le fossé parcellaire F18, orienté est-ouest, parallèlement à l'habitat, mais aussi à la voie dont il est distant de 42-43 mètres (fig. 22). Sa largeur varie de 1,30 mètre à l'ouest à 1,70 mètre à l'est, à l'approche de la Jouanne. Sa profondeur varie de 0,50 mètre à l'ouest à 0,70 mètre à l'est. Les profils observés sont trapézoïdaux ou en «U » très évasé, son comblement est constitué d'un limon brun,

Les quatre puits répartis sur l'habitat (F32, F145, F152 et F437: fig. 22 et 24), sont circulaires ou ovales; leurs diamètres varient de 2,10 à 2,50 mètres. Leurs chemisages en blocs de schiste, souvent de grandes dimensions, dégagent des lumières circulaires de 0,75 mètre à 1,10 mètre de diamètre et s'appuient directement sur les schistes altérés au fond de vastes creusements profonds de 2,60 mètres (F437), 2,80 mètres (F32), 3 mètres (F152) et 3,20 mètres (F145). Au contact de la nappe phréatique, leurs 
comblements recelaient sur 0,50 à 0,70 mètre d'épaisseur de gros blocs de grès et une vase molle et grise, mais peu de mobilier, quelques pièces de cuir ${ }^{10}$.

\section{Des modes de construction différents}

Pour les pièces A, B et I, les murs donnant sur la pente sont plus épais. En effet, c'est à cet endroit que les contraintes liées à la poussée des terres se font sentir le plus fortement. Les pièces $\mathrm{F} / \mathrm{G}$ qui matérialisent la cellule initiale sont construites sur des solins continus, comme les structures les plus légères (l'auvent $C$ ). Les adjonctions postérieures sont construites sur la base de murs-bahut (pièces A, B et I) ou de murs maçonnés (pièce $\mathrm{K}$ ). Chronologiquement, nous percevons une évolution du solin vers le mur-bahut et le mur lié au mortier.

Un mode de construction mixte a été déterminé dans la pièce B (aile ouest : fig. 27). Le mur nord peu fondé, est composé de petits blocs de pierres tandis que les autres murs, deux fois plus larges, fondés de 0,50 mètre, liés à leurs angles, sont constitués de gros blocs de schiste.

\section{La création d'un habitat au nord-ouest de la voie}

Situé au nord-ouest du site, il empiète sur la voie de l'horizon II (fig. 22). Des perturbations récentes l'entament largement, tant à l'ouest qu'au nord. Les structures fouillées ont révélé, à défaut de mobilier, deux états dans leur développement (fig. 27, bas).

100 L'état A se développe au nord du fossé F359 sur neuf mètres de long et sur une profondeur de sept mètres: les restes d'un bâtiment sur solin (F110, 111 et 113) dessinent l'angle d'un bâtiment précédé d'un trottoir construit, large de 1,70 mètre et couvert d'un portique matérialisé par le solin F109. L'état B, construit au détriment du précédent, se caractérise par trois murs dessinant une pièce rectangulaire, de $8 \mathrm{x}$ 10 mètres, incomplète à l'ouest. Les fondations, larges de 0,70 mètre et profondes d'autant, sont suffisantes pour porter non seulement des murs maçonnés ou des mursbahut mais aussi un étage. Ici, de la même manière que pour l'habitat au sud de la voie (cf. supra), se confirme l'évolution, du solin vers le mur-bahut / mur maçonné.

\section{La céramique de l'horizon III (E. Coffineau)}

101 La seconde phase de l'occupation gallo-romaine connaît une constante extension le long de la voie Le Mans-Rennes à la fin du $\mathrm{I}^{\mathrm{er}}$ siècle et durant tout le II $\mathrm{II}^{\mathrm{e}}$ siècle de notre ère. Les céramiques proviennent essentiellement du comblement de la cave $\mathrm{K}$ (fig. 29 et 30). 
Figure 29 : Entrammes, « La Carie » : choix de céramique de l'Horizon III. Figure 29: Selection of pottery from Horizon III.

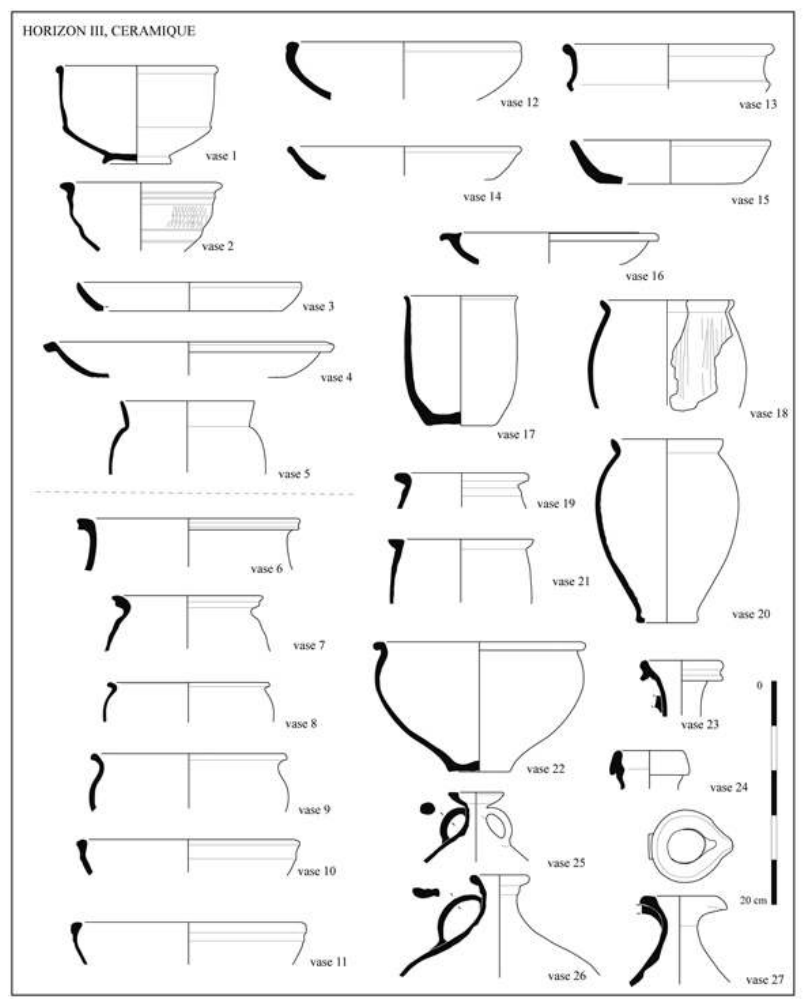

Figure 30 : Entrammes, « La Carie » : choix de céramique de l'Horizon III (suite). Figure 30: Selection of pottery from Horizon III (continued).

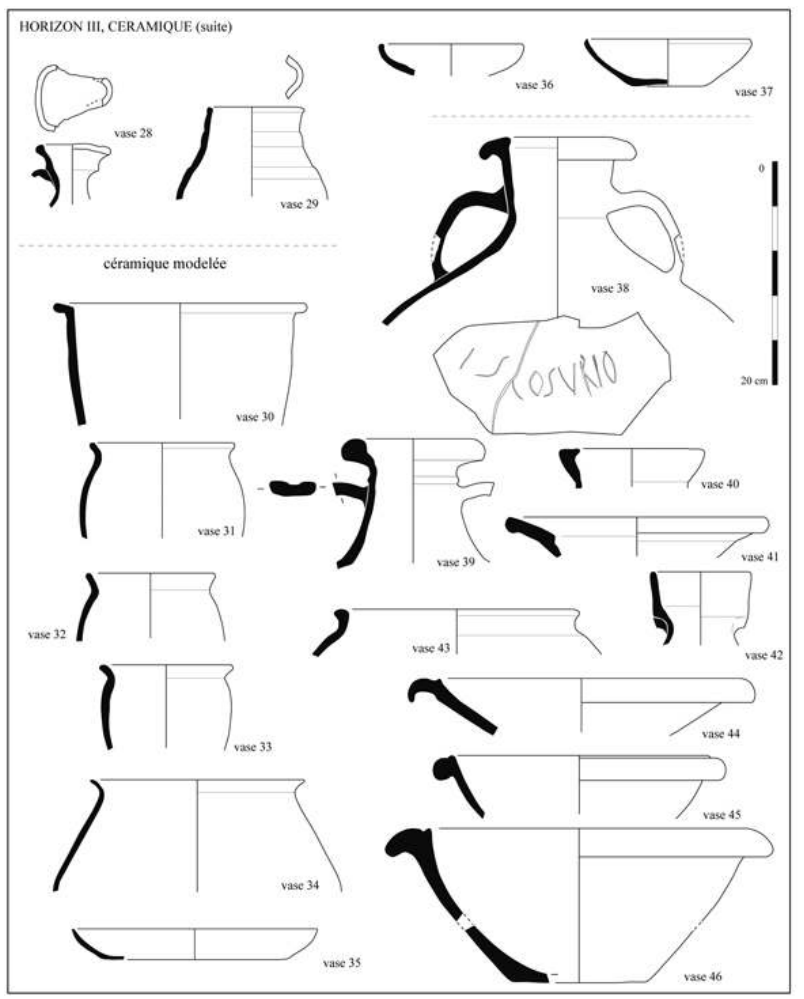




\section{La céramique sigillée}

102 La sigillée du sud de la Gaule, encore présente à la période flavienne et au début du $\mathrm{II}^{\mathrm{e}}$ siècle, est vite supplantée dans le courant $\mathrm{du} \mathrm{II}^{\mathrm{e}}$ siècle par les productions «standards » du centre de la Gaule. S'y distinguent des formes lisses, mais surtout la forme moulée Drag. 37. Le début du III siècle n'est plus représenté que par de rares pièces de Lezoux ou de Lubié.

\section{Les céramiques fines}

103 Cette catégorie est figurée, à l'image de la période précédente, par quelques gobelets à paroi fine très fragmentés et par une majorité de vases en terra nigra, au répertoire dominé par les coupes (vingt-trois bords). Ces vases proviennent des mêmes officines que dans la période précédente, du centre de la Gaule, d'Aquitaine et de l'ouest. Produits de la fin du $\mathrm{I}^{\mathrm{er}}$ siècle jusqu'au début du $\mathrm{II}^{\mathrm{e}}$ siècle, ils correspondent au début de l'horizon III, la période flavienne. Les coupes sont majoritairement à panse carénée de type «Menez 96 " (cinq vases dont le vase 1 : fig. 29). Les autres coupes sont à panse arrondie ornée de dépressions ou de guillochis (vase 2). Les assiettes sont à fond plat, de type «Menez 1 » (vase 3) ou de type "Centre», «Menez 13a» (vase 4). Les formes fermées sont des gobelets à lèvre haute, « Menez 145 » et « 146 » (vase 5).

\section{La céramique commune}

Il s'agit d'une vaisselle culinaire constituée de pots à cuire (vingt-six vases) essentiellement des pots ovoïdes à pâte grise, siliceuse. Leurs lèvres sont moulurées (fig. 29 : vases 6 et 7), avec des comparaisons dans la nécropole de Jublains (Boissel et Diehl, 1971) ou arrondies (vases 8 et 9).

Les écuelles et les marmites sont aussi utilisées pour la cuisson des aliments, certaines seraient des productions locales (vase 10). D'autres, issues du Val de Loire, et plus particulièrement de l'atelier de Thésée-Pouillé (Loir-et-Cher), sont à pâte brune finement micacée (vases 11 et 12). Quelques jattes carénées complètent ce corpus (vase 13).

106 Les assiettes sont à fond plat et à paroi oblique (fig. 29 : vases 14 et 15). Les gobelets sont à pâte brune, aux surfaces noires, soigneusement lissées, à l'exception d'un gobelet tronconique à pâte grossière de teinte grise (vase 17). L'un d'eux a une série de bandes lissées verticales sur la panse (vase 18). Ils sont dépourvus de col et ont une lèvre déversée arrondie (vase 19) en amande (vase 20) ou aplatie (vase 21).

Les cruches, dotées d'une ou deux anses, sont majoritairement non engobées. Leurs lèvres souvent en poulie (fig. 29: vase 23) ressemblent aux productions de Jublains (Naveau, 1997) et de Mazières-en-Mauges (Berthaud, 2000). Certaines sont des variantes locales (vase 24). Les autres sont à pâte micacée orange et brune dont l'une est engobée et à lèvre aplatie rentrante (vase 25), ou bien encore à lèvre arrondie déversée (vase 26). Enfin, des cruches à pâte grise, aux surfaces enfumées, sont munies d'un bec verseur (vase 27) ou simplement pincé (fig. 30 : vase 28). Le pichet engobé de rouge à bec verseur, réalisé par pincement et étirement de la lèvre (vase 29), est une forme moins commune.

Sont aussi présentes des poteries façonnées par modelage ou par montage. Elles sont à pâte siliceuse de couleur brune ou noire et leurs surfaces sont soigneusement lissées. 
Les pots et les gobelets tronconiques ont de faibles diamètres à l'ouverture et leurs lèvres sont déversées et arrondies (fig. 30 : vases 30 à 33), rarement effilée (vase 34). Les assiettes sont à fond plat et à bord fin (vase 35) ou légèrement rentrant (vases 36 et 37). Des productions semblables sont présentes à Mazières-en-Mauges (Berthaud, 2000), au Mans (Guillier, 1995) et à Jublains.

\section{Les amphores et dolia}

Les amphores du sud de la Gaule (Gauloise 4 de Narbonnaise, Dressel 9 lyonnaise, variante de Dressel 7/11) et de Bétique (Dressel 20) sont associées à des Gauloise 4 et 5 de la vallée de la Loire, notamment de l'atelier de Thésée-Pouillé (Loir-et-Cher) (Cadalen-Lesieur, 2005). Ces variantes semblent fabriquées au cours du milieu du $\mathrm{II}^{\mathrm{e}}$ et jusqu'au III $^{\mathrm{e}}$ siècle (Barthélémy-Sylvand et al., 2005). Les bords sont à lèvre aplatie (fig. 30 : vase 38), arrondie (vase 39) ou formant un méplat (Barthélémy-Sylvant et al., 2005). Des dérivés de G4 et G5 à pâte micacée orange sont engobés de blanc (vase 40). Quelques formes particulières sont à relever : à lèvre plate déversée (vase 41 : fig. 30) ou "en tulipe" (vase 42). Les deux exemplaires à lèvre plate sont semblables à ceux produits à Rezé (Loire-Atlantique) situés entre le milieu du ${ }_{\mathrm{II}}^{\mathrm{e}}$ siècle et le début du III ${ }^{\mathrm{e}}$ siècle (Pirault et al., 2001). Cependant, leur pâte micacée brune est plus proche des productions de Thésée-Pouillé (Cadalen-Lesieur, 2005).

110 Les dolia tournés à lèvre déversée arrondie (fig. 30 : vase 43) montrent des parallèles produits entre la fin du $\mathrm{I}^{\text {er }}$ et durant tout le $\mathrm{II}^{\mathrm{e}}$ siècle en Indre-et-Loire dans l'atelier de Mougon (Schweitz et al., 1986), en Loire-Atlantique à Rezé (Pirault et al., 2001) et Mazières-en-Mauges (Berthaud, 2000).

\section{Tèles et mortiers}

111 D'autres céramiques sont particulièrement destinées à la préparation des aliments : une tèle à lèvre en collerette (fig. 30 : vase 44 ) et des mortiers à lèvre épaisse débordante (vases 45 et 46). Certains à pâte micacée brun clair sont semblables à ceux de Jublains (Chuniaud et Mortreau, 2002, p. 164).

\section{La céramique de l'horizon III : conclusion}

112 L'étude de ces céramiques confirme les grandes tendances relevées régionalement. Cela s'observe dans l'importation prédominante durant le Haut-Empire, de productions du Centre, ce qui s'inscrit dans des échanges commerciaux tournés vers le Val de Loire jusqu'à la vallée de l'Allier. On note aussi l'imitation locale de certaines d'entre elles (les amphores à fond plat) et la présence constante de vases non tournés. Enfin, mentionnons un graffite d'appartenance, à consonance gauloise, gravé sur une amphore : Cosurio (fig. 30 : vase 38), le seul nom de personne connu sur l'agglomération gallo-romaine d'Entrammes.

\section{L'instrumentum}

Le mobilier autre que la céramique est peu présent (fig. 31). Dans le comblement du puits F145, notons la présence d'une clef en fer, longue de 14,6 centimètres, à retrait et translation (Manning, 1985, $\mathrm{n}^{\circ}$ 023-025). Ce type de clef, courant, trouve de nombreux 
parallèles en Gaule, en Grande-Bretagne ou en Germanie (op. cit.). Localement, une clef comparable a été découverte à Jublains (Naveau, 1998, cat. $\mathrm{n}^{\circ} 323$ p. 106). Dans le comblement du puits F152, ont été mis au jour un fragment d'anse de seau en fer et sa patte d'accrochage en fer plat, cordiforme, percée de deux petits trous de fixation. Nous devons signaler dans la pièce $\mathrm{A}$, la découverte d'une pointe de flèche en fer. Cet objet à emmanchement à douille est long de $73 \mathrm{~mm}$, large à la base de $30 \mathrm{~mm}$ et épais de 11-12 mm, le diamètre de la douille est de $12 \mathrm{~mm}$. Le corps de la pointe de flèche est de forme triangulaire lancéolée, à deux ailerons, se terminant en une pointe acérée. Ce type d'objet, peu courant régionalement, pourrait avoir été utilisé pour la chasse. Signalons encore un petit poids (de pêche ?) en plomb, deux pesons en terre cuite et deux palets taillés dans des tuiles (un seul est représenté : F145).

Figure 31 : Entrammes, « La Carie » : l'instrumentum, le mobilier métallique, en terre-cuite et les meules antiques.

Figure 31: Instrumentum, metal furnishing, terracotta and ancient millstones.

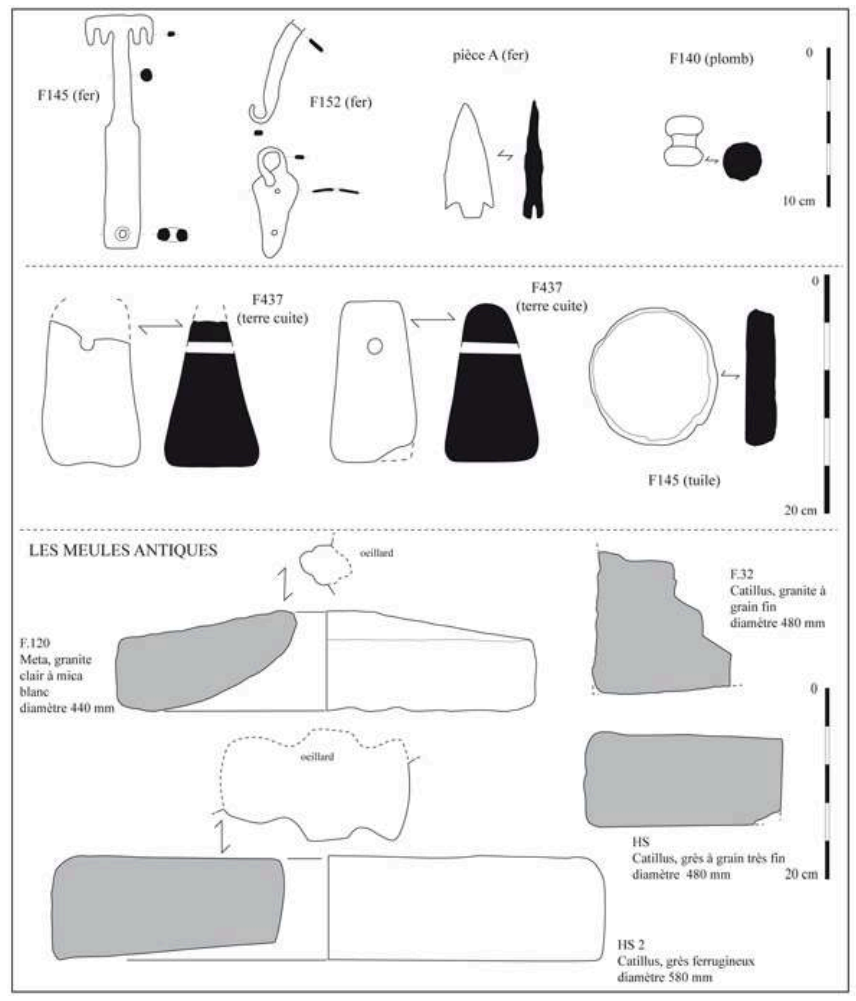

114 Le matériel de mouture, très fragmenté, a été mis au jour pour moitié hors stratigraphie (HS), il s'agit d'une meta et de trois catilli (fig. 31). La meta F120 percée d'un œillard polylobé devait posséder un système de réglage d'écartement des meules. Sur la grande courante HS2 ont été observés trois traits singuliers, un système permettant de recevoir une anille de calage/centrage en double queue d'aronde traversante, une faible pente de sa surface de mouture $\left(5^{\circ}\right)$, alors que la moyenne "normalisée» de cette pente serait de l'ordre de 14-15 (Berthaud, 2000) et un diamètre important, critère ne s'entendant que comparé avec les diamètres des autres meules (tab. 5). Ce tableau montre une évolution caractérisée par l'augmentation des diamètres de l'époque gauloise à l'époque antique, liée à une diminution des épaisseurs et à une accentuation de la pente des surfaces de mouture. À Bliesbruck, les meules de fort diamètre, pourvues d'une anille en double queue d'aronde, se rapporteraient à des 
"moulins à sang ", actionnés par traction animale ou humaine (Van Ossel et Defgnee, 2001), plus productifs que les «moulins à bras » : le diamètre de HS2 rentre dans la fourchette proposée pour ces moulins à sang.

Tableau 5 : Entrammes, «La Carie » : diamètres comparés des meules gauloises (G) et antiques (A) (en $\mathrm{mm}$ ).

Table 5: Diameters compared to Gallic (G) and ancient (A) millstones (in $\mathrm{mm}$ ).

\begin{tabular}{|c|c|c|c|}
\hline $\mathbf{N}^{\circ}$ & $\boldsymbol{\emptyset}$ & $\mathbf{N}^{\circ}$ & $\boldsymbol{\emptyset}$ \\
\hline F286(G) & 350 & F120 (A) & 440 \\
\hline F325 (G) & 350 & F32(A) & 470 \\
\hline F145(G) & 360 & HS1 (A) & 480 \\
\hline F223(G) & 370 & F32(A) & 480 \\
\hline F7 (G) & 380 & HS2 (A) & 580 \\
\hline F251 (G) & 380 & \multicolumn{3}{|l}{} \\
\cline { 1 - 2 }
\end{tabular}

\section{Extension et abandon de l'habitat de l'horizon III}

L'habitat se déploie maintenant au sud et au nord de la nouvelle chaussée dont les limites reprennent celles des horizons précédents, pérennisant cet axe. L'habitat nordouest sur solin, est agrandi et élevé en partie en dur. Cet habitat, se substituant à une zone artisanale, indiquerait une extension de l'occupation vers l'ouest, en direction de l'oppidum et peut-être, un rejet plus loin, en périphérie des activités à risques (céramique par exemple).

Au sud de la voie, l'habitat s'étend en suivant les mêmes limites et contraintes que celles observées sur les horizons I et II. L'occupation se développe à la période flavienne, à partir d'un noyau central restreint (les pièces $\mathrm{F}$ et $\mathrm{G}$ ). L'adjonction de deux ailes (état 2) matérialiserait un essor économique. Le dernier état serait marqué par un démantèlement de la propriété. Ces vestiges ainsi que leur organisation, nous font songer à un "habitat "; quelques éléments, notamment dans l'aile ouest, peuvent être assimilés à un four de séchage de grains (malterie ?) ou un fumoir (fig. 28) et éventuellement à des activités de battage (espaces $\mathrm{D}$ et $\mathrm{E}$ ) ? Les plans pourraient se comparer à ceux de nombreuses maisons urbaines, peu luxueuses, mises au jour en Gaule, où les nombreuses pièces d'habitation, à usage artisanal ou commercial, s'organisent le long d'une galerie couverte, encadrant une vaste cour intérieure.

Ici, le plan diffère par une large ouverture vers la rue, au nord. Pour des raisons de sécurité, mais aussi afin de ne pas exposer la vie privée, la cour intérieure de la maison urbaine était fermée de tous côtés. En Mayenne, à Jublains, c'est ce que l'on observe dans le quartier de La Grande Boissière (Bocquet et al., 2004). Or, ce n'est pas le cas à 
«La Carie » pour les états 1 et 2, ainsi que pour la partie occidentale de l'habitat pour l'état 3. Nous pouvons estimer que des liens tissés entre la voie et l'habitat sud sont marqués par l'existence de cette ouverture sur la voie. Plusieurs indices, un four (pièce B) et d'éventuelles activités de battage, d'indéniables possibilités de stockage (la pièce/cave $\mathrm{K}$, fig. 25), la position du site en périphérie du chef-lieu de pagus qui se développe plus à l'est, ainsi que les liens supposés privilégiés habitat/voie, permettent d'envisager deux hypothèses principales. Peuvent être évoqués un établissement de type auberge ou gîte d'étape, mais aussi un lieu de transformation et de vente de produits agricoles; à ce propos, mentionnons la découverte d'une meule à traction, vraisemblablement liée à une activité de meunerie (fig. 31 : HS2).

Enfin, l'habitat est abandonné à la fin de la période antonine ou au début de la période sévérienne, cet abandon précoce observé aussi à Jublains (Bocquet et al., 2004) pouvant être un signe des crises de la période sévérienne. Peu d'éléments nous renseignent sur les modalités de cet abandon. Le mobilier qui signe ce dernier vers la fin de la période antonine ou légèrement plus tard témoigne d'une longue durée d'occupation depuis l'orée de la période flavienne. Le corpus des monnaies confirme ces observations (tab. 9: $\mathrm{n}^{\circ}$ M1 à M8). Aucune trace de destruction, un incendie par exemple, n'est présente. La cave $\mathrm{K}$ serait remblayée massivement, en une seule fois. L'étude de la sigillée montre un pic de l'occupation sous les règnes d'Antonin le Pieux et MarcAurèle, pour voir ensuite une désaffection du site sans doute vers Commode, les premières années $d u \mathrm{III}^{\mathrm{e}}$ siècle montrant encore une faible activité : les bâtiments ne sont pas complètement détruits et désertés comme le soulignent les rares éléments de l'horizon IV s'y trouvant encore : quelques monnaies.

\section{Sigillée et verrerie : rupture et continuité}

Les deux études suivantes ont été regroupées pour des raisons de commodité mais aussi et surtout, pour illustrer de manière précise l'évolution diachronique d'un type particulier d'objet présent dans différents horizons, la sigillée en est le cas d'espèce le plus représentatif. L'étude de la céramique sigillée montre aussi une linéarité de l'occupation du site au Haut-Empire; il n'y a pas de césure chronologique entre les horizons II et III. L'étude de la verrerie offre un lot restreint ( 96 restes pour un NMI de 41) qui - s'il présente quelques pièces $d u{ }^{\text {er }}$ siècle (souvent sans plus de précision), souvent issus de contextes plus tardifs - est surtout représenté par des éléments de la fin $d u{ }^{e r}$ et $d u{ }^{e}{ }^{e}$ siècle, liés au service de table, pouvant en cela conforter les hypothèses émises supra.

\section{La céramique sigillée (R. Delage)}

Il s'agit d'un ensemble de 507 fragments correspondant, selon les modes de comptage, à 161 ou 263 individus $^{11}$. Elle se répartit en petits lots au sein d'une soixantaine d'ensembles, à l'exception du remplissage, avec 64 vases de la cave (pièce K). La période d'utilisation des sigillées sur le site couvre toute l'histoire impériale. L'essentiel de la consommation concerne toutefois le Haut-Empire (fig. $32^{12}$ ). Leur utilisation, des années 10 aux années 180 , est régulière et ne connaît pas de rupture, mais des variations peu significatives. 
Figure 32 : Entrammes, « La Carie » : représentation graphique de la probabilité d'apparition sur le site de la céramique sigillée, toutes périodes et provenances confondues (corpus $263 \mathrm{NMIp} /$ analyse par tranches de 10 ans). L'abscisse représente l'échelle du temps, l'ordonnée la valeur statistique du lot.

Figure 32: Graph showing the probability of appearance on the site of terra sigillata or samian ware, all periods and origins combined (corpus $263 \mathrm{NMIp/analysis} \mathrm{at} \mathrm{10-year} \mathrm{intervals).} \mathrm{The} x$-axis represents time, the $y$-axis the statistical value of the batch.

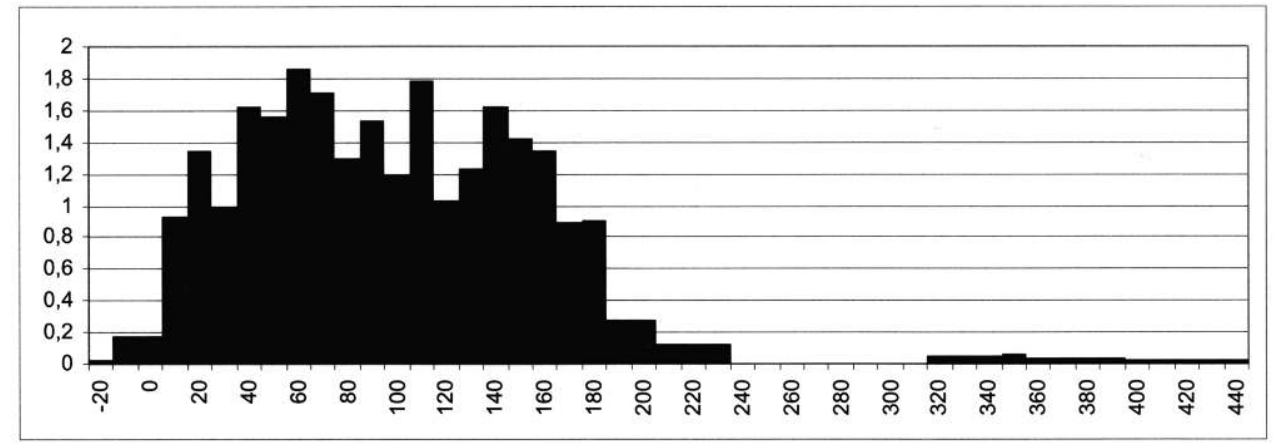

\section{Les cinq groupes de production (tab. 6)}

Les sigillées du centre de la Gaule, le premier groupe, représentent $53 \%$ des NMIp. Issues des centres de production de la vallée de l'Allier, elles sont utilisées à Entrammes dès le début du $\mathrm{I}^{\mathrm{er}}$ siècle et disparaissent au $\mathrm{III}^{\mathrm{e}}$ siècle. Le second groupe est celui du Sud de la Gaule avec un total de $38 \%$ des NMIp. La période de diffusion de ces vaisselles à Entrammes ne dépasse pas le milieu du II ${ }^{\mathrm{e}}$ siècle. Les trois autres groupes de production attestés ne comptent que quelques individus ne dépassant pas $5 \%$ des NMIp. Le premier est celui du centre-ouest avec $4,6 \%$, diffusé pendant quelques décennies, en première moitié du $\mathrm{II}^{\mathrm{e}}$ siècle. Viennent ensuite les productions d'Argonne, avec 2,7 \% des NMIp, avec exclusivement des pièces du Bas Empire. Enfin, le groupe des sigillées de type italique, uniquement attesté dans l'ouest aux périodes augustéenne et tibérienne, ne figure qu'à hauteur de $2 \%$ des NMIp, avec cinq individus.

Tableau 6 : Entrammes, « La Carie » : quantification des céramiques sigillées.

Table 6: quantification of terra sigillata.

\begin{tabular}{|l|c|c|c|c|c|c|}
\hline Groupe & NR & \%NR & NMI & \%NMI & NMIp & $\%$ NMIp \\
\hline Italique & 6 & $1 \%$ & 2 & $1 \%$ & 5 & $2 \%$ \\
\hline Sud Gaule ou Italique & 1 & & 1 & & 1 & \\
\hline Sud Gaule & $\mathbf{1 8 8}$ & $\mathbf{3 7 \%}$ & $\mathbf{6 3}$ & $\mathbf{3 9 \%}$ & $\mathbf{9 9}$ & $\mathbf{3 8 \%}$ \\
\hline Centre Ouest Gaule & 32 & $6,30 \%$ & 7 & $4,30 \%$ & 12 & $4,60 \%$ \\
\hline Centre Gaule & $\mathbf{2 7 2}$ & $\mathbf{5 4 \%}$ & $\mathbf{8 5}$ & $\mathbf{5 3 \%}$ & $\mathbf{1 3 9}$ & $\mathbf{5 3 \%}$ \\
\hline Argonne & 8 & $1,60 \%$ & 3 & $1,90 \%$ & 7 & $2,70 \%$ \\
\hline total & $\mathbf{5 0 7}$ & $\mathbf{1 0 0} \%$ & $\mathbf{1 6 1}$ & $\mathbf{1 0 0 \%}$ & $\mathbf{2 6 3}$ & $\mathbf{1 0 0} \%$ \\
\hline
\end{tabular}

Des proportions similaires ont été mises en évidence lors de l'étude du quartier des Boissières à Jublains, puisque vaisselles du centre et du sud y sont créditées de $56 \%$ et $40 \%$ des NMIp (sur la base de 4885 individus). Seule différence notable avec 
Entrammes, les groupes marginaux dont la représentation est moindre : 3,2 \% pour le centre-ouest et 0,3\% pour les sigillées italiques (Delage, 2006a).

\section{La sigillée italique}

Les pièces d'Entrammes correspondent aux services les plus classiques de cette production, l'assiette Co12-3 (Halt. Serv. Ic : fig. $33^{13}, \mathrm{n}^{\circ}$ 1) et la coupelle Co22-1 (Halt. 8, non représentée). Notons la présence d'une estampille de graphie [MENA]/AVILI (fig. 34, $\mathrm{n}^{\circ}$ 2) dont un exemplaire a été trouvé sur l'atelier de la Muette à Lyon (Rhône) (Lasfargues et al., 1976, p. 50-51, réf. VII). Elle n'a pas été reprise dans le catalogue des estampilles de Lyon (Genin et al., 1996, p. 193-213) car des analyses ont montré que le potier qui s'en servait, devait être implanté à Vienne/Saint-Romain-en-Gal (Rhône) (Desbat et Picon, 1992, p.396; fig. 34, n 1 ; Oxé et al., 2000, p.150, réf. 380-2.). Entrammes constitue, à l'heure actuelle, la seconde attestation de la diffusion des vaisselles de MENA dans l'ouest après celle d'Angers. L'essentiel des découvertes concerne les camps militaires ou les établissements en lien avec les grandes voies de commerce et d'approvisionnement des troupes (fig. $34, n^{\circ} 1$ ).

Tableau 7 : Entrammes, "La Carie " : répertoire détaillé des céramiques sigillées présentées sur les figures $33,34,35$ et 37 . NR : nombre de restes.

Table 7: Detailed inventory of terra sigillata shown in figures $33,34,35$ and 37 . NR: number of other.

\begin{tabular}{|c|c|c|c|c|c|c|c|}
\hline $\begin{array}{l}\mathrm{n}^{\circ} \mathrm{de} \\
\text { figure }\end{array}$ & $\begin{array}{c}\text { Référence } \\
\text { archéologique }\end{array}$ & $\begin{array}{l}\text { Origine } \\
\text {. }\end{array}$ & $\begin{array}{c}\text { Référence } \\
\text { typologique }\end{array}$ & $\begin{array}{l}\text { Datation } \\
\text { proposée }\end{array}$ & $\mathrm{NR}$ & Style décoratif & $\begin{array}{l}\text { Estampille } \\
\end{array}$ \\
\hline $33, \mathrm{n}^{\circ} 01$ & 253 & ITAL-ind. & Col2.3 & $-10 / 20$ & 1 & & \\
\hline $33, \mathrm{n}^{\circ} 02$ & 209 & SG-Montans & \begin{tabular}{|l|} 
D19 \\
\end{tabular} & $10 / 40$ & 1 & & \\
\hline $33, \mathrm{n}^{\circ} 03$ & 286 deca & SG-La Graufesenque & D17 & $20 / 50$ & 6 & & \\
\hline $33, \mathrm{n}^{\circ} 04$ & 002-combl cave & \begin{tabular}{|l|} 
CG-Lezoux \\
\end{tabular} & L062 (D17) & $10 / 30$ & 8 & & \\
\hline $33, \mathrm{n}^{\circ} 05$ & 202 & CG-Lezoux & \begin{tabular}{|l|} 
L066 \\
(D15/17)
\end{tabular} & $30 / 70$ & 6 & & \\
\hline $33, \mathrm{n}^{\circ} 06$ & 179 & SG-La Graufesenque & D27 & $40 / 80$ & 1 & & \\
\hline $33, \mathrm{n}^{\circ} 07$ & 002-combl cave & CG-ind. & \begin{tabular}{|l} 
L039 (R05) \\
\end{tabular} & $10 / 40$ & 1 & & \\
\hline $33, \mathrm{n}^{\circ} 08$ & 253 & SG-La Graufesenque & \begin{tabular}{|l|l|}
$\mathrm{D} 24 / 25$ \\
\end{tabular} & $40 / 60$ & 2 & & \\
\hline $33, \mathrm{n}^{\circ} 09$ & M134 deca & SG-La Graufesenque & D18 & $40 / 60$ & 1 & & \\
\hline $33, \mathrm{n}^{\circ} 10$ & 237 & SG-La Graufesenque & $\mathrm{VeA} 2$ & $60 / 120$ & 7 & & \\
\hline $33, \mathrm{n}^{\circ} 11$ & 8 & \begin{tabular}{|l|} 
CG-ind. \\
\end{tabular} & \begin{tabular}{|l|} 
L036 (D33) \\
\end{tabular} & $110 / 140$ & 1 & & \\
\hline $33, \mathrm{n}^{0} 12$ & $002 / 207$ & COG-ind. & C11 & $90 / 140$ & 1 & & \\
\hline $33, \mathrm{n}^{\circ} 13$ & $002 / 207$ & CG-ind. & \begin{tabular}{|l|}
$.088(\mathrm{D} 38)$ \\
\end{tabular} & $110 / 140$ & 3 & & \\
\hline $33, \mathrm{n}^{0} 14$ & $002 / 207$ & CG-Terre-Franche & \begin{tabular}{|l} 
L088 (D38) \\
\end{tabular} & $140 / 190$ & 1 & & \\
\hline $33, \mathrm{n}^{\circ} 15$ & $002 / 207$ & CG-ind. & \begin{tabular}{|l}
$\mathrm{L} 043$ (C23) \\
\end{tabular} & $140 / 170$ & 2 & & \\
\hline $33, \mathrm{n}^{\circ} 16$ & $002 / 207$ & CG-ind. & \begin{tabular}{|l} 
L102(D72) \\
\end{tabular} & $160 / 240$ & 3 & & \\
\hline $33, \mathrm{n}^{\circ} 17$ & F8 et $002 / 207$ & $\begin{array}{l}\text { CG-Lezoux } \\
\end{array}$ & \begin{tabular}{|l|} 
L032 (W79) \\
\end{tabular} & $160 / 210$ & 9 & & \begin{tabular}{|l|} 
PATERNIM \\
\end{tabular} \\
\hline $34, \mathrm{n}^{\circ} 02$ & 386 & Italique-Vienne & Ind. & $-10 / 10$ & 1 & & MENA/AVILI \\
\hline $34, n^{\circ} 03$ & F8 et $002 / 207$ & CG-Lezoux & L032 (W79) & $160 / 210$ & 9 & & \begin{tabular}{|l|} 
PATERNIM \\
\end{tabular} \\
\hline $34, n^{\circ} 04$ & $002 / 207$ & CG-Terre-Franche & \begin{tabular}{|l}
$\mathrm{L} 036$ (D33) \\
\end{tabular} & $140 / 190$ & 1 & & \begin{tabular}{|l|} 
POTTINIM \\
\end{tabular} \\
\hline $35, n^{\circ} 01$ & 308 & \begin{tabular}{|l} 
CG-Lezoux \\
\end{tabular} & \begin{tabular}{|l|l} 
D29 \\
\end{tabular} & $10 / 30$ & 8 & & \\
\hline $35, \mathrm{n}^{\circ} 02$ & 308 & SG-La Graufesenque & D29 & $20 / 40$ & 1 & & \\
\hline $35, \mathrm{n}^{\circ} 03$ & 179 & CG-Lezoux & D37? & $60 / 90$ & 1 & & \\
\hline $35, \mathrm{n}^{\circ} 04$ & 280 & SG-La Graufesenque & D37 & $60 / 100$ & 1 & & \\
\hline $35, n^{\circ} 05$ & M134 deca & CG-Lezoux & D37 & $60 / 90$ & 1 & & \\
\hline $35, \mathrm{n}^{\circ} 06$ & 10 & SG-La Graufesenque & D37 & $80 / 120$ & 2 & & \\
\hline $35, \mathrm{n}^{\circ} 07$ & 138 & SG-La Graufesenque & D37 & $80 / 120$ & 3 & & \\
\hline $37, \mathrm{n}^{\circ} 08$ & 161 & CG-Lezoux & D37 & $140 / 170$ & 1 & & \\
\hline $37, \mathrm{n}^{\circ} 09$ & 160 & CG-Lezoux & D37 & $130 / 160$ & 1 & QVINTILIANVS & \\
\hline $37, \mathrm{n}^{\circ} 10$ & 161 & CG-Lezoux & D37 & $130 / 150$ & 2 & BVTRIO? & \\
\hline $37, \mathrm{n}^{0} 11$ & $002 / 207$ & CG-Lezoux & D37 & $140 / 170$ & 5 & CINNAMVS/PVGNVS & \\
\hline $37, \mathrm{n}^{\circ} 12$ & $002 / 207$ & CG-Lezoux & D37 & $160 / 210$ & 2 & & \begin{tabular}{|l} 
[PATER]NFE \\
\end{tabular} \\
\hline $37, \mathrm{n}^{\circ} 13$ & 158 & CG-Lubié & D37 & $190 / 240$ & 1 & BANVVS I & \\
\hline
\end{tabular}


Figure 33 : Entrammes, « La Carie » : la céramique sigillée présentée par ordre chronologique de production. Italique : 1 ; Montans : 2 ; La Graufesenque : 3, 6, 8, 9,10; centre Gaule / Lezoux : 4, 5, 7, 11,13 à 17 ; Centre-Ouest : 12.

Figure 33: Terra sigillata presented in chronological order of production. Italy: 1; Montans (Tarn): 2 ; La Graufesenque (near Millau, Aveyron): 3, 6, 8, 9,10; central Gaul / Lezoux (Auvergne): 4, 5, 7, 11, 13 to 17 ; Centre-West: 12.

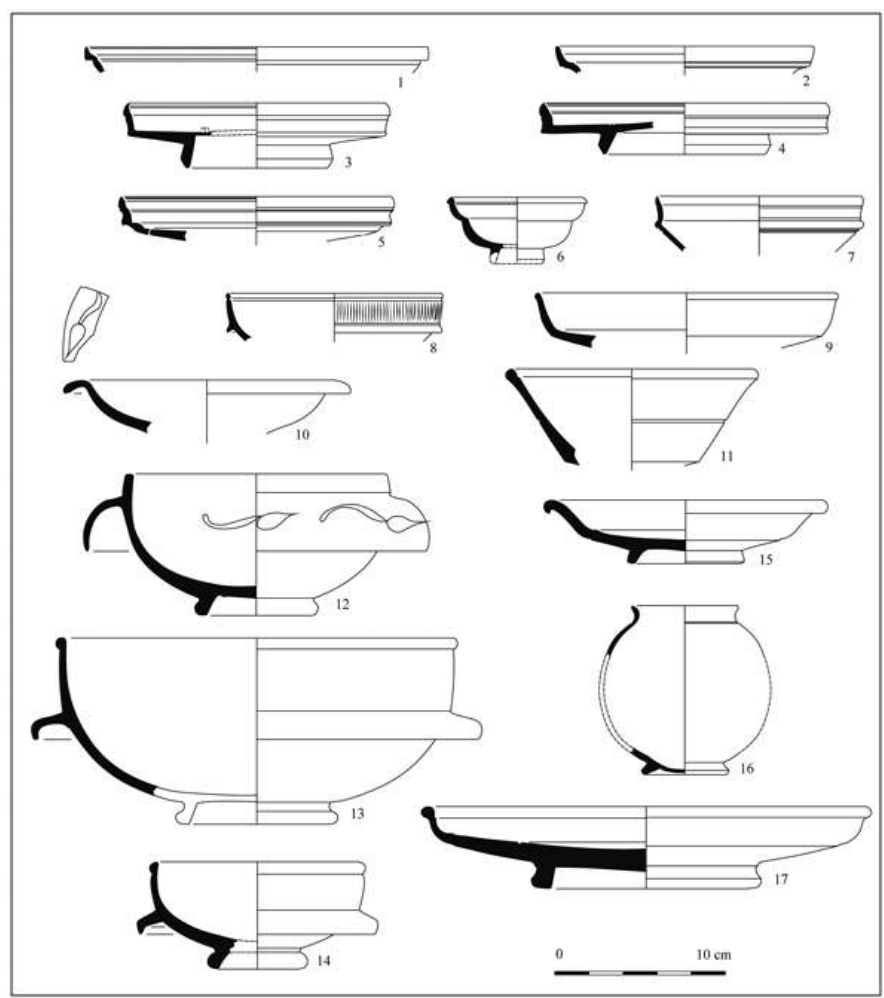


Figure 34 : Entrammes, « La Carie » : estampilles sur céramique sigillée. 1. diffusion des estampilles de Vienne " MENA/AVILI » (d'après Oxé et al., 2000) (une attestation à Rome ne Figure pas sur la carte) ; 2 : estampille [MENA]/AVILI ; 3 : estampille de PATERNVS ; 4 : estampille de POTTINVS ?

Figure 34: Identification mark on terra sigillata. 1. Dissemination of Viennese marks "MENA/AVILI" (from Oxé et al., 2000) (a certification in Rome is not shown on the map); 2: [MENA]/AVILI mark; 3 : PATERNVS mark; 4: POTTINVS mark?

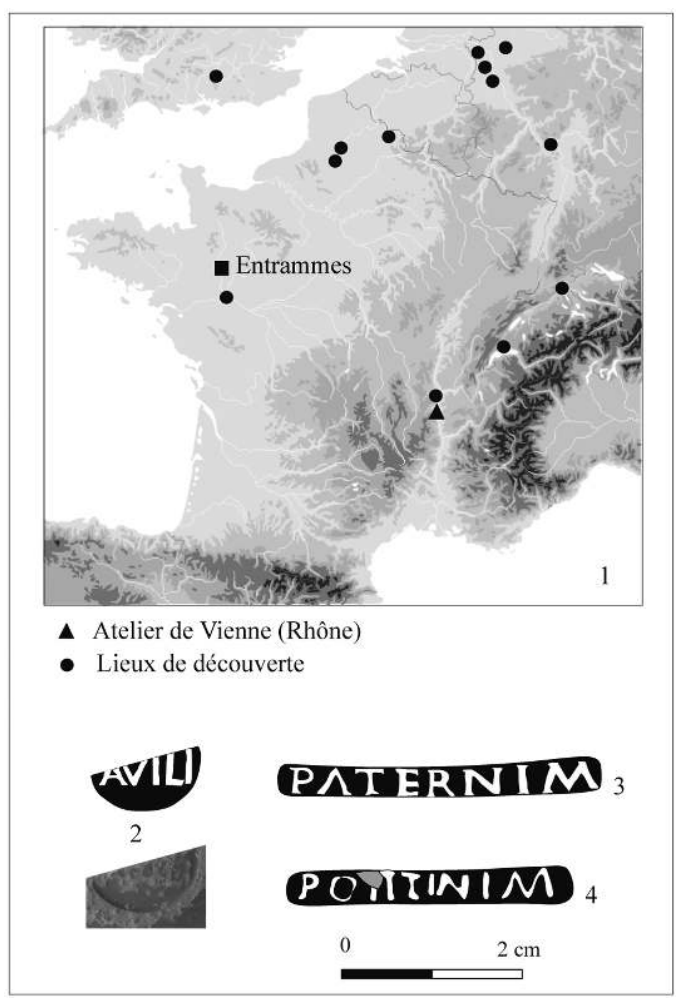

\section{Les sigillées du sud de la Gaule}

Bien que les datations assignées aux sigillées du Sud de la Gaule, présentes sur le site, couvrent près d'un siècle et demi, ce sont essentiellement les productions du milieu du $\mathrm{I}^{\mathrm{er}}$ siècle et, dans une moindre mesure, de la période flavienne, qui sont attestées. Les sigillées de Millau-la Graufesenque (Aveyron) constituent le lot majoritaire avec $93 \%$ des NMIp (fig. 33, n 3, 6, 8 à 10 ; fig. 35, n 2, 4, 6 et 7), à l'image de Jublains ( $94 \%$ des NMIp sur la base de 1947 individus). Seuls trois vases sont issus de l'autre pôle de production majeur du sud de la Gaule qu'est Montans (Tarn) (fig. 33, n²). En fait, dans l'ouest, seuls les sites gallo-romains de la façade atlantique livrent des lots plus conséquents de ces vaisselles, du fait d'un commerce atlantique actif (Martin, 1999). Le répertoire des sigillées méridionales est relativement homogène, puisque les trois principales classes morphologiques de la vaisselle de table et de présentation sont représentées dans des proportions à peu près égales : assiette/plat, coupelle et coupe. Les quatre formes dominantes appartiennent d'ailleurs à chacune d'entre elles. Il s'agit en premier lieu de la coupe hémisphérique moulée D37 (18,2 \% des NMIp : fig. 35, $\mathrm{n}^{\circ} 4,6$ et 7), suivie des assiettes/plats D18 (9,1\%: fig. $\left.33, n^{\circ} 9\right)$ et VeA2 $\left(8,1 \%: n^{\circ} 10\right)$, mais aussi de la coupelle bilobée D27 $\left(8,1 \%: n^{\circ} 6\right)$. 
Figure 35 : Entrammes, "La Carie » : décors sur céramique sigillée présentés par ordre chronologique de création (1, 3, 5 : Lezoux ; 2, 4, 6, 7 : La Graufesenque).

Figure 35: Decorated terra sigillata presented in chronological order of creation $(1,3,5$ : Lezoux (Auvergne); 2, 4, 6, 7: La Graufesenque (near Millau, Aveyron).

\section{Les sigillées du centre de la Gaule}

Plusieurs phases de leur commercialisation peuvent être appréhendées à partir des données d'Entrammes. La première coïncide avec la période de fabrication des sigillées de mode $\mathrm{A}$, à pâte siliceuse et vernis poreux, au cours du $\mathrm{i}^{\mathrm{er}}$ siècle (fig. $33, \mathrm{n}^{\circ} 4,5$ et 7 ; fig. $35, n^{\circ} 1,3$ et 5), elles arrivent régulièrement, mais en faibles proportions. Seule exception, les deux premières décennies $\mathrm{du} \mathrm{I}^{\mathrm{er}}$ siècle. Elles témoignent de la volonté commerciale des potiers arvernes de conquérir, dès leurs débuts, les marchés de l'ouest de la Gaule, jusque-là timidement approvisionnés par les sigillées de type italique. Notons qu'au sein du quartier des Boissières à Jublains, ce pic apparaît moins prédominant car les sigillées du centre résistent mieux, après les années trente, à la concurrence des vaisselles méridionales et maintiennent ainsi, contrairement à Entrammes, un niveau d'approvisionnement élevé.

La seconde phase commerciale mise en évidence couvre la plus grande partie du $\mathrm{II}^{\mathrm{e}}$ siècle. Elle se caractérise par un fort accroissement de l'utilisation des vaisselles du centre de la Gaule: elles présentent désormais les qualités «standards» des céramiques sigillées de grande consommation du monde romain occidental (mode C) tandis que les ateliers acquièrent progressivement une capacité de production qui leur permet d'approvisionner les marchés et de faire face à leurs concurrents. Au $\mathrm{II}^{\mathrm{e}}$ siècle, la probabilité d'apparition sur le site de nouvelles pièces est relativement constante et presque deux fois plus élevée que celle $\mathrm{du} \mathrm{I}^{\mathrm{er}}$ siècle. Le plus fort potentiel de consommation réside, toutefois, dans le milieu du $\mathrm{II}^{\mathrm{e}}$ siècle, comme le montre le graphique de la fig. 36. La consommation au début du $\mathrm{III}^{\mathrm{e}}$ siècle est en revanche, en net retrait (fig. $37, \mathrm{n}^{\circ} 12$ et 13 ). Le nombre de pièces potentiellement attribuables à cette période est même inférieur à celui mis en évidence au $\mathrm{I}^{\mathrm{er}}$ siècle. 
Figure 36 : Entrammes, "La Carie » : représentation graphique de la probabilité d'apparition sur le site de la céramique sigillée du centre de la Gaule (corpus 139 NMIp / analyse par tranches de 10 ans). L'abscisse représente l'échelle du temps, l'ordonnée la valeur statistique du lot.

Figure 36: Graph showing the probability of appearance on the site of terra sigillata in the centre of Gaul (corpus 139 NMIp/analysis in 10-year stages). The $x$-axis represents time, the y-axis represents the statistical value of the batch.

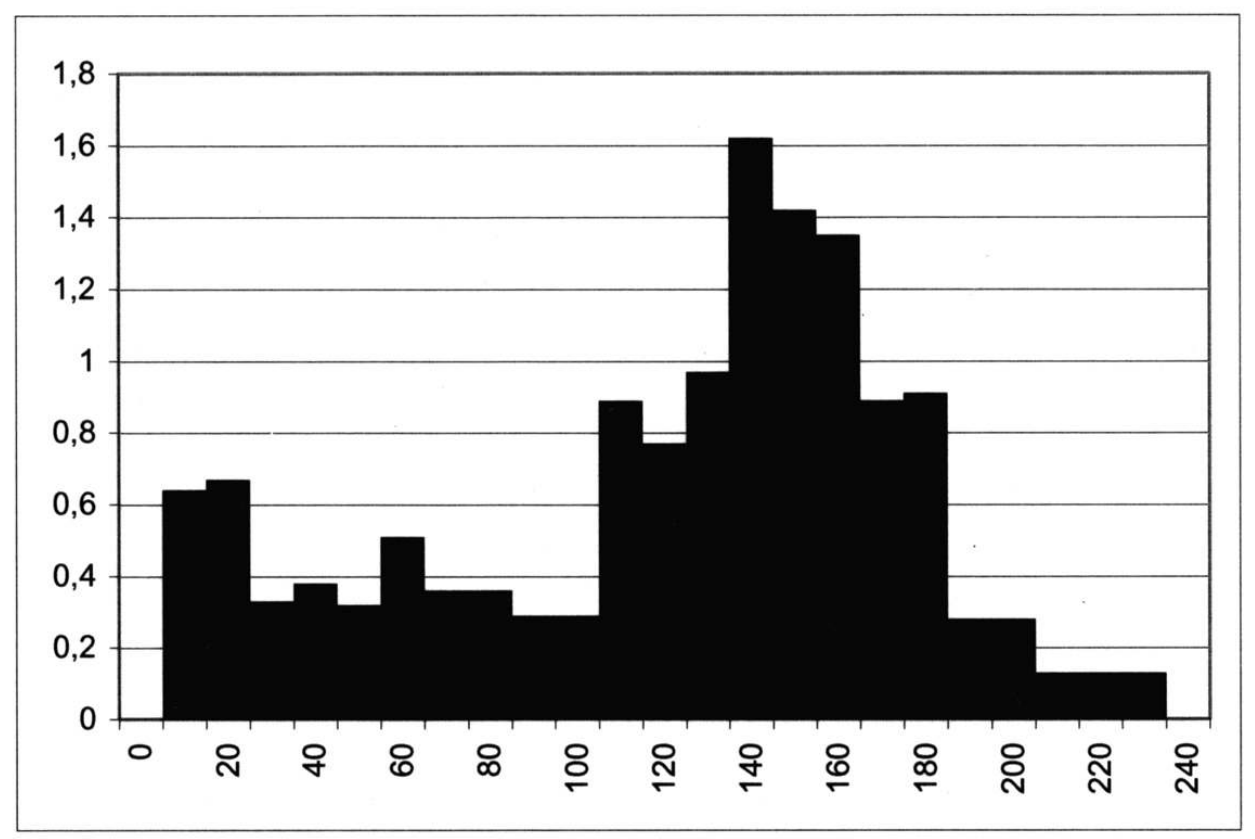

Figure 37 : Entrammes, « La Carie » : décors sur céramique sigillée présentés par ordre chronologique de création (8 à 12 : Lezoux ; 13 : Lubié).

Figure 37: Decoration on terra sigillata in chronological order of creation (8 to 12: Lezoux (Auvergne); 13: Lubié).

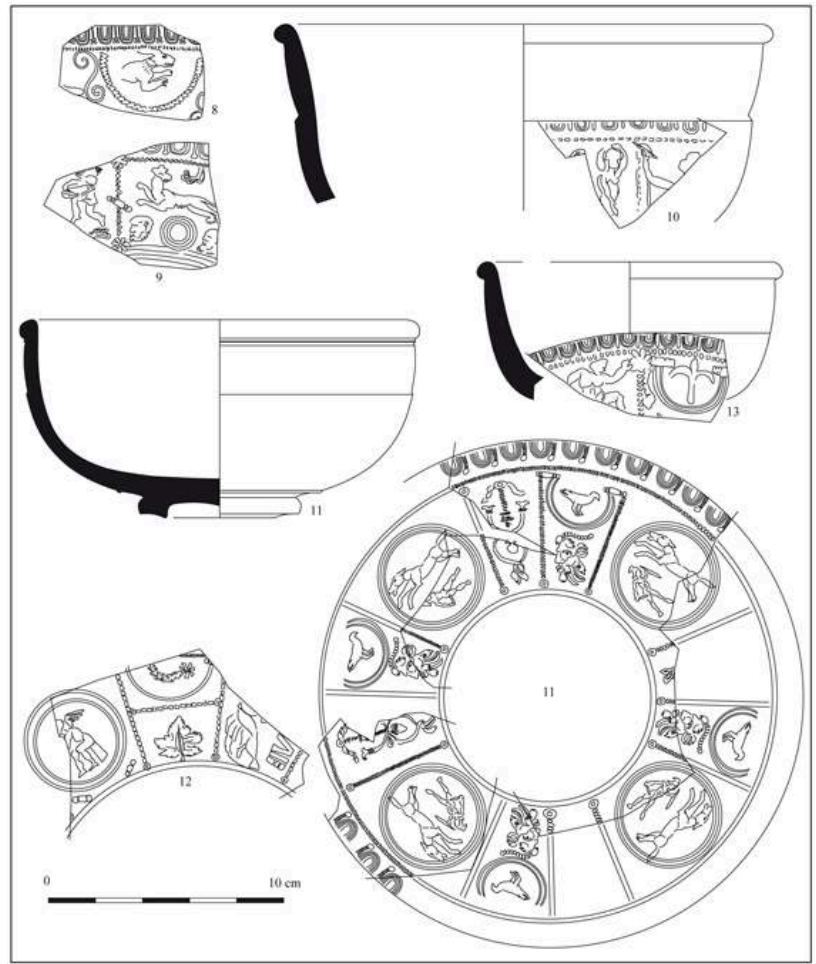


La domination, à Entrammes, des productions de Lezoux (Puy-de-Dôme), avec 56,1 \% des NMIp n'est pas une surprise (fig. 37). Les autres centres de production attestés, Les Martres-de-Veyre (Puy-de-Dôme), Lubié et Toulon-sur-Allier (Allier) ou Gueugnon (Sâone-et-Loire), représentent 5 à $6 \%$ des NMIp. Des proportions identiques ont été obtenues lors de l'étude du quartier des Boissières à Jublains.

Le répertoire morphologique de ces sigillées est plus tranché que celui des vases du sud. Les coupes sont présentes à hauteur de $40 \%$ des NMIp, alors que les deux autres classes principales, assiette/plat et coupelle, se contentent de 21 et $26 \%$ chacune. Une forme domine le répertoire : la coupe hémisphérique moulée D37 : elle représente près de $32 \%$ des NMIp (fig. 35 et 37, $n^{\circ} 3,5,8$ à 13). Toutes les autres se situent loin derrière elle. L'assiette L043 (C23 : fig. 33, $\mathrm{n}^{\circ}$ 15) et la coupelle L036 (D33 : $\left.\mathrm{n}^{\circ} 11\right)$ ne comptent que quelques individus.

129 Un petit lot de marques de potier a pu être recueilli, dont quatre estampilles (PATERNVS, IVLLINVS, PATERNVS II et POTTINVS ?), une rosette et une palme. Notons que deux sont liées à la même "officine »: PATERNVS, l'une des plus importantes du centre de la Gaule au cours de la seconde moitié du II ${ }^{\mathrm{e}}$ siècle (fig. $34, \mathrm{n}^{\circ} 3$ et 4 ).

\section{La sigillée du centre-ouest}

Son corpus se caractérise à Entrammes, comme sur la plupart des sites du Haut-Empire dans l'Ouest de la Gaule, par une prédominance des coupes D37 (7 NMIp : $58 \%$ du répertoire). Les autres formes attestées sont également bien connues : la coupe $\mathrm{C} 11$ (fig. 33, $\left.n^{\circ} 12\right)$ et le service VeA (deux occurrences chacune). À Rezé (Loire-Atlantique), Jublains (Mayenne), Allonnes (Sarthe), Thésée (Loir-et-Cher), elles font partie des pièces les plus courantes (Guitton, 2004 ; Delage, 1997, 2005 et 2006b).

\section{La sigillée d'Argonne}

131 Le corpus d'Entrammes, réduit, atteste une occupation du site au IV siècle (aucune pièce $d u v^{e}$ siècle n'est notée). Deux vases hémisphériques $\mathrm{Ch} .320$ sont pourvus de décors à la molette appartenant aux groupes 1 ( $2^{\mathrm{e}}$ et $3^{\mathrm{e}}$ quarts du IV siècle) et $5\left(3^{\mathrm{e}}\right.$ et $4^{\mathrm{e}}$ quarts du Iv siècle). Des formes Ch. $324 a$ et Ch. $324 \mathrm{~d}$ (une occurrence chacune), ainsi que trois individus sans caractérisation typologique, complètent ce répertoire modeste.

\section{La céramique sigillée d'Entrammes, premières conclusions}

Les résultats de l'étude des céramiques sigillées recueillies à «La Carie » s'inscrivent parfaitement dans nos schémas de connaissances de leur diffusion dans l'ouest de la Gaule. La confrontation des quantifications entre les lots d'Entrammes et ceux des fouilles récentes de Jublains offre des données similaires, permettant de dégager les grandes tendances du commerce de ces vaisselles chez les Diablintes.

Si les premières sigillées qui parviennent sur ce territoire sont celles issues des ateliers d'Italie ou de la vallée du Rhône à la période augustéenne, elles demeurent relativement marginales. En fait, ce sont les productions lézoviennes précoces, des années 10-30, qui commencent à susciter l'intérêt du plus grand nombre. Très vite toutefois, ces productions arvernes sont concurrencées par celles de La Graufesenque. La qualité des pièces rutènes et surtout l'abondance de l'offre relèguent les premières au rang de second choix dès le deuxième quart du $\mathrm{I}^{\text {er }}$ siècle. Il faut attendre les 
premières décennies du $\mathrm{II}^{\mathrm{e}}$ siècle pour que de nouveaux rapports de force s'établissent. Des vaisselles issues d'ateliers arvernes en profonde mutation, mais aussi d'ateliers pictons (centre-ouest) font leur apparition. Celles du centre finissent par s'imposer à partir du milieu du $\mathrm{II}^{\mathrm{e}}$ siècle, éliminant ainsi rapidement toute concurrence. Jusqu'à la fin du Haut-Empire, elles constitueront le seul choix dans ce domaine.

Bien que certains ateliers de Lezoux poursuivent une activité au IV siècle, leurs vases ne sont plus diffusés en territoire diablinte. Ce sont les vaisselles d'Argonne qui prennent le relais, dans des proportions toutefois nettement inférieures à ce que fut le commerce des sigillées au Haut-Empire.

\section{La verrerie antique (L. Simon)}

Le site a livré quelques verreries des deux premiers siècles de notre ère et une seule du Bas-Empire. La cohérence de ce corpus, ainsi intéressante, est marquée par des vases d'usage courant, liés au service de table (fig. 38).

Les vases moulés sont représentés par des coupes Is. $3^{14}$. Un individu est polychrome, marbré de bleu, lie de vin et blanc ( $\left.n^{\circ} 1\right)$, et les autres sont bleu-vert ou bleus $\left(n^{\circ} 2-3\right)$. Ce type est daté de la période augustéenne aux alentours du milieu du $\mathrm{I}^{\mathrm{er}}$ siècle (polychromes) ou à la fin du $\mathrm{I}^{\mathrm{er}}$ siècle /début du $\mathrm{II}^{\mathrm{e}}$ siècle (" couleur naturelle »). Les contextes d'Entrammes vont du milieu du $\mathrm{I}^{\mathrm{er}}$ siècle à la fin du $\mathrm{II}^{\mathrm{e}}$ siècle/début du III (pièce $\mathrm{K}$ ).

Les autres récipients sont obtenus par soufflage. Le gobelet bleu cobalt de forme Is. 12 $\left(\mathrm{n}^{\circ} 4\right)$, une production $\mathrm{du} \mathrm{I}^{\mathrm{er}}$ siècle, est résiduel dans son contexte de découverte : la pièce $\mathrm{K}$. Le gobelet vert clair $\mathrm{n}^{\circ} 5$ (pièce $\mathrm{K}$ ), relève du type Is. 33 var., est daté du milieu $\mathrm{du} \mathrm{I}^{\mathrm{er}}$ siècle au deuxième quart du $\mathrm{II}^{\mathrm{e}}$ siècle et pourrait, entre autres, avoir été produit à Jublains (Simon, à paraître). Du même remplissage provient un gobelet bleu-vert à lèvre épaissie $\left(n^{\circ} 6\right)$, d'un type bien représenté dans l'Ouest de la Gaule (Is. 36b var.) notamment à Jublains (production locale). Il est en usage de la seconde moitié du $\mathrm{I}^{\mathrm{er}}$ siècle au courant $\mathrm{du} \mathrm{II}^{\mathrm{e}}$ siècle. Un dernier gobelet, de teinte vert olive clair $\left(\mathrm{n}^{\circ} 7\right)$, répond au type Is. 106, daté du $\mathrm{IV}^{\mathrm{e}}$ siècle mais encore en usage au $\mathrm{v}^{\mathrm{e}}$. Il provient d'un niveau de voie de l'horizon IV. Une coupe vert clair de type Is.44/115 issue de la pièce $\mathrm{K}\left(\mathrm{n}^{\circ} 8\right)$, est datée largement (période claudienne au IV siècle).

Le pot globulaire côtelé $\left(n^{\circ} 9\right)$ singularisé par sa matière bleu cobalt brillante, s'apparente au type Is. $67 \mathrm{c}$, daté du milieu du $\mathrm{I}^{\mathrm{er}}$ siècle à la seconde moitié du $\mathrm{II}^{\mathrm{e}}$ siècle, au plus tard. Issu de la fosse 15 (horizon II : fig. 14), il diffère du type Is. 67c par une lèvre simple à la place d'un ourlet externe. Bien qu'atypique, il montre des similitudes avec une cruche de la nécropole d'Harfleur (Seine-Maritime), datée de la deuxième moitié du $\mathrm{I}^{\mathrm{er}}$ siècle (Verre et Merveilles, 1993, n 134) : même matière, module identique et espacement des côtes du même ordre.

Le fragment vert clair $n^{\circ} 10$, un vase fermé orné de filets rapportés à la base du col, correspond à une cruche Is. 52 ou à un pot Is. 94, est issu d'un contexte du dernier tiers $\mathrm{du} \mathrm{I}^{\mathrm{er}}$ siècle /premier tiers du $\mathrm{II}^{\mathrm{e}}$. Le pot Is. 94 serait représenté par des tessons de fonds " couleur naturelle » $\left(\mathrm{n}^{\circ} 11\right)$, issus de la pièce $\mathrm{K}$. Ce type est daté des $\mathrm{II}^{\mathrm{e}}-\mathrm{III} \mathrm{e}^{\mathrm{e}}$ siècles, avec des débuts dès la seconde moitié du $\mathrm{I}^{\mathrm{er}}$ siècle. Deux récipients soufflés dans un moule possèdent des marques circulaires sur leur fond ( $\left.n^{\circ} 12-13\right)$. Le premier, de section carrée et provenant de la pièce $K$, pourrait être une bouteille (Is. 50) ou un pot (Is. 62), 
types en usage de la période claudienne au $\mathrm{III}^{\mathrm{e}}$ siècle. Une même datation peut être proposée pour le $n^{\circ} 13$, très fragmenté.

Ce lot d'Entrammes comprend encore deux fragments de vitre coulée, deux pions de jeu ( $n^{\circ} 14$ et 15$)$ et trois perles côtelées ( $n^{\circ} 16$ à 18). Par sa diversité, ce matériel en verre, bien que modeste, offre un panorama intéressant de ce qui fut en usage dans ce quartier, essentiellement au cours des deux premiers siècles de notre ère. Nous y notons liés au service de table de nombreuses formes ouvertes, les coupes Is. 3, les gobelets Is. 12, Is. 33 var., Is. 36a var. et Is. 106. Enfin, mentionnons le joli pot globulaire côtelé de teinte bleu cobalt brillant ( $\left.\mathrm{n}^{\circ} 9\right)$, proche du type Is. 67c.

\section{De la voie tardive à la période carolingienne}

\section{Les témoins de l'Antiquité tardive : I'horizon IV}

L'habitat de l'horizon III est abandonné vers la fin de la période antonine ou légèrement plus tard, mais le Bas-Empire y est attesté par trois monnaies, signant une occupation mal caractérisée (fig. 39, haut; tab. 9, $\mathrm{n}^{\circ}$ M12, M13 et M15). Les remblais F389 et F283 formant la nouvelle chaussée (fig. 8 : sondages S9 et S13, fig. 15) ont livré six monnaies tardives (tab. 9, n ${ }^{\circ}$ M10 et M11, M14 et M16 à M18) qu'accompagnent quelques tessons de céramique sigillée d'Argonne de la deuxième moitié du IV siècle et un gobelet en verre, de teinte vert olive clair (fig. $38, \mathrm{n}^{\circ} 7$ ), du Iv ${ }^{e}$ siècle. Ce nouvel état de chaussée a une emprise de 5-6 mètres de large (fig. 39); le fossé F378, peu marqué, la borde ponctuellement au sud (fig. 8 : sondages 9 et 13 ; fig. 39). Son originalité réside dans une double gestion des matériaux : vers l'est, en direction du gué, les niveaux antérieurs ont été ôtés sur 0,15/0,20 mètre d'épaisseur, puis remplacés par de nouveaux (fig. 15). Vers l'ouest, on a un classique apport de remblais.

Le fait essentiel exprimé par ces quelques remarques est que l'axe Le Mans-Rennes est entretenu et emprunté, au moins jusqu'au ve siècle. 
Figure 38 : Entrammes, «La Carie ", la verrerie. Les vases moulés : $\mathrm{n}^{\circ} 1-3$ (coupes) ; les vases soufflés : $n^{\circ} 4-13$ (gobelets, coupe, pots, bouteilles); les pions de jeu : $n^{\circ} 14-15$; les perles : $n^{\circ} 16-18$.

Figure 38: The glass works. Moulded vases: $n^{\circ} 1-3$ (chalices); blown glass: $n^{\circ}$ 4-13 (goblets, chalice, jars, bottles); game pieces: $n^{\circ} 14-15$; beads: $n^{\circ} 16-18$.

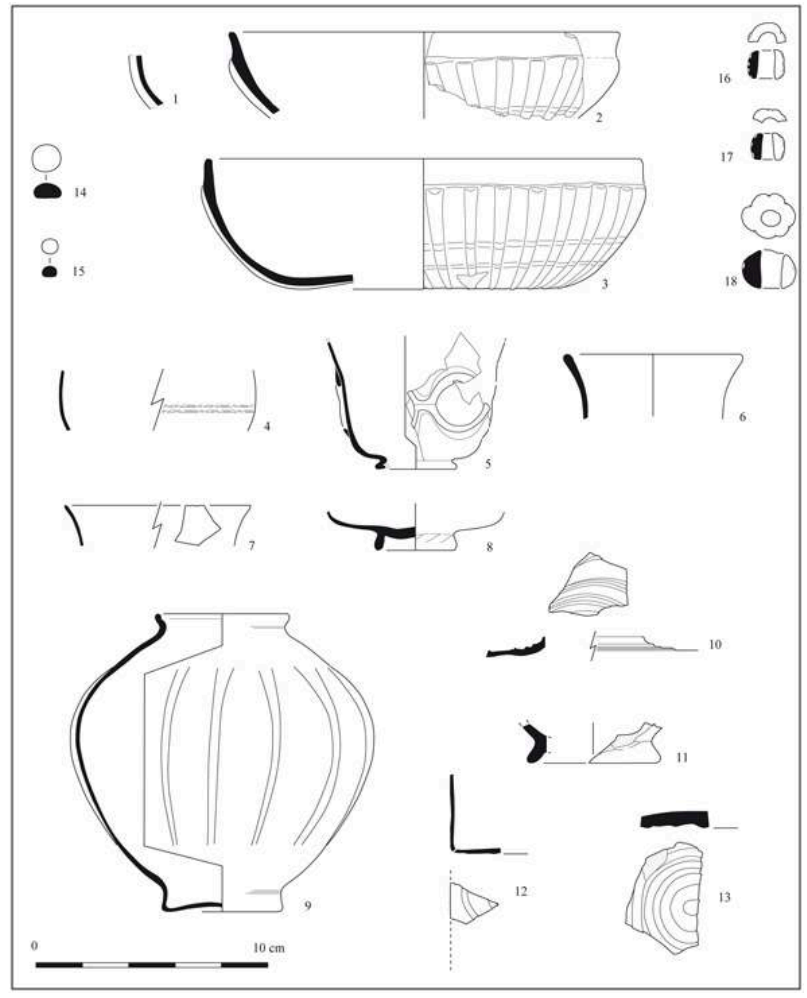


Figure 39 : Entrammes, « La Carie » : la voie tardive (Horizon IV) et la nécropole mérovingienne (Horizon V).

Figure 39: The late road (Horizon IV) and the Merovingian necropolis: Horizon V.

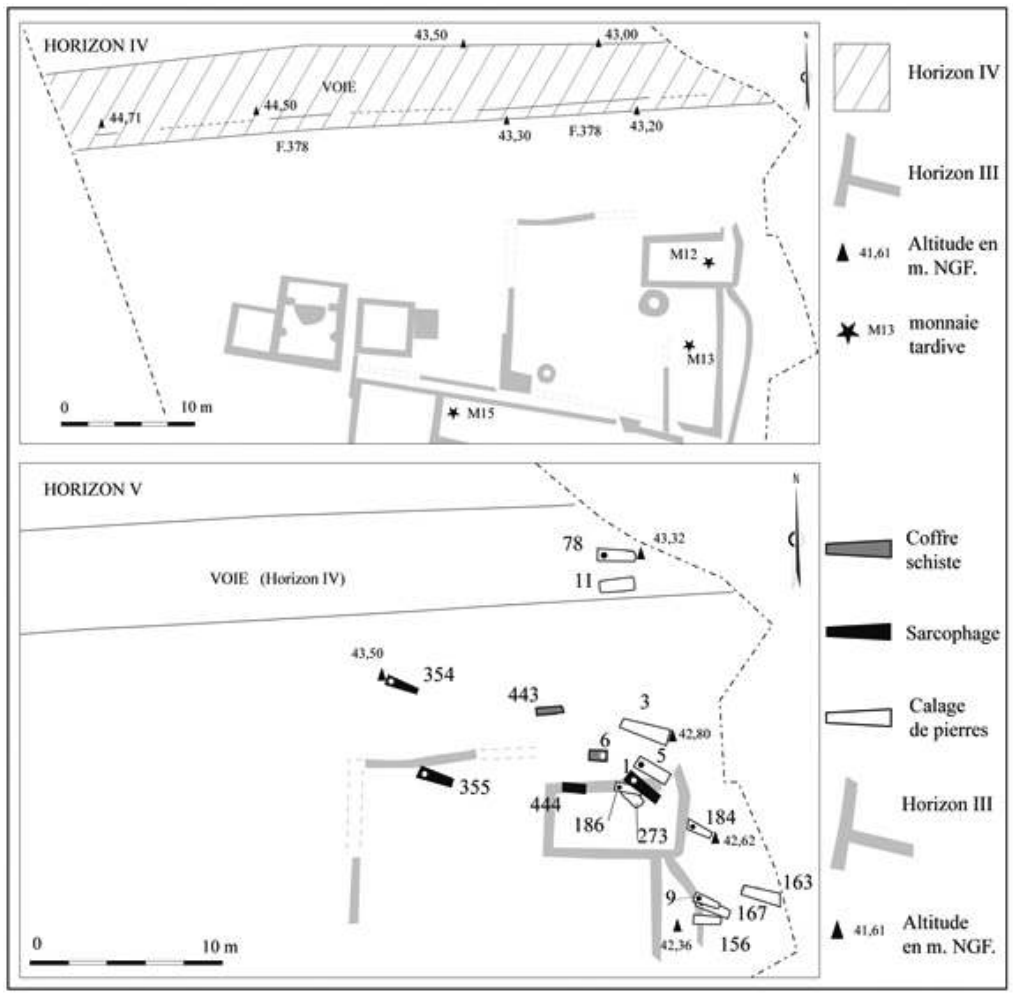

\section{Quelques sépultures mérovingiennes en bord de voie : I'horizon V}

Dix-sept sépultures individuelles à inhumation, attribuables à la période mérovingienne, ont été découvertes (fig. 39, bas et tab. 8). Elles sont en très mauvais état de conservation et trois ont livré des restes osseux. Les sarcophages, révélés par des fonds de cuves, indiquent une érosion du site d'environ 0,40-0,50 mètre, au minimum. 
Tableau 8 : Entrammes, «La Carie » : les principales caractéristiques des sépultures de la nécropole mérovingienne (les dimensions sont exprimées en mètres et mentionnent successivement la longueur, la largeur puis la profondeur des fosses).

Table 8: The main features of the tombs in the Merovingian necropolis (metric dimensions giving successively length, width and depth of the graves).

\begin{tabular}{|c|c|c|c|c|c|}
\hline $\mathbf{N}^{\circ}$ & Type & orientation & dimensions & mobilier & squelette \\
\hline $\mathbf{1}$ & sarcophage en falun & ONO - ESE & $2,1 \times 0,60 \times 0,20$ & - & $\mathrm{X}$ \\
\hline $\mathbf{3}$ & calage de pierres & ESE - ONO & $2,50 \times 1 \times 0,20$ & - & - \\
\hline $\mathbf{5}$ & calage de pierres & ONO - ESE & $2 \times 0,70 \times 0,20$ & - & - \\
\hline $\mathbf{6}$ & coffre en schiste & ESE - ONO & $1 \times 0,55 \times 0,20$ & - & - \\
\hline $\mathbf{9}$ & calage de pierres & ONO - ESE & $1,40 \times 0,60 \times 0,20$ & - & - \\
\hline $\mathbf{1 1}$ & calage de pierres & E - O ou O - E & $1,90 \times 0,75 \times 0,28$ & - & - \\
\hline $\mathbf{7 8}$ & calage de pierres & O - E & $2,50 \times 0,80 \times 0,15$ & - & - \\
\hline $\mathbf{1 5 6}$ & calage de pierres & O - E ou E - O & $1,50, \times 0,70 \times 0,20$ & - & - \\
\hline $\mathbf{1 6 3}$ & calage de pierres & ESE - ONO ? & $2,10 ? \times 0,80 \times 0,20$ & - & - \\
\hline $\mathbf{1 6 7}$ & calage de pierres & ONO - ESE & $2,20 \times 0,60 \times 0,15$ & $\mathrm{X}$ & - \\
\hline $\mathbf{1 8 4}$ & calage de pierres & ONO - ESE & $2 \times 0,80 \times 0,10$ & - & - \\
\hline $\mathbf{1 8 6}$ & calage de pierres & O - E & $1,60, \times 0,60 \times 0,08$ & - & $\mathrm{X}$ \\
\hline $\mathbf{2 7 3}$ & calage de pierres (ponctuel) & ONO - ESE ou & $1,70 \times 0,60 \times 0,15$ & - & $\mathrm{X}$ \\
\cline { 2 - 3 } & & ESE - ONO & & & - \\
\hline $\mathbf{3 5 4}$ & sarcophage en calcaire & ONO - ESE & $1,70 \times 0,50 \times ?$ & - & - \\
\hline $\mathbf{3 5 5}$ & sarcophage en calcaire & ONO - ESE & $1,80 \times 0,58 \times ?$ & - & - \\
\hline $\mathbf{4 4 3}$ & coffre en schiste & E - O ou O - E & $1,50 \times 0,50 \times 0,05$ & - & - \\
\hline $\mathbf{4 4 4}$ & sarcophage en falun & E - O ou O - E & très incomplet & - & - \\
\hline
\end{tabular}

\section{Implantation et répartition}

Cette petite nécropole, organisée en rangées nord-sud, est, comme nombre de cimetières mérovingiens mayennais, située à proximité d'une voie, c'est un « argument en faveur d'une continuité d'utilisation de ces axes au début de la période médiévale » (Colleter, 2003). Les vestiges se développent sur un axe ouest-nord-ouest - est-sud-est, sur une longueur de vingt-cinq mètres et se densifient vers l'est, vers la Jouanne. La présence de deux fonds de sarcophages (F354 et F355) à l'extrémité ouest de la nécropole et une des rares relations stratigraphiques observées (le sarcophage F1 recoupe une inhumation à calage de pierres), permettent d'envisager un développement de la nécropole d'est en ouest, les sarcophages et les coffres en schiste étant les éléments les plus récents.

\section{Orientations, types de tombes et matériaux utilisés}

L'orientation préférentielle ouest-nord-ouest - est-sud-est ou ouest - est (12 cas), suit les observations locales (Colleter, 2003). Ici, trois grands types de tombes ont été mis en évidence, en fonction des matériaux choisis. Le premier, les coffres en schiste ardoisier (F6 et F443), caractérise le sud du département (ibid.). Ce matériau est utilisé du BasEmpire au haut Moyen Âge. Le deuxième est identifié par deux sarcophages en calcaire coquillier ou falun (F1 et F444) et deux en calcaire fin (F354 et F355), découverts sous la forme de fonds de cuves ou de fragments. En Mayenne, le falun, originaire essentiellement du secteur de Doué-la-Fontaine (Maine-et-Loire), est fréquemment employé. Les autres nécropoles d'Entrammes recelaient nombre de sarcophages en falun. Le calcaire, moins commun, est mentionné dans l'église (ibid.). Le troisième type regroupe les inhumations délimitées par des calages de pierres probablement destinés 
à maintenir un coffrage en bois ou tout autre type de structure utilisant ce matériau (couvercle...).

\section{Le mobilier}

Le seul objet en place provient de la tombe F167, au niveau de l'épaule gauche. C'est une fibule à charnière en alliage cuivreux, ansée symétrique, longue de $40 \mathrm{~mm}$ et large de 5 . Son décor est constitué de dix ocelles, ses flancs et ses extrémités sont marqués d'incisions verticales. Elle se rattache aux fibules de type I BB21-e de C. Lorren (2001, p. 86 et s. et pl. VIII-IX) et est attribuable au VII siècle et au début du VIII ${ }^{e}$. Hors stratigraphie, près de la tombe F184, a été découverte une plaque-boucle en alliage cuivreux, étamée, constituée d'une plaque à cinq bossettes, décorée d'entrelacs, de la boucle et de son ardillon, elle est du type IV BBE-f de C. Lorren (2001, p. 256-272 et pl. XXXII), et semble dater de la fin $\mathrm{du} \mathrm{vI}^{\mathrm{e}}$ ou de la première moitié du vII ${ }^{\mathrm{e}}$ siècle.

\section{Les dernières traces de l'occupation de la voie?}

Ce modeste ensemble matérialise une continuité de l'occupation du gué sur la Jouanne et de la voie, signant la dernière occupation structurée du site. Cette voie antique Le Mans-Rennes, dans son tracé à l'ouest d'Entrammes, serait donc toujours active au haut Moyen Âge, comme l'estime Jean-Claude Meuret (1993, p. 262). Enfin, ces sépultures signalent une timide reprise territoriale de plus d'un siècle, en opposition à la déprise signant l'horizon IV.

\section{Une occupation discrète, la période carolingienne : l'horizon VI}

Elle est représentée par de rares tessons de céramique caractéristiques des $\mathrm{x}^{\mathrm{e}}$ et $\mathrm{XI}^{\mathrm{e}}$ siècles. Ils étaient accompagnés d'une bague sigillaire en bronze de type carolingien (Valais, 2005). Nous y voyons une colombe vue du dessus, les ailes déployées et repliées vers l'arrière, probable représentation de l'Esprit-Saint. Ces tessons de céramique sont des fragments de panses décorées à la molette aux motifs de rectangles et de losanges (fig. 40, vase 1) ainsi que des pots à pâte granuleuse beige et orange (vases 2 et 3 ) dont un est doté d'un bord en bandeau (vase 3) et d'un bord de pichet (vase 4). Nombre d'entre eux se trouvaient en surface des couches antiques ou dans le comblement supérieur du puits F153 (vases 5 et 6). Ces éléments pourraient être liés à des campagnes de récupération de matériaux de construction, à l'image du site proche du " 63 de la rue du Maine » (fig. 3) (Guillier, 2006a), mais aussi à tout autre type d'activité (simple passage, travaux agricoles, habitat modeste arasé...). 
Figure 40 : Entrammes, « La Carie » : la céramique carolingienne. Figure 40: Carolingian pottery.

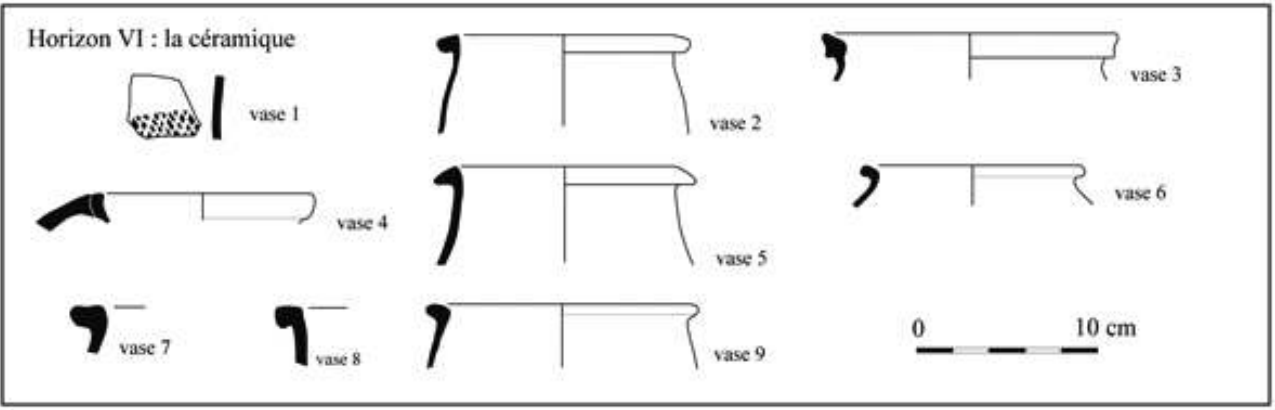

\section{Conclusions}

Depuis la mise au jour des thermes antiques par J. Naveau en 1987, les découvertes sur Entrammes sont restées ponctuelles. Notre intervention à «La Carie » vient, vingt ans après, modestement compléter nos connaissances sur Entrammes et plus précisément sur une occupation située environ à mi-chemin de l'oppidum celtique du Port-du-Salut et des thermes gallo-romains. Cette situation entre ces deux pôles, le long d'une même voie fait que ce site revêt un intérêt tout particulier. En effet, les deux périodes principales d'occupation, laténienne et gallo-romaine, sont largement représentées par une voie et un habitat qui évoluent de pair, mais pas toujours selon les mêmes modalités. Les éléments matériels mis au jour, les structures et leur organisation, qui s'échelonnent en six horizons chronologiques sont d'importants points de repère locaux ou régionaux. Ils affinent nos connaissances sur les Aulerques Diablintes de l'époque gauloise à l'époque antique et permettent d'entrevoir l'évolution d'un habitat groupé d'époque gauloise et de son mobilier pour la première fois dans les Pays de la Loire.

\section{Flux et reflux}

En premier lieu, nous manquons d'informations précises sur les articulations chronologique, hiérarchique ou fonctionnelle existant entre l'oppidum et le site de « La Carie ». Les éléments à notre disposition sont trop morcelés pour envisager un modèle précis d'évolution. Il est toutefois possible, dans un premier temps, d'envisager que les vestiges mis au jour correspondent à une extension ou au développement, d'un village ouvert situé à l'ouest (mais pourquoi pas aussi à l'est ?), le long de la voie ancienne. L'abandon clair du site de «La Carie » à La Tène D2, témoignerait du regroupement de l'occupation dans l'oppidum, à l'instar de Manching (Fichtl, 2005, p. 177). La voie pourrait être encore en service.

En revanche, après un hiatus d'environ un siècle dans l'habitat, l'occupation tibérienne (voire un peu plus hâtive), pourrait être le reflet d'une extension non de l'ouest vers l'est comme précédemment, mais au contraire de l'est vers l'ouest, à partir de la ville antique d'Entrammes, créée et déplacée sur une situation topographique plus favorable vers le début de l'occupation romaine à partir de l'oppidum du Port-du-Salut. Le renforcement de l'occupation aux périodes flavienne et antonine confirme l'extension est-ouest supposée, un habitat se substituant à un secteur à vocation artisanale; sa 
localisation de l'autre côté de la Jouanne par rapport au centre urbain présumé, indiquerait la présence d'un faubourg.

Le secteur occidental d'Entrammes continue d'être occupé pendant l'Antiquité Tardive, comme en témoigne la voie. Nous pouvons émettre l'hypothèse d'un déplacement ou d'un resserrement de l'occupation maintenant vers l'est, en direction du centre antique, autour des thermes et du cœur de ville. Rappelons que ces thermes montrent une transformation en édifice de culte chrétien, au plus tard au VII siècle (Naveau, 1992b) et que la paroisse d'Entrammes aurait été fondée par saint Julien à la fin du IV siècle ou au début du siècle suivant. Nous pouvons alors comprendre l'absence de rupture dans l'occupation du site. La continuité de l'occupation entre l'Antiquité et le haut Moyen Âge, perçue par J. Naveau (1991b) au travers des éléments présents dans le bourg, est aussi mise en évidence, quoique de façon moins marquée, dans une zone excentrée telle que "La Carie», réoccupée par une petite nécropole, signant une dernière et brève extension du bourg vers l'ouest, au delà de la Jouanne.

Nous tenons à remercier toutes les personnes qui ont collaboré au bon déroulement des opérations: Bernard Mandy (SRA), Nelly Le Meur (SRA), et Gilbert Aguesse, Sylvie Barbier. Nous remercions l'équipe de l'Inrap qui s'est particulièrement investie dans la fouille de ce site : Laurent Aubry, Dominique Doyen, Marc Dumas, Fabrice Edin, Gilles Feuillet, Serge Koseev, Dominique Guimard (topographie), Christian Le Goffic, RoseMarie Le Rouzic, Yann Letho Duclos, Sandra Marchand, Jean-François Nauleau (DAO), Emmanuelle Pean, Fabien Sanz Pascual et Fanny Tournier.

\section{BIBLIOGRAPHIE}

Actus pontificum Cenomannis in urbe degentium, index nominum par E. vALLÉE, archives historiques du Maine, 2, Éd. G. Busson et A. Ledru, Le Mans, 1901.

ANGOT A., 1910 - Dictionnaire historique topographique et bibliographique de la Mayenne, 4 vol., Laval, Goupil, 1900-1910, 3569 p.

BARTHELEMY-SYLVAND C., CHAMBOND M.-P. et COUVIN F., 2005 - « Les amphores ligériennes en région Centre (Carnute, Turon, Biturige), de la période augustéenne à la fin du Haut-Empire ", Société française d'étude de la céramique antique en Gaule, actes du congrès de Blois, p. 159-176.

BASTIEN P., 1980 - «Le monnayage de l'atelier de Lyon », (XI), De la réforme monétaire de Dioclétien à la fermeture temporaire de l'atelier en 316 (294-316), Wetteren, 274 p., 69 pl.

BERTHAUD G. (dir.), 2000 - Mazières-en-Mauges gallo-romain (Maine-et-Loire). Un quartier à vocation artisanale et domestique, Angers : ARDA et Afan, $262 \mathrm{p}$.

BOCQUET A., CHUNIAUD K. et NAVEAU J., 2004 - « Le quartier antique de La Grande Boissière à Jublains (Mayenne) », Revue archéologique de l'Ouest, $\mathrm{n}^{\circ}$ 21, p. 131-174.

BOISSEL R. et DIEHL R., 1971 - « La nécropole gallo-romaine méridionale de Noeodunum (Jublains) (prospections de 1970 et 1971) », Bulletin de la commission historique et archéologique de la Mayenne, $n^{\circ} 25$ (242), p. 3-52. 
BOISSEL R., DIEHL R. et NAVEAU J., 1972 - « L'oppidum de Moulay (fouilles de l'été 1972) », Bulletin de la commission historique et archéologique de la Mayenne, $\mathrm{n}^{\circ}$ 29, p. 3-35.

BOUVET J.-P., 1997 - « Les céramiques de l'âge du Fer », in NAVEAU J. (dir.), 1997, Recherches sur Jublains (Mayenne) et sur la cité des Diablintes, Rennes, Éd. RAO (coll. Documents archéologiques de l'Ouest), p. 222-240.

BOUVET J.-P., BRODEUR J., CHEVET P., MORTREAU M. et SIRAUDEAU J., 2003 - « Un oppidum au château d'Angers (Maine-et-Loire) », in MANDY B. et DE SAULCE A. (dir.), « Les Marges de l'Armorique à l'âge du Fer - Archéologie et histoire : culture matérielle et sources écrites, Actes du XXIII ${ }^{\mathrm{e}}$ colloque de l'AFEAF », Revue archéologique de l'Ouest, supplément n 10, p. 173-187.

BUCHSENSCHUTZ O., COLIN A., KRAUSZ S., LEVERY M., SOYER C. et VILLARD A., 1993 - Le village celtique des Arènes à Levroux. Description des structures, $8^{\mathrm{e}}$ supplément à la Revue archéologique du Centre, Levroux 2. Levroux : FERAC et ADEL, $217 \mathrm{p}$.

BUCHSENSCHUTZ O., COLIN A., FIRMIN G., FISCHER B., GUILLAUMET J.-P., KRAUSZ S., LEVERY M., MARINVAL P., ORELLANA L. et PIERRET A., 2000 - Le village celtique des Arènes à Levroux. Synthèses, $19^{e}$ supplément à la Revue archéologique du Centre, Levroux 5. Levroux : FERAC et ADEL, 333 p.

CADALEN-LESIEUR J., 2005 - « La céramique gallo-romaine sur le site de Thésée-Pouillé (Loir-etCher) », Société française d'étude de la céramique antique en Gaule, actes du congrès de Blois, p. 205-244. CAMPY M. et MACAIRE J.J., 2003 - Géologie de la surface : érosion, transfert et stockage de matériaux dans les environnements continentaux, Paris, éditions Dunod, $2^{\mathrm{e}}$ édition, $440 \mathrm{p}$.

CHEVALLIER R., 1997 - Les Voies romaines, Paris, éditions Picard, 343 p.

Chuniaud K. et Mortreau M., 2002 - «Un ensemble céramique de la première moitié du II siècle sur le site de La Grande Boissière à Jublains (Mayenne) ", Société française d'étude de la céramique antique en Gaule, Actes du Congrès de Bayeux, p. 159-176.

COLLETER R., 2003 - Les Cimetières mérovingiens en Mayenne (vi ${ }^{e}$-viiie siècle), La Mayenne - Archéologie, histoire, supplément $\mathrm{n}^{\circ} 11$, Société d'archéologie et d'histoire de La Mayenne, Laval, $208 \mathrm{p}$.

DELAGE R., 1997 - « Premier aperçu de la diffusion de la céramique sigillée du groupe Centre-Ouest dans l'Ouest de la Gaule (régions Pays de la Loire et Bretagne) ", Société française d'étude de la céramique antique en Gaule, Actes du Congrès du Mans, p. 279-292.

DELAGE R., 2005 - «Les céramiques sigillées du Centre-Ouest », in TUFFREAU-LIBRE M., Céramiques antiques en Val de Loire, Orléans, p. 50-51.

DELAGE R., 2006a - La céramique sigillée du site du Taillis des Boissières à Jublains, Rapport d'études, conseil général de Mayenne (direction du patrimoine et des musées).

DELAGE R., 2006b - « Sigillée du groupe Centre-Ouest à Thésée (Loir-et-Cher) », Société française d'étude de la céramique antique en Gaule, Actes du Congrès de Pézénas, p. 569-578.

DELOZE V., (à paraître) - « Les matériaux de construction et de mouture antique, La Carie II à Entrammes (Mayenne) », in Marchand G. et QUERRE G., Roches et sociétés de la préhistoire, Colloque de Rennes, 28-30 avril 2010, Presses universitaires de Rennes.

DEMAROLLE J.-M., 2005 - « Artisanat et sacré en Gaule romaine : de modestes jalons ", in POLFER. M., Artisanat et économie romaine : Italie et provinces occidentales de l'Empire, Actes du $3^{e}$ colloque International d'Erpeldange (Luxembourg) sur l'artisanat romain, 14-16 octobre 2004, Éditions Monique Mergoil, Monographies instrumentum, 32, p. 39-54. 
DESBAT A. et PICON M., 1992 - « Les importations précoces de sigillées à Saint-Romain-en-Gal (Rhône) », in RCRF Acta, 31-32, p. 391-414.

DUFAŸ B., 1996 - « Les fours de potiers gallo-romains : synthèse et classification, un nouveau panorama ", Société française d'étude de la céramique antique en Gaule, Actes du congrès de Dijon, 16-19 mai 1996, p. 297-312.

ELMER G., 1941 - « Die Münzprägung der gallischen Kaiser in Köln, Trier und Mailand », Bonner Jahrbücher, 146, Darmstadt, p. 1-106.

FICHTL S., 2005 - La ville celtique. Les oppida de 150 av. J.-C à 15 ap. J.-C, Paris, éditions Errance, édition corrigée et augmentée, $238 \mathrm{p}$.

GENIN M. et al., 1996 - « Corpus des marques lyonnaises sur sigillée et imitations de sigillée », in DESBAT A. et al., « Les productions des ateliers de potiers antiques de Lyon », Gallia, n 53, p. 193-213.

GRICOURT D., 1999 - « La trouvaille de monnaies constantiniennes de La Chapelle-lès-Luxeuil (ensemble 1)», Trésors monétaires, XVIII, 140 p., 13 pl.

GUILLIER G., 1995 - « Un aspect méconnu de la céramique du Haut-Empire : la vaisselle modelée, l'exemple du Mans (Sarthe) ", Société française d'étude de la céramique antique en Gaule, actes du congrès de Rouen, p. 217-234.

GUILLIER G., 2005 - « Une nécropole de l'Antiquité tardive le long de la voie Le Mans-Lisieux : Pontôme à Saint-Jean-d'Assé (Sarthe) », Bulletin de la Société d'agriculture, sciences et arts de la Sarthe, Le Mans (mémoires 2003), p. 19-36.

GUILLIER G., 2006a - Rapport de diagnostic archéologique, commune d'Entrammes (Mayenne), « 63 rue du Maine », Inrap Grand-Ouest, Service régional de l'archéologie des Pays de la Loire, 19 p., 9 fig., 26 photos, 4 annexes.

GUILLIER G., 2006b - Entrammes (Mayenne), La Carie II, rapport d'opération de fouille d'archéologie préventive, Inrap Grand-Ouest, Service régional de l'archéologie des Pays de la Loire, vol. I : 168 p. ; vol II : 71 pl., 75 photos, annexes.

GUILLIER G., AUXIETTE G. et CHEREL A.-F., 2006 - « L'établissement rural de La Tène moyenne de "La Gaudine" à Vivoin (Sarthe) et ses activités de transformation ", Revue archéologique de l'Ouest, $\mathrm{n}^{\circ} 23$, p. $45-70$

GUITTON D., 2004 - «Contribution à l'étude de la diffusion des céramiques sigillées du groupe Centre-Ouest : l'estuaire de la Loire ", Société française d'étude de la céramique antique en Gaule, Actes du Congrès de Vallauris, p. 289-314.

HOLLARD D. ET PILON F., (à paraître) - « Le trésor et les monnaies de site de l'“Espace du Palais” à Rouen (Seine-Maritime) », Trésors monétaires, XXII.

ISINGS C., 1957 - Roman Glass from Dated Finds, Groningen-Djakarta, Archeologia Traiectina, II, 185 p. KAEMMERER M. et REVEL J.-C., 1989 - « Signification des précipitations d'origine biologique de fer et de manganèse dans les alluvions quaternaires du Sébou (Maroc) ", Bulletin de l'Association française d'étude du Quaternaire, nº 4, Paris, p. 213-218.

LANGOUET L. et GOULPEAU L., 1975 - « Sur l'utilisation statistique et cartographique des séries d'objets archéologiques » Dossiers du CERAA, Centre régional d'archéologie d'Alet, n³, p. 95-118.

LASFARGUES A., LASFARGUES J. et VERTET H., 1976 - « Les estampilles sur sigillée lisse de l'atelier augustéen de la Muette à Lyon », Figlina, n 1, p. 39-87. 
LE GOFF E., 1994 - Datation et caractérisation d'ensembles homogènes de mobilier : le fossé de l'avant-cour de l'habitat fortifié de Saint-Symphorien à Paule (Côtes-d'Armor), Mémoire de DEA, Rennes II.

LE GOFF E., 2003 - « "Armorique” et "Bretagne” : réflexion sur l'assimilation de ces concepts pour la fin de l'âge du Fer », in Mandy B. et DE SAULCE A., (dir.), « Les Marges de l'Armorique à l'âge du Fer, archéologie et histoire : culture matérielle et sources écrites, Actes du XXIII ${ }^{\mathrm{e}}$ colloque de l'AFEAF », Revue archéologique de l'Ouest, supplément n 10, p. 103-117.

LEROUX G., 2002 - « Le franchissement de la Seiche par la voie antique Rennes (Condate)-Angers (Juliomagus). Fouille, datation et typologie du pont-long de la Basse-Chaussée à Visseiche (Ille-etVilaine) », Revue archéologique de l'Ouest, n 19, p. 129-170.

LORREN C., 2001 - Fibules et plaques-boucles à l'époque mérovingienne en Normandie, Mémoires de l'AFAM, t. VIII, Paris, 554 p.

MAGUER P., 2000 - Cholet : « Les Natteries », DFS de Sauvetage Urgent, Afan, Service régional de l'archéologie des Pays de la Loire, autoroute A87, tronçon 1, Angers-Mortagne-sur-Sèvre, 259 p., $61 \mathrm{pl}$.

MAGUER P., CHEREL A.-F. et AUXIETTE G., 2003 - « Nouvelles données sur les habitats de l'âge du Fer dans le nord de la Sarthe (commune de Vivoin, autoroute A28) », in Mandy B. et DE SAULCE A., (dir.), « Les Marges de l'Armorique à l'âge du Fer, archéologie et histoire : culture matérielle et sources écrites, Actes du XXIII ${ }^{\mathrm{e}}$ colloque de l'AFEAF », Revue archéologique de l'Ouest, supplément $\mathrm{n}^{\circ} 10$, p. 213-234.

MANIGAULT B. et MENILLET F. avec la collaboration de PLAINE J., LE HERISSE A., LIGOUIS B. et LANGEVIN C., 1987 - Carte géologique de la France à 1/50 000, feuille de Meslay-du-Maine (356), Éditions du BRGM, Orléans, une carte.

MANNING W.-H., 1985 - Catalogue of the romano-british iron tools, fittings and weapons in the British Museum, Londres, 1985, 197 p. 85 pl.

MARTIN TH., 1999 - «Le port de Bordeaux et la diffusion atlantique des sigillées montanaises », Pallas, 50, p. 27-41.

MENEZ Y., 1985 - Les céramiques fumigées de l'ouest de la Gaule, Cahiers de Quimper Antique, 2, 128 p., $44 \mathrm{pl}$.

MENEZ Y., 1996 - « Une ferme de l'Armorique gauloise, La Boisanne à Plouër-sur-Rance (Côtesd'Armor) ", Documents de l'Archéologie française, n 58, M.S.H., 272 p., 34 pl.

MENEZ Y. et VILLARD-LE TIEC A., 2003 - Tumulus de l'âge du bronze et sanctuaire antique de Kergroas à Paule, Conseil général des Côtes-d'Armor, Service régional de l'archéologie de Bretagne, UMR 6566, $90 \mathrm{p}$.

MENILLET F., PLAINE J., MANIGAULT B. et LE HERISSE A., 1988 - Carte géologique de la France à 1/50 000, feuille de Meslay-du-Maine (356), Éditions du BRGM, Orléans, notice, 79 p.

MEURET J.-C., 1993 - Peuplement, pouvoir et paysage sur la marche Anjou-Bretagne (des origines au Moyen Âge), La Mayenne : Archéologie, Histoire, supplément $n^{\circ} 4$, Société d'archéologie et d'histoire de la Mayenne, Laval, $656 \mathrm{p}$.

MORTREAU M., 2005 - «Le mobilier de deux caves du début du I ${ }^{\text {er }}$ siècle après J.-C. à Angers/ Juliomagus (Maine-et-Loire) », Société française d'étude de la céramique antique en Gaule, actes du congrès de Blois, p. 83-98. 
MORTREAU M. et SIRAUDEAU J. 1997 - « Les ensembles céramiques précoces d'Angers (Maine-et-Loire) : "Le site de la Gaumont-Saint-Martin" ", Société française d'étude de la céramique antique en Gaule, actes du congrès de Mans, p. 67-84.

NAVEAU J., 1977 - « Fouille d'un fossé de l'âge du fer dans la carrière d'Ecorcé à Entrammes (Mayenne) », Bulletin de la commission historique et archéologique de la Mayenne, $\mathrm{n}^{\circ}$ 46, p. 3-23.

NAVEAU J., 1982 - «Le temple celto-romain et le camp protohistorique du Port-du-Salut à Entrammes (Mayenne) », La Mayenne : Archéologie, Histoire, t. 4. Société d'archéologie et d'histoire de la Mayenne, Laval, p. 17-78.

NAVEAU J., 1991a - «Les thermes gallo-romains de l'église d'Entrammes (Mayenne) », La Mayenne: Archéologie, Histoire, supplément n 1, Les thermes romains d'Entrammes, 1991. Société d'archéologie et d'histoire de la Mayenne, Laval, p. 7-62.

NAVEAU J., 1991b - «L'impact d'un gué sur le peuplement antique : l'environnement archéologique des thermes d'Entrammes (Mayenne) », La Mayenne: Archéologie, Histoire, supplément n 1, Les thermes romains d'Entrammes, Laval, p. 87-104.

NAVEAU J., 1992a - La Mayenne 53, Carte archéologique de la Gaule, Paris, Académie des inscriptions et belles-lettres, $176 \mathrm{p}$.

NAVEAU J., 1992b - « Les thermes d'Entrammes (Mayenne) », Revue archéologique de l'Ouest, 9, p. 129-159.

NAVEAU J., 1998 - Le chasseur, l'agriculteur et l'artisan, Guide du musée archéologique départemental de Jublains (Mayenne), Laval, 1998, 175 p.

NAVEAU J. (dir.), 1997 - Recherches sur Jublains (Mayenne) et sur la cité des Diablintes, Rennes, éd. RAO (coll. « Documents archéologiques de l'Ouest », 352 p.

NILLESSE 0., 2003 - « Les établissements ruraux gaulois de Marcé (Maine-et-Loire) et la hiérarchisation des aedificia ", in Mandy B. et De SAULCE A., (dir.), Les Marges de l'Armorique à l'âge du Fer, Archéologie et Histoire : culture matérielle et sources écrites. Actes du XXIIIe colloque de l'AFEAF, Revue archéologique de l'Ouest, supplément $\mathrm{n}^{\circ}$ 10, p. 149-172.

OXÉ A., COMFORT H. et KENRICK P., 2000 - Corpus Vasorum Arretinorum, A Catalogue of the Signatures, Shapes and Chronology of Italian Sigillata, Bonn, R. Habelt (Coll. « Antiquitas »), 554 p.

PETIT J.-P., 2005 - « L'artisanat alimentaire dans les petites villes gallo-romaines de Bliesbruck (France, département Moselle) et Schwarzenacker, (Allemagne, Land de Sarre), au iiie siècle apr. J.-C. », in POLFER M., Artisanat et économie romaine : Italie et provinces occidentales de l'Empire. Actes du 3 e colloque international d'Erpeldange (Lux.) sur l'artisanat romain, 14-16 octobre 2004, Éditions Monique Mergoil, Monographies instrumentum, 32, p. 169-193.

PETORIN N., PEAN E. et MERCIER-DOUCET F., 2004 - « Entrammes (Mayenne). Echangeur RN 162 - RD 103 : Diagnostic Archéologique, 19 au 30 janvier 2004 », Drac des Pays-de-la-Loire, Service régional de l'archéologie, Inrap, 13 p, annexes.

PIRAULT L., HUET N. et LE BOULAIRE C., 2001 - « L'atelier de potier de La Bourderie à Rezé (LoireAtlantlique) et sa production », Revue archéologique de l'Ouest, 18, p. 145-171.

PONTON D'AMÉCOURT (vicomte de), 1883 - Recherches des monnaies mérovingiennes du Cenomannicum, Revue historique et archéologique du Maine, Mamers, Le Mans, t. 10, 11 et 12, 1881-1882, p. 149-151. 
REGINATO A., 2000 - « Officine de la Gravisse à Aiguillon », in 2000 ans de pots en Aquitaine, Musée de la poterie des hospices de la Madeleine à Saint-Émilion, catalogue d'exposition, juin-décembre 2000, p. 9-14.

ROUSSEL L., 2003 - Mâlain-Mediolanum. Une ville gallo-romaine. Vingt-cinq ans de fouilles archéologiques 1968 - 1993, Cahiers du Mesmontois, 74, Mâlain, 2003, 493 p.

SANTROT M.-H. et J., 1979 - Céramiques communes gallo-romaines d'Aquitaine, Paris : éditions du CNRS, 1979, 262 p., 67 fig.

SCHWEITZ D., TOULIER C., FERDIERE A., FEHRNBAC X. et BLANC P.-M., 1986 - « L'atelier de potier de Mougon (Couzilles, Indre-et-Loire) », Revue archéologique du Centre de la France, 25, 1, p. 37-77.

SIMON L., (à paraître) - « L'atelier de verrier », in BOCQUET A. (dir.), Évolution d'un quartier urbain entre le Ier s. av. J.-C. et le IXe s. ap. J.-C. : le site du Taillis des Boissières à Jublains (Mayenne).

SIREIX C., 1994 - « Officines de potiers du second âge du Fer dans le sud-ouest de la Gaule :

organisation, structures de cuisson et productions », Aquitania, XII, p. 95-109.

STÖCKLI, W.-E., 1979 - Die Gross und importekeramik von Manching. Die Ausgrabungen in Manching, Band 8, Wiesdaden, $270 \mathrm{p}$.

SWAN V.-G., 1984 - The pottery kilns of roman Britain, Royal Commission on Historical Monuments, Supplementary Series : 5, Londres, $179 \mathrm{p}$.

TCHERNIA A., 1986 - Le vin de l'Italie romaine, BEFAR 261, Rome, 410 p.

VALAIS A., 2005 - RN 162, Entrammes (53), Opération 2003-96, phase 2, Rapport de diagnostic archéologique, Drac des Pays-de-la-Loire, Service régional de l'archéologie, Inrap, 52 p. VAN OSSEL P. et DEFGNEE A., $2001-C$ =hampion, Hamois. Une villa romaine chez les Condruses. Archéologie, environnement et économie d'une exploitation agricole antique de la Moyenne Belgique, Namur : Ministère de la Région wallonne, Études et Documents d'Archéologie, 7, 280 p., 191 ill. Verre et Merveilles, 1993 - Mille ans de verre dans le nord-ouest de la Gaule, Catalogue d'exposition, Guiry-en-Vexin, $132 \mathrm{p}$.

\section{ANNEXES}

Annexe : le catalogue des monnaies (F. Pilon)

Dix-sept monnaies ont été recueillies à la fouille et une au diagnostic. Elles sont numérotées de M1 à M18 (tab.9) et témoignent d'une occupation entre le début du $\mathrm{II}^{\mathrm{e}}$ siècle après J.-C. et la fin du $\mathrm{IV}^{\mathrm{e}}$ siècle, avec une forte proportion de monnaies du BasEmpire au niveau de la voie, mais ne rendent pas compte de l'intégralité de l'occupation du site, notamment en ce qui concerne l'occupation gauloise et le $\mathrm{I}^{\mathrm{er}}$ siècle après J.-C. 
Tableau 9 : Entrammes, «La Carie » : catalogue des monnaies antiques. Table 9 : Catalogue of Roman Empire coins.

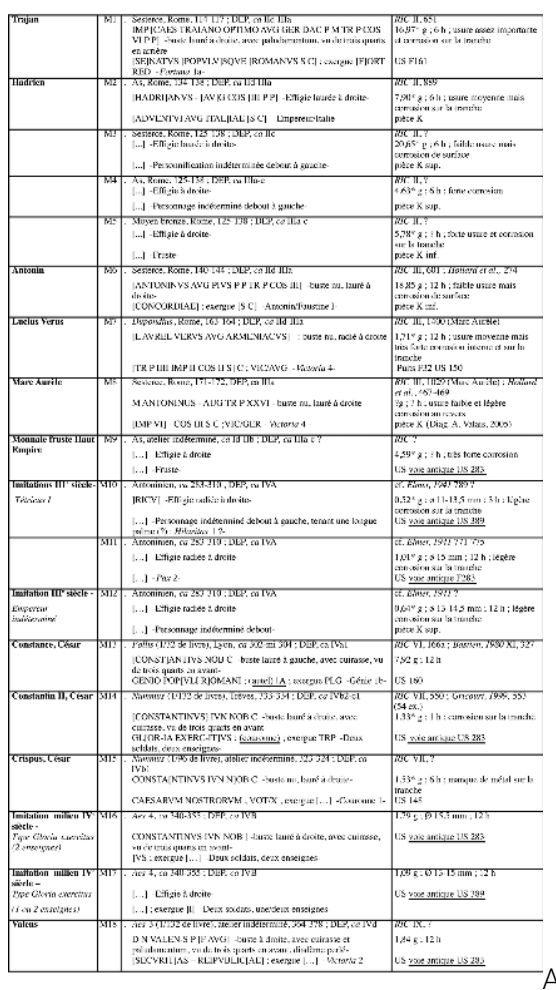

Abréviations : DEP - Date estimative de perte ; ZA, B - $1^{\mathrm{e}}$ $2^{\mathrm{e}}$ moitié du Zème siècle ; $Z a, b, c, d-1^{\mathrm{e}}, 2^{\mathrm{e}}, 3^{\mathrm{e}}, 4^{\mathrm{e}}$ quart du Zème siècle $; Z x 1,2-1^{\mathrm{e}}, 2^{\mathrm{e}}$ moitié du xème quart du Zème siècle. La DEP est un intervalle de temps représentant la période pendant laquelle on estime qu'une monnaie a été égarée, déposée, thésaurisée, en prenant en compte différents facteurs d'usure.

Abbreviations: DEP - Estimated Date Lost; ZA, B - 1st, 2nd half of Z century; Za, b,c,d - 1st, 2nd, 3rd, 4 th quarter of $Z$ century; $Z \times 1,2-1$ st, 2 nd half of $x$ quarter of $Z$ century. The Estimated Date Lost is an estimate, taking into account various wear factors, of the period the coin was mislaid, deposited, or hoarded.

\section{NOTES}

2. Interamnis signifiant « entre les eaux », est formé de la préposition latine inter (entre, parmi, au milieu de) et de amnis (cours d'eau rapide, fleuve, rivière). Cette référence à une situation géographique particulière, s'appliquerait plus à notre sens à l'oppidum qu'à la ville antique.

3. Un article spécifique est consacré aux matériaux de construction du site de «La Carie » : V. Deloze, 2012.

4. Dans la description des structures archéologiques plus en avant dans le texte, nous avons dénommé, pour plus de facilité de lecture, «schiste», cette "ignimbrite rhyolitique à débit schisteux ».

5. En l'occurrence, le terme de «fossé-limite» est préférable à celui de «fossé bordier ». Un fossé bordier, par définition, marque au plus près la zone de circulation proprement dite, alors que le fossé-limite matérialiserait l'emprise totale de la voie.

6. Il s'agit cette fois de fossés bordiers, car ils limitent la bande de roulement de la voie, et non plus de fossés-limites. 
7. Ce même phénomène, peut-être moins marqué, s'observe aussi sur l'horizon I. S'agitil déjà d'une portion de terrain non aedificandi ?

8. Ou bouche à feu, c'est-à-dire l'endroit où le bois était brûlé (et non pas dans l'alandier).

9. Des études spécifiques ayant notamment trait principalement à la céramique sigillée et, dans une moindre mesure, à la verrerie, font l'objet d'un chapitre à part entière (chapitre 5), afin de ne pas scinder des lots dont la vision globale justifie pleinement une étude transversale.

10. Il s'agit de fragments dégradés et très lacunaires. Le matériau est de mauvaise qualité : la plupart des éléments est délaminée. Ils correspondent à des souliers, fermés par laçage et une carbinata d'enfant a été identifiée. Régionalement, il a été mis au jour des sculponae (semelles de bois) et des chaussures à semelles de cuir clouées à SaintJean-d'Assé (Sarthe) (Guillier, 2005) et des éléments attribuables à des calcei à Mazièresen-Mauges (Maine-et-Loire) (Berthaud, 2000).

11. Le comptage en NMI repose sur la prise en compte des seuls critères de forme (identification des bords et des fonds). Celui en NMI pondéré (NMIp) est un dénombrement reposant sur tous les critères observables (formes, techniques, décors, estampilles, etc.), tout en tenant compte, bien évidemment, d'éventuels collages.

12. Les fourchettes chronologiques assignées aux sigillées sont proposées sur la base de plusieurs critères: caractéristiques techniques, forme et, le cas échéant, marque épigraphique et décor moulé. Pour les pièces moulées, une confrontation systématique est opérée entre la datation dite "stylistique " (qu'il s'agisse de styles nominatifs ou de manières décoratives) et la datation technique du support, à savoir le vase moulé. Ces datations correspondent ainsi, avant tout, à des propositions de production/diffusion des vases. Les graphiques utilisant ces données ont été obtenus grâce à la méthode « du nombre probable d'apparition des vases par intervalles de 10 ans " (Langouët et Goulpeau, 1975). Elle permet de mettre en avant les datations les plus fines, tout en réduisant l'impact toujours déformant des nombreux fragments associés, par manque de critères, à des fourchettes chronologiques larges.

13. Le tableau 7 détaille pour les figures $33,34,35$ et 37 , les principales informations livrées pour chacun des vases présentés.

14. Is. : abréviation de Isings, 1957.

\section{RÉSUMÉS}

À mi-chemin entre oppidum gaulois et thermes antiques, le site de «La Carie » à Entrammes, installé près d'un gué sur un affluent de la Mayenne, a livré une succession stratigraphique débutant vers le milieu de La Tène moyenne, prenant son ampleur au Haut-Empire et finissant par une petite nécropole mérovingienne. Ces éléments s'organisent au sud, puis des deux côtés d'une large voie gauloise puis antique. L'habitat gaulois, peu dense, va en se complexifiant avant un abandon vers la fin de La Tène D1. Sur les mêmes bases, le site est réoccupé à partir de Tibère, 
des fours de potiers marquant la création d'une zone artisanale périphérique au nouveau cheflieu du pagus gallo-romain d'Entrammes. À la période flavienne, de nouvelles structures sont élevées et agrandies jusqu'au début de la période sévérienne. Au Bas-Empire, si l'habitat est abandonné, la voie continue d'être utilisée ; une petite nécropole mérovingienne atteste de la permanence de cette dernière au moins jusqu'au viII ${ }^{\mathrm{e}}$ siècle. Enfin, mentionnons qu'un abondant mobilier, peu diversifié, illustre l'occupation, essentiellement de la période gauloise à la fin du Haut-Empire.

Midway between the Gallic oppidum and the ancient spa, just before a ford on a Mayenne tributary, the site of "La Carie" at Entrammes has yielded a stratigraphic succession dating from the mid Celtic (La Tène) period, reaching its zenith during the time of the early Roman Empire with its end denoted by a small Merovingian necropolis. These elements are all arranged firstly to the south and then on either side of a large ancient Gallic well. Gallic habitation, firstly insignificant, became more complex before being abandoned towards the end of La Tène D1. Using the same base, the site was reoccupied from the time of Tiberius; potter's kilns indicating the installation of a craft area were found on the periphery of the new administrative town of Entrammes, the former pagus. During the Flavian period, further structures were erected and enlarged through to the beginning of the Severan period. During the Late Empire, although the habitation was abandoned, the road continued to be used; a small Merovingian necropolis ensuring its permanence up to at least the fifteenth century. Finally, we should mention that abundant furniture, not particularly varied, illustrates occupation primarily from the Gallic period to the end of the Early Empire.

\section{INDEX}

Mots-clés : diablintes, Mayenne, La Tène moyenne, Haut-Empire, Bas-Empire, voie gauloise et antique, habitat, nécropole, céramique, four

Keywords : diablintes, Mayenne, Mid Tène, Roman Empire, late Empire, Merovingian necropolis, gallic and gallo-roman road, habitation, potter's kilns, ceramics, glass

\section{AUTEURS}

\section{GÉRARD GUILLIER}

Institut national de recherches archéologiques préventives (Inrap Grand-Ouest) et UMR 8546 CNRS/ENS Paris.

\section{EMMANUELLE COFFINEAU}

Inrap Grand-Ouest

RICHARD DELAGE

Inrap Grand-Ouest

\section{VALÉRIEDELOZE}

(avec la contribution de.) Inrap Grand-Ouest et UMR 6566 Rennes

\section{ALAIN VALAIS}

(avec la contribution de.) Inrap Grand-Ouest 


\section{SÉVERINE LEMAITRE}

(avec la contribution de.) Université de Poitiers

\section{FABIEN PILON}

(avec la contribution de.) 10 rue des Chardonnerets, 37170 Chambray-les-Tours.

\section{LAURE SIMON}

(avec la contribution de.) Inrap Grand-Ouest et UMR 6566 Rennes 